Portland State University

PDXScholar

1971

\title{
The utilization of aides in public welfare; analysis, evaluation, and proposal
}

\author{
Leonard Mark Robinson \\ Portland State University \\ Shirley Ann Youngstrom \\ Portland State University
}

Follow this and additional works at: https://pdxscholar.library.pdx.edu/open_access_etds

Part of the Policy Design, Analysis, and Evaluation Commons, Social Policy Commons, Social Welfare Commons, and the Social Work Commons

Let us know how access to this document benefits you.

\section{Recommended Citation}

Robinson, Leonard Mark and Youngstrom, Shirley Ann, "The utilization of aides in public welfare; analysis, evaluation, and proposal" (1971). Dissertations and Theses. Paper 1469.

https://doi.org/10.15760/etd.1468

This Thesis is brought to you for free and open access. It has been accepted for inclusion in Dissertations and Theses by an authorized administrator of PDXScholar. Please contact us if we can make this document more accessible: pdxscholar@pdx.edu. 
AN ABSTRACT OF THE THESIS OF Leonard Mark Robinson and Shirley Ann Youngstrom for the Master in Social Work presented May 21, 1971.

Title: The Utilization of Welfare Aides: Analysis, Eviluation, and Proposal.

APPR OVED BY MEMBERS OF THE THESIS COMMITTEE;

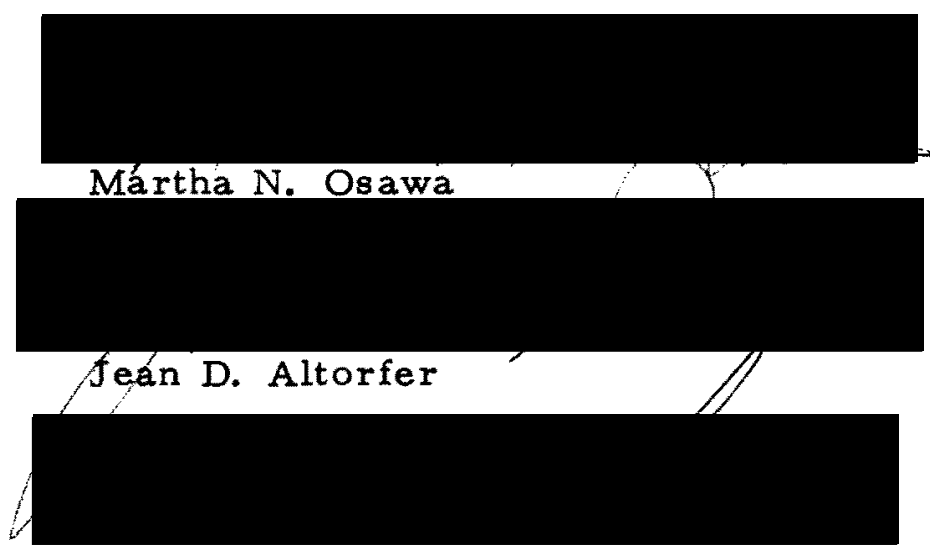

Helen A. Ellsworth

The purpose of this project was to trace the developments which led to the utilization of para-professional persons as service aides in public welfare departments and to examine, in particular, the developments in Oregon at the state and county levels. The establishment of such programs was mandated in the Social Security Amendments of 1967.

A review of the 1967 legislation showed the legislative intent to 
be inconsistent with the stated purposes of the program. This inconsistency, it was found, has been reflected in Oregon's aide program.

The theoretical origins underlying the aide concept were also examined in order to provide a fuller understanding of the means which were finally selected in Oregon to meet the legislative requirements. The aide program which evolved in Oregon has been marked by confusion in two major areas, the establishment of goals and the definition of roles. Specific problems which emerged within these two areas were analyzed in detail, with special attention being given to the progress which has been made.

To conclude, a theoretical model for the utilization of aides was proposed. While limited by its generality, the model does delineate the objectives which are considered essential to the establishment of an aide program based upon the research which was done in conjunction with this study. 
THE UTILIZATION OF AIDES IN PUBLIC WELFARE:

ANALYSIS, EVALUATION, AND PROPOSAL

\author{
by \\ Leonard Mark Robinson \\ and
}

Shirley Ann Youngstrom

A thesis submitted in partial fulfillment of the requirements for the degree of

MASTER OF SOCIAL WORK

Portland State University

1971 
TO THE OFFICE OF GRADUATE STUDIES:

The members of the Committee approve the thesis

of Leonard Mark Robinson and Shirley Ann Youngstrom

presented May 21, 1971.

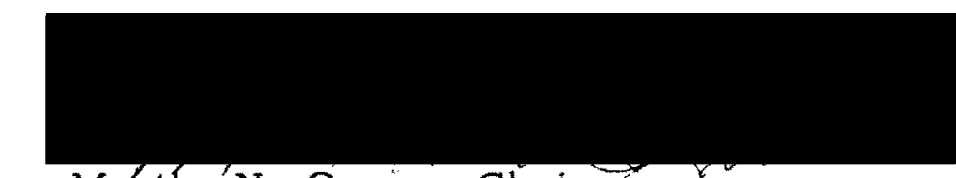

Martha'N. Ozawa, Chairman

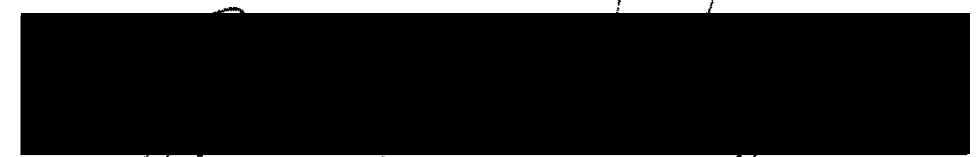

Jean D. Altorfer

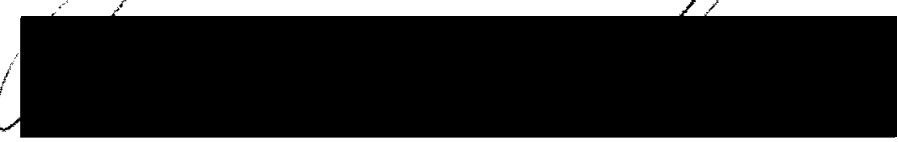

Helen A. Ellsworth

\section{A PPR OVED:}

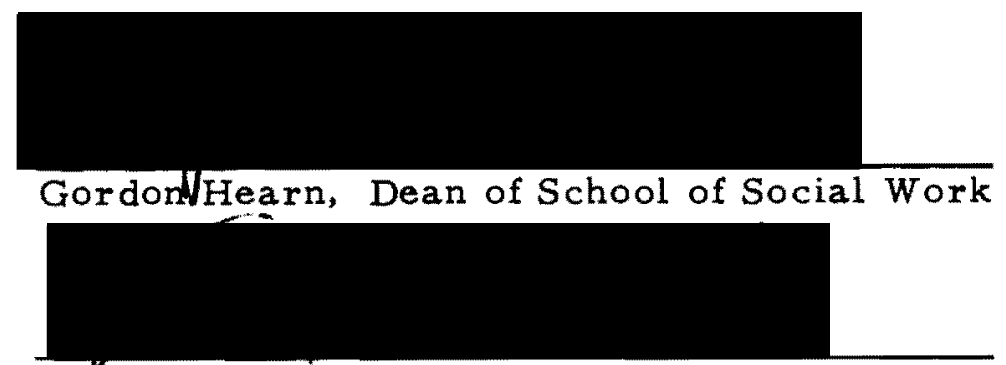

David T. Clark, Dean of Graduate Studies

May 24, 1971 


\section{ACKNOWLEDGEMENTS}

The authors: wish to express their thanks and appreciation to the members of their thesis committee who not only served as the stimulus for this project, but also willingly contributed their time and effort in bringing the project to its fruition.

We also extend our special thanks to the many staff members, not only from Multnomah County Public Welfare, but also from the State, Public Welfare Division, who became our most important resource. The spirit of cooperation and openness displayed by these individuals certainly testifies to their desire for constructive change. 


\section{TABLE OF CONTENTS}

PAGE

ACKNOWLEDGEMENTS . . . . . . . . . . . . . $\mathrm{iii}$

CHA PTER

LEGISLATIVE INTENT . . . . . . . . . 1

Introduction ........... . . 1

Methodological Approach Employed . . . 2

Stated Purpose of Bill . . . . . . . 3

Closed Rule Limitation . . . . . . . 4

Legislative Rationale . . . . . . 6

The Value of Work and Work Incentive. . . 9

Employment in Public Versus

Private Sector . . . . . . . 17

Provisions for Implementation . . . . . 18

Concluding Statement . . . . . . . 22

II THEORETICAL ORIGINS AND EARLY

PROGRAM DEVELOPMENT . . . . . . . 23

Overview ............. 23

Theoretical Origins . . . . . . 23

New Careers Program........ 31

New Careers Concept

Implementation of Concept

Developments in Oregon 
Work Incentive Program . . . . . .

Early Establishment Developments in Oregon

WIN Operating Structure

ANALYSIS AND CRITIQUE . . . . . . . . . 58

Overview . . . . . . . . . 58

Administration of Program ...... 61

Community Senior Workers

New Careerists

Model Cities Aides

WIN Aides

Negative Predisposition

Staff Perspective on the Program . . . 104

Lack of Clarity in Role

Definitions

Major Consequences of

Goal Confusion

Areas in Need of Change

Aide, Perspective on the Program . . . 118

Self-Image and Role

Prescriptions

Training and Supervision

Effectiveness on the Job

Future Goals

Statistical Analysis . . . . . . . . 127

Conclusion: A Program on the Move . . . 129

THEORETICAL MODEL . . . . . . . 133

Introduction . . . . . . . . . . . . 133 


$$
\begin{array}{r}
\text { General Objective } \quad \cdot \cdot \cdot \cdot \\
\text { Permanent Employment } \\
\text { Enhancement of Agency }
\end{array}
$$

Enhancement of Agency

Specific Objectives . . . . . . . . . . 139

Determination of $\mathrm{Job}$

Categories

Service Area Model

Individual Career Determination

Supportive Services

Financial Provisions

Training and Supervision

Alleviation of Role Conflict

Implications for Future Research . . . . 


\section{CHAPTER I}

\section{LEGISLATIVE INTENT}

\section{INTRODUCTION}

The first chapter of this thesis represents an attempt to probe the rationale and reasoning behind one piece of legislation which was a primary cause for the full development of an aide program. Some of the philosophical and moral arguments that were central to the adoption of this area of social policy will be dealt with in this chapter. This is by no means an exhaustive study of all the legislation that enabled an aide program to be developed. The 1967 Social Security Amendments, in particular section 204 of Public Law 90-248, was the most important because it mandated that states initiate a work incentive program by July 1, 1969, or the states would be subject to loss of Federal Funds. This in itself gave every state the impetus to quickly develop a full-scale aide program. The following analysis of the legislative intent is presented to help one recognize the cogent reasons as to why this particular strategy became a major social policy decision in the field of Public Welfare and Manpower Development.

An evaluation of legislative intent is necessarily of a subjective nature even though one makes stringent attempts to be objective. In 
analyzing legislative intent, certain information must be examined and then conclusions must be based on that information. Thus the analys is of the legislative intent in this chapter must be understood in terms of the limits of the material examined by the authors.

Even with this limitation, it is important to understand why a legislative act has certain features included or omitted. This particular study was done to determine the goals and objectives of the law so that these goals and objectives could be put to an evaluative test in the analysis of the resultant programs. If laws are to be properly evaluated, then the legislative intent must be made as clear as possible.

\section{METHODOLOGICAL APPROACH EMPLOYED}

In determining methodologically how to approach the problem one must first decide at what level to probe for comments and statements made by the actors in the legislative process. For this study, it was decided that this kind of legislation should be examined in the context of what was available to the general public. Therefore, material used was that made public, such as the statements made on the floor of Congress and in committee hearings where testimony was published for public use. This approach could be criticized on the grounds that it is naive to view the legislative process in this manner since many people say that what happens beyond the range of public 
knowledge is what really affects legislation. There is a definite reason why this approach was taken for this study, however. The rationale is that Public Welfare is one of the issues that concerns the public. The public is concerned with Public Welfare because of the size of the tax expenditures. If the Congress of the United States chooses a remedy for this purported problem via a specific program, then the public should understand what the program will accomplish. The public cannot guess and be certain of the reasons for the enactment of a law based on what goes on behind the scenes in Washington. Therefore, the legislation must be examined on the basis of what is available for public examination.

\section{STATED PUR POSE OF BILL}

That part of the 1967 Social Security Amendments being examined is referred to as the Work Incentive Program sometimes called WIN. The bill is aimed specifically at Public Assistance recipients in the Aid for the Dependent Children category (AFDC). ${ }^{1}$

The purpose of this part of the bill is to require the establishment of a program utilizing all available manpower services, including those authorized under other provisions of law, under which individuals receiving aid to families with dependent children will be furnished incentives, opportunities, and necessary services in order for (1) the employment of such individuals in the regular economy, (2) the training of such individuals for

${ }^{1}$ Complete text of the Work Incentive Section of the 1967 Social Security Amendments is cited in Appendix A. 
work in the regular economy, and (3) the participation of such individuals in special work projects, thus restoring the families of such individuals to independence and useful roles in their communities. It is expected that the individuals participating in the program established under this part will acquire a sense of dignity, self-worth, and confidence which will flow from being recognized as a wage-earning member of society and that the example of a working adult in these families will have beneficial effects on the children in such families. 2

One does not have to examine this statement of purpose closely to see that this enactment was to have had a profound effect on the lives and life styles of millions of human beings. It was this statement of purpose that would ultimately be tested for validity in the programs which grew out of this piece of legislation.

\section{CLOSED RULE LIMITATION}

One quickly discovers significant variables that affect a piece of legislation as it is in the process of becoming a law. One such variable in the formulation of the particular piece of legislation in question was the fact that no amendments could be made when it was first discussed on the floor of the House of Representatives.

This resolution contained a variety of sections including the raising of benefits for Social Security recipients. In fact, there were so many parts to this resolution that it is almost incongruous to believe that the democratic process could be carried out on the floor

\section{2}

Old Age Survivors Disability Health Insurance Amendments, Statutes at Large, LXXXI, Sec. 205 (1968). 
of the House in an eight hour debate on this measure. Each Representative had the choice of voting for or against the entire package presented in House Resolution 12080. This forced each Congressman to decide whether or not the good points of the bill outweighed the bad ones. The dilemma for many Congressmen is summarily expressed in the following two quotations:

Mr. Chairman it is regrettable that this bill comes before us under a closed rule. This is a typical case where a modified closed rule would have been in order. There are many things in the bill that this Committee should consider with a view to changing them, if that is the will of the Committee. Under the present procedure, however, we must either vote for the entire bill or against it. 3

Mr. Chairman, in general I am in favor of H.R. 12080 the Social Security Amendments of 1967, but $I$ am opposed to certain provisions written into this legislation with respect to aid to dependent children and the medicaid programs. This bill comes to the floor today under a closed rule so we have to vote for it or against it: we cannot offer amendments designed to correct the inequities contained in the provisions for needy children and the medical assistance programs. 4

When it came time to vote on the resolution only three people actually voted against the bill. The two people previously quoted felt that the positives of the resolution outweighed the negatives and also voted yes.

3 U.S., Congress, House, Representative Multer speaking for the Social Security Amendments of 1967, H. Res. 12080, 90th Cong., lst sess., August 17, 1967. Congressional Record CXIII, p. 23103.

4 U.S., Congress, House, Representative Boland speaking for the Social Security Amendments of 1967, H. Res. 12080, 90th Cong., lst sess., August 17, 1967. Congressional Record CXIII, p. 23125.

5 U.S., Congress, House, Vote on Social Security Amendments of 1967, H. Res. 12080, 90th Cong., lst sess., August 17, 1967. Congressional Record CXIII, p. 23142. 


\section{LEGISLATIVE RATIONALE}

A critical and important question is What were the logical steps taken by the legislators in designing the rationale of the legislation? The line of reasoning followed in Congress will first be stated step by step and then will be explained in more detail, supported by actual statements made by Representatives and Senators. The major problem which became the first matter of concern was the fact that the Public Welfare System was experiencing exceedingly high-rising costs. This was attributed to the increasing number of people on the welfare rolls, especially in the AFDC category. Looking to the future state of welfare, many legislators were concerned with the cyclical nature of the problem and sought a means of breaking that cycle. Most felt that if they could get such persons off welfare and onto the pay rolls, they would succeed in reducing the cost of welfare and also break a link in the cyclical chain, as there would be a reduction in the number of children on welfare. As stated previously, the legislators had as their first priority jobs in the regular economy; as their second, training for jobs in the regular economy; as their third, special work projects if needed.

The next step in the development of the rationale for this proposal was related to the means by which these priorities were to be implemented. With regard to the first, the words "regular 
economy" tended to imply that a public agency should be construed as an integral segment of the proposal. The decision was reached that these people would be better placed in the public sector of the regular economy than the private sector. One argument for this conclusion was that there was a manpower shortage in public and community work and that this program would help to alleviate this shortage. It was recognized that for the vast majority of welfare recipients skill levels did not meet the necessary requirements for the kind of jobs which existed in this area of work. It was therefore decided that such individuals should be utilized in the new role of the sub-professional or para-professional. Thus Congress felt that this program would serve to remove people from welfare and place them in an area of the economy that was sorely lacking in manpower. Mr. Schwengel of lowa stated,

The proposal in the legislation will make significant and long overdue changes in the law which governs aid to dependent children, and child welfare programs. Each State will be required to develop a program for each family on ADC rolls designed to get the job for the adult member of the family so that this family can be removed from the welfare rolls.

Congressman Feighan was more emphatic in his statement,

For the first time this program will be characterized by the positive approach of working with members of the recipient

${ }^{6}$ U.S. Congress, House, Representative Schwengel speaking for the Social Security Amendments of 1967, H. Res. 12080, 90th Cong., 1st sess., August 17, 1967. Congressional Record CXIII, p. 23089 . 
family to get them jobs and off welfare. 7

Mr. Rhodes of Pennsylvania expressed succinctly this idea.

A principal goal of the amendments is to make people on the AF DC program self sufficient so that they may no longer require public assistance. 8

Even Mr. Polanco-Abreu: of Puerto Rico expressed his optimism

that this program would be successful.

Puerto Rico intends to use these funds to increase work skills and accelerate the downward curve of the caseload in our subsistence rolls; to help these people help themselves. 9

The feeling of frustration shared by many Congressmen about

the growing number of welfare recipients is conveyed in the following statement by Congressman Robison:

Perhaps nothing can be done about this, but I would agree that it is the responsibility of this Congress to try to reverse the hard-to-explain upward surge of relief rolls, 10

It is precisely this feeling of frustration that leads one to wonder if

7 U.S., Congress, House, Representative Feighan speaking on the Social Security Amendments of 1967, H. Res.12080, 90th Cong., lst sess., August 17, 1967. Congressional Record CXIII, p. 23102.

${ }^{8}$ U.S., Congress, House, Representative Rhodes speaking for the Social Security Amendments of 1967, H. Res. 12080, 90th Cong. , 1st sess., August 17, 1967. Congressional Record CXIII, p. 23107.

${ }^{9}$ U.S., Congress, House, Representative Polanco-Abreu speaking for the Social Security Amendments of 1967, H. Res. 12080 , 90th Cong., 1st sess., August 17, 1967. Congressional Record CXIII, p. 23116.

${ }^{10}$ U.S., Congress, House, Representative Robis on speaking for the Social Security Amendments of 1967, H. Res. 12080, 90th Cong., 1st sess., August 17, 1967. Congressional Record CXIII, p. 23123. 
the proposed solution to the problem was really an adequate one or just another possible solution for the sake of trying anything. In answer to Representative Robison's own question which he raised, he said,

Maybe we are not going at it in the right way: right now, I do not know, but I do know we ought to try, and if we fail, to try something else. 11

\section{THE VALUE OF WORK AND WORK INCENTIVE}

From the material presented, one begins to draw the conclusion that for many people the work incentive concept was a key to the solution of an exceedingly complex problem. Mr. Pucinski was groping for a way to break the cycle of poverty when he said, ". . . we must take steps to create a viable alternative to the crushing cycle of ignorance, poverty, and welfare. "12 Conservatives and liberals alike were mesmerized by the work incentive plan as a panacea for solving the problem. Senator Ribicoff of Connecticut predicted that,

- . the future will show that these provisions the chairman has been able to work out will have a most significant impact on the war on poverty and will have a beneficial effect in taking people off welfare. 13

11

Ibid.

${ }^{12}$ U.S., Congress, House, Representative Pucinski speaking for the Social Security Amendments of 1967, H. Res. 12080, 90th Cong., 1st sess., August 17, 1967. Congressional Record CXIII, p. 23124.

${ }^{13}$ U.S. , Congress, Senate, Senator Ribicoff speaking for the 
A different view of work incentive, as a value in and of itself, was also utilized to justify the program by some legislators. The traditional value of work as explicated by many of the Protestant Reformation leaders seems to have helped prepare the way for this line of reasoning.

In the plan for reorganization of poor relief at Zurich, which was drafted by Zwingli in 1525, all mendicancy was strictly forbidden; travellers were to be relieved on condition that they left the town next day; provision was to be made for the sick and aged in special relief who wore ornaments or luxurious clothes, who failed to attend church, or who played cards or was otherwise disreputable. The basis of his whole scheme was the duty of industry and the danger of relaxing the incentive to work. 14

The value of work in giving relief to the poor was an integral part of the development of relief measures in England. In fact, England went to great lengths to establish the workhouses which have been so graphically described in novels, such as Oliver Twist by Charles Dickens.

A number of legislators concurred with this religious concept and the historical precedence in England as is shown in the following statement by Representative Mills.

Mr. Chairman, we have written into this bill certain requirements that a state must now meet. Those requirements are set out in the report in detail. We want the states to have a work

Social Security Amendments of 1967, H. Res, 12080, 90th Cong., lst sess., November 17, 1967. Congressional Record CXIII, p. 32587.

${ }^{14} \mathrm{R}$. H. Tawney, Religion and the Rise of Capitalism. (New York: 1962), p. 101 . 
and training program. We want the states to see fit that those who are drawing as unemployed fathers and/or drawing as mothers, unless there is good cause for them not to be required to take it, that they take training and then work. Is there anything wrong with that? What in the world is wrong with requiring these people to submit themselves, if they are to draw public funds, to a test of their ability to learn a job? Is that not the way that we should go? Is that not the thing we should do? 15

The concept of work as a spiritual value in and of itself was also expressed by Senator Brooke of Massachusetts,

For those who can work or could work, given the proper training and opportunities, there is something about relief which cripples the spirit and violates the recipient's sense of honor and self-respect. 16

The preceding quotations are only a sample of many statements made on the floor of Congress by Senators and Representatives. Wilbur Mills, chairman of the House Ways and Means Committee summed up this argument when he said, "My goodness alive. You would think that the American way of life was built on a dole system, to hear some people talk." 17

When the work incentive provisions were first being discussed in

${ }^{15}$ U.S., Congress, House, Representative Mills speaking for the Social Security Amendments of 1967, H. Res. 12080, 90th Cong., 1st sess., August 17, 1967. Congressional Record CXIII, p. 23053.

${ }^{16}$ U.S., Congress, Senate, Senator Brooke speaking for the Social Security Amendments of 1967, H. Res, 12080, 90th Cong., 1st sess., November 20, 1967, Congressional Record CXIII, p. 33191 .

17 U.S., Congress, House, Representative Mills speaking for Social Security Amendments of 1967, H. Res. 12080, 90th Cong., 1st sess., December 13, 1967. Congressional Record CXIII, p. 36366. 
the House of Representatives, it was in the spirit of the mandatory work or training for all AFDC recipients. The House of Representatives never really attempted to deal with this issue because of the rule that there could be no amendments attached to the bill. It was in the Senate that the concept of the inherent value of work was presented on the floor, and the consequences of forced work were considered in relation to the nuclear family.

Some of the following statements are representative of the attitude of those in the Senate and later in the House of RepresentativesSenate Conference Committee. These arguments did finally win support for the concept of maintaining a strong nuclear family.

Yet the work incentive plan which the committee has proposed although constructive in its general purpose, takes a step in the direction of the broken home. It will force mothers who have children attending school to work during or after school hours, during months when school is in session and during vacation period. 18

Another Senator stated, "But in many cases a mother's most important place is in the home attending to the needs of her children. "19 In the House some of the same sentiments were expressed as

${ }^{18}$ U.S., Congress, Senate, Senator Robert Kennedy speaking against part of the Social Security Amendments of 1967, H. Res. 12080, 90th Cong., lst sess., November 27, 1970. Congressional Record CXIII, p. 26766.

${ }^{19}$ U.S., Congress, Senate, Senator Tydings speaking against a part of the Social Security Amendments of 1967, H. Res. 12080, 90th Cong., lst sess., December 14, 1967. Congressional Record CXIII, p. 36766. 
evidenced by the following statement,

- . and I am equally opposed to the provision which would be mandatory on the states beginning Januaryl, 1969 to encourage States and State and local welfare agencies to put pressure on mothers of dependent children to leave home and go to work. 20

This dilemma of work versus the role of the mother in the home is one example of the types of questions that must be dealt with when a domestic social policy as far reaching as this one is made. The issue under discussion happens to be one that was carefully considered on the floor of Congress and in committee hearings sufficiently to obtain a solution based on the consideration of the many facets of the problem. There will, however, be other key dilemmas posed in this study concerning this bill for which a satisfactory solution was never found.

In lengthy testimony before the House Ways and Means Committee and the Senate Finance Committee there were those who testified in favor of the work incentive portion of the resolution. A small sample of the type of people who testified and the content of their testimony will be presented next in order to convey to the reader those points that appeared to be the most salient. In a document published by the Illinois State Chamber of Commerce entitled Relief

${ }^{20}$ U.S., Congress, House, Representative Boland speaking against a part of the Social Security Amendments of 1967, H. Res. 12080, 90th Cong., lst sess., August 17, 1967. Congressional Record CXIII, p. 23125. 
Rolls or Pay Rolls? A Searching Look at Public Aid in Illinois and

How It Concerns Every Businessman, the following statement

appeared, "Thousands of Illinois employers have successfully

employed aide recipients. This has had a direct effect on public aid rolls. "2 1 This was the businessman's endorsement of work as a possible means of lowering the number of welfare recipients. This particular piece of testimony received the accolades of some of the committee members. The National Association of Counties made the following recommendation to the House Committee:

Congress should make permanent the unemployed parent and community work training program associated with AFDC. This would help make welfare recipients self-supporting and in the long run reduce welfare costs.

This gave legitimacy to the argument for the adoption of the program from another level of government.

There was also testimony given to show the therapeutic value of work. It was described in a manner similar to that of a prescription being described to relieve an ailment. Dr. L. C. Meredith of the Ohio Medical Association wrote, "This intent is commendable in that it helps the individual build self-reliance and self-respect. "23 Even a technical consultant on Public Social Policy from the Social Welfare

21

Ibid., p. 1880 .

22

Ibid., p. 1787.

23 Ibid., p. 1686. 
Assembly agreed with the need for recipients to work,

Recognizing the high value placed by all Americans, including assistance recipients, on the opportunity to earn their living, we favor expanded provisions for work and training programs and the recommendations for equitable treatment in the exemption of earnings.

This testimony along with many of the legislators was based on the untested hypothesis that there existed droves of welfare recipients who were looking for work.

One way to test the potential success of a program is to examine its historical precedents. Programs built on the concept of forced work were attempted in England centuries ago, marking the advent of the old workhouse system. This concept closely parallels special work projects, though they generally were more humane. Unfortunately for England, the poor did not disappear as a result of placing them in the workhouses. The New Deal of the 1930's in the United States and the development of the original Social Security Act in the United States was also heralded as the final solution to the welfare problem. While work projects of the New Deal did help some, the results of that program in no way indicate that the development of special work projects through a Work Incentive Program in the $1960^{\prime} \mathrm{s}$ would be any more successful in removing people from the welfare rolls.

$$
24 \text { Ibid. , p. } 1582 .
$$


Different church groups, social welfare groups, and organized labor were also sharing their concerns about the Work Incentive proposals. The Council for Christian Social Action of the United Church of Christ said,

While there have been numerous and legitimate complaints of ill-conceived projects and faulty operations, the basic idea is sound and merits expanded implementation in the light of the best job training experience. ${ }^{25}$

The Reverend Joseph Alves of the Social Policy and Action Committee of the National Association of Social Workers of Massachusetts took the opposite view in stating that the Title II provisions freezing AF DC caseload and forcing work were morally and financially unsound. 26 George Meany of the AFL-CIO viewed forced work as punitive and thought that the punitive welfare provisions in the report unfairly and unjustly penalized the nation's poor. ${ }^{27}$ The question of work is one that is still not resolved and possibly the one most critical question that must be answered before any work program can truly be designed to resolve certain social problems.

\section{EMPLOYMENT IN THE PUBLIC VERSUS THE PRIVATE SECTOR}

One of the further mandates of the program was that the AFDC

$$
\begin{aligned}
& 25 \text { Ibid., p. } 1276 . \\
& 26 \text { Ibid. } \\
& 27 \text { Ibid. }
\end{aligned}
$$


recipients would work in the public sector not the private sector. The positive argument that appeared to be the strongest for this concept was that there was a manpower shortage in the area of public employees and that the welfare recipients who were to be put to work could help close this gap. One such argument heard in committee testimony was as follows. The nation was confronted with serious shortages of qualified personnel in the welfare field. The administration recommended in H. R. 5710 programs designed to combat those shortages. $^{28}$

In analyzing why the emphasis was placed on establishing jobs in the public sector it appears that it is the arguments that are not discussed which possibly have the most significance. While these arguments cannot be tested in this paper as set forth in the original guidelines, they should be stated in order to have them on record. One such consideration is that if the thrust of this legislation would have been to secure jobs in the private sector, immense cooperation would have been required from the private sector which may or may not have been forthcoming. Public agencies were given no choice; and in order for State Welfare Departments to continue to receive funds after a certain date they had to comply with the law in hiring and 
training paraprofessionals. Another possible consideration is that politically it would have been more difficult to pass legislation that would implicate the private sector of the economy. It seems highly unlikely that private industry would have wanted to get involved in the hiring of poor-risk welfare recipients.

\section{PROVISIONS FOR IMPLEMENTATION}

A recurring problem with the examination of this law is that it failed to establish guidelines and to answer obvious questions which were raised by the passage of the law. One such question was that if people who are on AFDC are put to work, then what happens to the children who are not in school and whose mother is working? This question was raised in House Committee hearings by Mitchell

Ginsberg, Commissioner of the New York City Welfare Department, 29 who asked if there were enough day care slots for all the children who needed them, and if there were enough slots, would the ADC mother working for a low wage be able to pay for that care? It is difficult to imagine someone wanting to go to work and put her child in a day care setting that would result in less take home money than the amount which she received while on welfare. An economic advantage

29 Ibid., p. 1838. 
of working must be maintained if this law is to get people to go to work and drop off welfare.

Also, since this bill was primarily designed to reduce the number of welfare recipients, it should have taken into consideration the effect on the next generation. The Congress did not adequately consider the quality of day care and its possible effects on the AFDC child. Surely, the Congress would not want to remove the mother from welfare only to have the child become a problem 10 or 15 years hence as a result of inadequate day care. There was discussion of day care, but no master plan was incorporated into the law that would guarantee day care which would be sufficient to encourage mothers to stay employed and feel comfortable about their children's care.

Another facet of this legislation that must be evaluated is the permanency of the job that is to be found for the welfare recipient. If this law was to have meaningful impact, in terms of a decline in the number of welfare recipients, it would have had to provide jobs that would be of a lasting nature or job training that would be meaningful enough to secure a job permanently. One aspect of the permanency of the jobs which should be tested is that concerned with whether or not the public employing agencies utilized these paraprofessionals in such a manner that they would always have a place on the staff. If the answer to this question is yes, then the conclusion one could draw 
would be that the welfare population of the present time would decrease.

The legislation in its final form, however, did not guarantee

a permanent job to these people. Representative Kastenmeier alluded

to this potential flaw in the legislative program when he said,

The fact is that jobs are not available in the private sector for those with such little training and education and the community work and training programs required by this bill are likely to be simply make work. 30

The above quote describes two areas of potential deficiency in the law's ability to reduce the welfare number. One that has been referred to previously is the problem of what to do with the private sector of the economy. If jobs are not available for these people, then the program which was a result of this act must correct these limiting characteristics of the individual through a job training program so that person will be employable in the private sector of the economy. The second potential deficiency is that the desire to make work for people should not be an end in and of itself, but it should lead to that final goal of providing a permanent job.

Continuing with the same trend of thought, the Illinois State Chamber of Commerce made the statement that, "Public Aid Administrators know that training programs, to be of value, must be geared

${ }^{30}$ U. S. , Congress, House, Representative Kastenmeier speaking against a part of the 1967 Social Security Amendments, H. Res. 12080 , 90 th Cong., 1st sess., August 17, 1967, Congressional Record CXIII, p. 23128 . 
to the needs of business. $1{ }^{31}$ As one pursues this subject, it can readily be seen that this proposed utilization of the paraprofessional was not written into the law. However, the law in an unstated manner does imply that the private sector of the economy would have to employ these people at a later date because employment in public agencies would necessarily be for long periods of time.

This then raises the whole notion of who would be best qualified to train the aides. Are public agencies such as Public Welfare really the best vehicle to train these people for employment? This question was never dealt with in the public testimony on this resolution. The only conclusion that can be drawn by the authors is that the validity of Public Welfare to be used as a training ground was something that was beyond reproach.

There was another implicit assumption made by the legislators that was to have major ramifications on the implementation of the program. This assumption was one that the Congress could set a deadline for implementation of a large-scale program without establishing any proper guidelines to facilitate the development of the program. It is true that many times the Administrative Regulations ameliorate many of the dichotomous goals of a law. However, in this case some of the aspects of the law were so vague that the States had

${ }^{31}$ U.S., Congress, House, Committee on Ways and Means, op. cit., p. 1880. 
almost no chance to run a successful program and still meet the July 1, 1969 deadline. The evaluation of how successful the States were in meeting this deadline will be examined in Chapter III with specific reference to the State of Oregon.

\section{CONCLUDING STATEMENT}

The rationale for the formulation of the work incentive program has thus been presented with some underlying philosophical principles. Together with the major intent of decreasing the number of people on welfare, an attempt was begun at state and local levels to implement a program by July 1, 1969. The preceding developments and what happened after the passage of the 1967 amendment will be described in detail in the next chapter. 
CHAPTER II

\section{THEORETICAL ORIGINS AND EARLY DEVELOPMENT}

\section{OVERVIEW}

This chapter represents an attempt to link the concept of the nonprofessional worker in human services with its theoretical origins and to trace its development in the New Careers and the WIN programs. This will serve to preface a discussion of the implementation of the 1967 Social Security Amendment legislation here in Oregon as related to those programs.

\section{THEORETICAL ORIGINS}

One might look upon the development of the non-professional concept as an evolutionary process, one which began at a relatively simple level and became increasingly complex and refined. The process began when indigenous workers were used in community action projects. An indigenous worker is one who is drawn to work in the community in which he lives.

As early as. 1937, local residents were employed in antidelinquency programs in the Chicago Area Project. ${ }^{1}$ It was found that

"Ernest W. Burgess et al. "The Chicago Area Project," Yearbook of the National Probation Association, 1937. 
such persons could reach their "own people" more effectively than professional workers. In an assessment of the Chicago Area Project, the following statement appears:

A sharp question has been raised by leaders of the Social Work professional regarding the competence of such persons, whose qualifications rested on assets of character and personality trait rather than on formal training and education. Leaders of the Area Project have always encouraged talented workers in this field to obtain as much training in the group work and social work fields as they could. However, they have regarded the talent for this work as the primary value. 2

The indigenous non-professional, then, is an individual who because of his knowledge of the community--its belief systems, its basic societal orientation, its patterns of communication--is able to relate more effectively to the residents of the community. They listen to him because they know he is working for the good of the community. There is an element of trust which is not present when an outsider comes to work within the community. Further, his employment ". . represents a demonstration of confidence in the capacity of the area resident. . . ${ }^{3}$ which is basic to assuring the residents' participation in and commitment to the project.

${ }^{2}$ Solomon Kobrin, "The Chicago Area Project--A 25 Year Assessment," The Annals of the American Academy of Political and Social Science, Philadelphia, CCCXII. (March, 1959), p. 24.

${ }^{3}$ Frank Riessman, The Revolution in Social Work: The New Non-professional, Training Department - Mobilization for Youth and Urban Studies Center (Rutgers University: October, 1963). 
The growth in community action programs reflected the concomitant interest in the expansion of human services in all areas. Industrialism and automation, urbanization, mobility and many other as pects of American society's accelerated way of life pushed the issue of human need into the foreground. But with it came the realization that there were not enough professionals to meet the need. The indigenous worker then came to be utilized in many areas of community life--health, mental health, education, and welfare. ${ }^{4}$ Rather than indigenous worker(s), however, they were more generally referred to as "aides": psychiatric aides, teacher aides, case aides. With this came a great effort to recruit more people into human service professions; but the manpower shortage persisted, growing steadily worse. ${ }^{5}$ In the early part of the $60^{\prime} s$, authors interested in this perplexing problem began saying that this was not the correct approach, that professionals simply could not be trained fast enough--even if there were enough people who wanted to go through the long educational process necessary. ${ }^{6}$ This, coupled with the fact that professionals

${ }^{4}$ See, for example: The Use of Case Aides in Casework Agencies. National Social Welfare Assembly: New York, 1959; Lawton M. Powell and Alfred E. Goldman, "The Role of the Psychiatric aide: A Report on the Norristown Seminar, " Mental Hygiene, XLVI (April, 1962), pp. 288-298.

${ }^{5}$ National Social Welfare Assembly, Salaries and Working Conditions of Social Welfare Manpower in 1960 (New York, 1960), p. 42 .

${ }^{6}$ See William C. Richan, "A Theoretical Scheme for Determining 
were not always the most effective workers in certain areas of human service, seemed to lead to the conclusion that developing nonprofessional positions would be a more valid means of approaching the problem. This was succinctly stated by one author as follows:

In an era of acute shortage of professional personnel. . . social work must broaden its concept of the helping person to include the resources of the untrained or partially trained worker in the process. Stereotyped and proprietary attitudes regarding the role and function of the practicing worker will require painstaking and often painful re-examination. 7

Such re-examination would necessarily entail an analysis of the specific functions fulfilled by the professional in a given area and a delineation of those which could by fulfilled by persons with less formal training. The term non-professional does not, therefore, designate the specific nature of the tasks to be performed; rather

... it calls attention to the distinction between a professional orientation and a performance of various tasks by people whose training is less than that of professionals, but who may have specific contributions to make in the performance of tasks related to the helping professions. ${ }^{8}$

Thus, the non-professional had secured for himself a place in the human services. But there was yet another stage of development, this being concerned with a further specification of who should fill

Roles of Professional and Non-Professional Personnel, "Social Work, VI (October, 1961), pp. 22-28.

7 Verne Weed and William H. Denham, "Toward More Effective Use of the Non-professional Worker: A Recent Experiment," Social Work, VVI (October, 1961), p. 36.

${ }^{8}$ Riessman, The Revolution in Social Work, p. 1. 
these non-professional roles. In order that this not be taken out of context, one must look at what was happening in American society at the time. A book which appeared in 1962 pointed out in startling terms a major problem which had for the most part been overlooked or dealt with at an extremely superficial level. The book was Michael Harrington's The Other America, and the problem was poverty. In it, Harrington demonstrated that American society had been operating on the implicit assumption that the nation's basic economic problems had been solved and that it was now merely a matter of "learning to live decently amid luxury. "9 This may have been "the American scene" for some; but for 40 million to 50 million other citizens, existing at levels beneath those of human decency, it was not the case. They lived in "the other America," which was becoming increasingly invisible to the unseeing eye; poverty was hidden in a way it never was before. The flurry of poverty programs and studies which followed showed that this was not going to be an easy problem to solve, for it was difficult to find the core or major cause. On a very fundamental level, however, it seemed that poverty resulted when people did not have the money necessary to maintain themselves and their families at a decent level, that is at a level where they could afford to purchase nutritional foods, adequate clothing and shelter, and take care of

$$
{ }^{9} \text { Michael Harrington, The Other America (Baltimore, 1962), }
$$
p. 1 . 
educational and health needs. In most cases, they did not have the money because there were no jobs available, at least to persons with their level of training and experience. It is a fairly well-known fact today that poverty tends to be self-perpetuating. Good jobs require education and education requires the money to pay for it, which is available only if one's parent or oneself has a good job, and so on. Instead of directly addressing this basic problem--the cycle of poverty--legislation was passed primarily to improve the services delivered to the poor by public institutions. The Economic Opportunity Act of 1964, also referred to as the "poverty law," did emphasize maximum participation by the poor and the involvement of the consumer of the services in deciding how such services should be provided. Title II, Section A of this Act states:

The term "Community Action Program" means a program. . . which is developed, conducted and administered with the maximum feasible participation of residents of the area and members of low income groups. 10

A by-product of this was the creation of widespread employment of the poor in jobs which entailed a minimum of training and education. But these were primarily "dead-end jobs," jobs which promised no opportunity for advancement and little challenge once learned.

Then, in 1965, a book appeared which addressed this problem in a new way. Poverty, it maintained, was not going to be easy to

10 Arthur Pearl and Frank Riessman, New Careers for the Poor (New York, 1965), p. viii. 
eradicate for it is not a "superficial blemish on an otherwise healthy structure." The stop-gap measures which had been applied themselves had a perpetuating quality; and the poor could not be expected to do it themselves, for they lacked the necessary resources and power. Rather, it would entail immediate outside intervention involving a shift in the basic organizational and institutional structures. What was needed was stated in the title of the book itself--New Careers for the Poor. The approach was simple, hire the poor to serve the poor. This approach pointed up a fundamental paradox in American society:

The crisis on the one hand, involves the permanent poor and, on the other hand, involves an inability to provide, in sufficient numbers, persons to fill the most needed technological and professional roles. In over-simplified terms, there exist simultaneously large numbers of people without jobs and a great many jobs without people. 11

The manpower resources of the poor if properly directed coult meet the manpower shortages in the public sector. No longer could society look to the private sector where, due to increasing automation and advanced technology, jobs were becoming more and more scarce. The President's Commission on Automation estimated that the country's manpower needs for 1969 were: 1,200,000 in health services and medical institutions; $1,100,000$ in education; 700,000 in welfare; 650,000 in urban renewal and sanitation; and 350,000 in public protection. 12

11 Pearl and Riessman, p. 5.

12 Fred Powledge, New Careers, Public Affairs Pamphlet 
The proposal made in New Careers for the Poor was not, of course, based upon unfounded premises. Many pilot projects had been conducted within a new careers framework, that is utilizing the poor as a major part of the working team; but the term "new careers" had not yet been applied. One such project conducted by Harlem Youth Opportunities Unlimited, HARYOU, was based on the belief that "the use of persons only 'one step removed' from the client will improve the giving of service as well as providing. . . meaningful employment for Harlem's residents. "13 Another such project was the Mobilization for Youth Program which dealt with delinquency as resulting from a lack of adequate opportunity structures, and emphasized the necessity of involving low-income persons in any attempt to reshape their environment. ${ }^{14}$ It was not until the appearance of Pearl's and Riessman's book, however, that the basic concepts underlying such projects and the means of implementing the, were clearly delineated. Thus, what has evolved is the concept of the "non-professional in human services. "The ways in which this concept has been

Number 427 (Public Affairs Committee, Inc., 1968), p. 4.

${ }^{13}$ Harlem Youth Opportunities Unlimited, Inc., Youth in the Ghetto: A Study of the Consequences of Powerlessness and a Blueprint for Change (New York, 1964), p. 607.

${ }^{14}$ George Brager, "New Concepts and Patterns of Service: The Mobilization for Youth Program." An article printed in Mental Health of the Poor, by Riessman, Cohen and Pearl (New York, 1964), pp. $412-421$. 
implemented have varied, but for the purposes here, two will be discussed--those which have been predominant in Oregon.

\section{NEW CAREERS PROGRAM}

New Careers Concept

In this section the new careers concept will be more fully developed. New Careers should not be looked upon as a set of guideLines which, if followed, produces instant anything.

Rather it is a set of constantly changing theories; and basic to the theories is the idea that there is a difference between a job and a career, and the idea that the creation of mere jobs may be nice, but that it is not enough. 15

And the reason it is not enough lies in the fact that such jobs rarely are permanent; rarely are they incorporated into an agency structure. Thus, they are merely stop-gap measures which will have no effect on tomorrow's poverty and little on today's. The major reasons why the New Careers concept does represent a valid means of bettering the position of the poor are found in its basic premises:

1. More workers in human service fields are needed.

2. There are millions of people who could work in these fields but lack the necessary training and credentials.

3. It is possible to separate tasks of human services into categories, some of which could only be performed by

${ }^{15}$ Powledge, p. 3. 
professionals, but others which could be performed by nonprofessionals.

4. Non-professionals can be trained to do such tasks quickly and can continue training while working.

5. Most important, even while training, workers are involved in careers, not dead-end jobs.

6. Utilization and training of these workers will improve the quality of social services.

7. The entire society, including professionals and the institutions in which they function, will behefit from this, and the cost of such benefits will not be prohibitive. 16

It was in 1966 that the first major legislation directly implement-

ing a new careers program was passed.

In amendments to the Economic Opportunity Act, a new program was established (Title II, Sec. 205, E) to prepare lowincome persons to enter career employment in public services. This "Scheuer Amendment" marked congressional commitment to the idea that "new careers for the poor" was to be a major thrust toward creation of employment opportunities for those previously denied access to public service occupations. 17

This amendment provided about 35 million dollars for the employment and training of non-professionals, drawn from disadvantaged communities, in public services. It stipulated that educational leave and training time were to be given by participating agencies and that job classifications were to be restructured to allow for upward mobility.

\section{${ }^{16}$ Powledge, p. 4.}

17 Wilbur Finch. State of California Human Relations Agency, Department of Social Welfare, The Supervision and Training of Case Aides: A Reading Reference for Supervisors and Staff Trainers, Training Aid 39B (August, 1970), pp. 6-7. 
After the enactment of this amendment, several other laws followed which were concerned with providing directives and funding for New Careers projects in the public sector. In December of 1967. two amendments were appended to the Elementary and Secondary Education Act of 1965, Title I and Title V, which involved grants to state and local agencies employing or wishing to employ aides. The 1967 Amendments to the Economic Opportunity Act (1964) served to further strengthen the commitments of the Scheurer Amendment, especially in assuring that job opportunities would be made available to persons who had received training. Soon after, there followed the Social Security Amendments of 1967, in which this same commitment to a new career concept was specifically implemented in public welfare.

At this time, the training, employment, and use of preprofessionals in the provision of public welfare program services became a federal requirement upon the various states which administered the categorical aid programs. . 18

Other major pieces of legislation (which can only here be cited) furthering new career goals included: Higher Education Act Amendments (1967), Intergovernmental Manpower Act (1967), Vocational Education Act (1968), Vocational Rehabilitation Act Amendments (1968). ${ }^{19}$ Numerous policy statements issued by federal departments and bureaus as well as those of a number of citizen groups also called

${ }^{18}$ F. Wilbur Finch, Training Aid 39B, p. 7. ${ }^{19}$ Ibid. 
attention to the need for jobs for disadvantaged persons which would contain a real opportunity for growth and advancement.

Implementation of Concept

After this brief look at the overall development of the new careers concept, an examination of how this concept most productively can be implemented seems in order. Just the major points will be covered here. 20 The starting point of any program is its basic goals or objectives. These have been stated as including the following:

1. A sufficient number of jobs for those without work.

2. The jobs to be so defined and distributed that placements exist for the unskilled and uneducated.

3. The jobs to be permanent and provide opportunity for lifelong careers.

4. An opportunity for the motivated and talented poor to advance from low-skill entry jobs to any station available to the more favored members of society.

5. The work to contribute to the well-being of society. 21

As has already been indicated the achievement of these goals will entail sweeping changes in education, in the process of securing and changing employment, in the roles now delegated to professionals, as

20 A much more detailed analys is is found, of course, in Pearl and Riessman's New Careers for the Poor. Note particularly chapters VII, IX, and X.

${ }^{21}$ Pearl and Reissman, p. 2. 
well as in the basic belief systems surrounding these institutions.

At the administrative level, therefore, implementation could be analyzed in terms of four basic strategies: (1) employment, training, and use of preprofessional staff, (2) restructuring of all job assignments, (3) adoption of the social service team approach, and (4) expansion of opportunities for upward mobility. Each of these will be discussed separately.

To begin with, employment involves a selection process. Present screening techniques would defeat the program's purpose, for they are based on test scores, prior record, acadernic training, et cetera. The criteria, rather, should be the individual's actual performance on the job. Only this approach will provide the means whereby people, who have participated in society primarily by virtue of their deviance, can become contributors. This kind of system has the potential for uncovering capacities, as yet undeveloped, or rechanneling the use of such capacities. The point is to screen people into the program, not out, and then to "train them up." Training should be focused on the following areas:

1. instructing the aide in specific skills

2. teaching the aide to relate positively both to other staff members and to the people whom he serves

3. generating a feeling of belonging to the service team

4. developing in the aide a sense of competence and of fulfillment 
Such training tasks necessarily place a heavy burden on the supervisor whose means of relating to the aides will be of great importance in determining their success. After a brief orientation period, the aide should begin work in the agency--he should be utilized. The aide, then, is involved in on-the-job training. This is essential if he is to feel useful and be motivated to move forward.

The second administrative strategy involved in the implementation of a new careers program approach is that of restructuring all job assignments. This requires an analysis of the jobs now performed by professionals in order to determine those for which full professional training is not necessary, as well as those functions which would expand the scope of service, but for which there are no staff positions assigned. Then the number of jobs required at each level and the number of levels appropriate must be determined. As Pearl and Riessman pointed out, agencies using such an approach may not be able to engage in the kind of long-range study which the above would necessitate; but this does not mean that programs cannot be started, with the idea in mind that modifications can be made as the program develops. Once such programs are underway--especially in large, complex agencies - the real benefit of a thorough task analysis can be seen; for it becomes clear that:

The primary solution to manpower problems in public welfare, as in other human service agencies, must ultimately be found in the creation of a continuum of classification levels of staff, with 
responsibilities clearly differentiated at each level of professional development--a system wherein the expertise of each employee is recognized and fully utilized. 22

Adoption of the social service team approach is the third administrative strategy. This approach concerns itself with the issue of what type of agency structure would function most effectively to incorporate and utilize the newly created classification levels. The team approach places emphasis upon the relationship of the servicegiving staff to one another and to the client in the delivery of service. At the staff level, the need is for cooperation and mutual encouragement; for the group plays an important role in providing support and reinforcement. At the client level, the team is comprised of a group of specialists--each with expertise in a certain area which can be brought to bear on the solution of client problems. ${ }^{23}$ One principle which is very relevant to this approach is the "helper" principle, which means simply that a person helps himself in the process of helping others--whether it be other team members or clients. The help the individual gains is often in terms of personal growth, commitment to his role, and increased effectiveness. 24

\section{${ }^{22}$ Wilbur Finch, Training Aid 39B, p. 2.}

23 Ibid. , p. 27.

${ }^{24}$ For a fuller discussion of this principle, see: Frank Riessman, "The 'Helper' Principle, "Social Work, X (April, 1965), p. 2 . 
Last of the strategies of implementation is expanding the opportunities for upward mobility, or more simply, building a career ladder. Without this provision, the other strategies cannot operate effectively. There is no use, for example, in expending the resources it takes to do a comprehensive task analysis if there is no way for individuals to work their way through the designated levels. The structure must allow opportunities for individual development and permit advancement to duties of greater challenge and responsibility. Such advancement should be accompanied by earnings increments and access to promotional avenues not dependent solely upon formal training or education financed by the individual himself. This, of course, makes imperative the inclusion of an educational training component designed to help the individual qualify for whatever level his abilities and motivation will allow.

It is hoped that the preceding material indicates the components and strategies basic to developing new careers for the poor and that it has conveyed at least the "flavor" of the concepts which underly the new careers philosophy. Certainly, each agency involved in setting up a new careers program or in employing a new careers approach will structure it according to the special needs of the agency itself, as well as the staff and client population which it serves. Thus, while there are certain basic points which cannot be compromised if the stated 
program goals are to be achieved, there should be enough latitude allowed for in implementing them to meet the needs of the participating agency.

\section{Developments in Oregon}

Before concluding this section on new careers, Oregon's involvement in the program must be spelled out. There is at present only one New Careers Program Office in Oregon and it is Located in Portland. Early in 1968, the U.S. Department of Labor contacted the Portland Metropolitan Steering Commission (PMSC), inviting Portland to submit a proposal for a concentrated employment program (CEP) with a guarantee of the sum of $\$ 500,000$ for program development upon submittal. $^{25}$ New Careers was to be one of the components in this CEP program. Members of the PMSC drew up a rough draft briefly stating their acceptance of the idea and their willingness to develop such a program. Robert Willitz was appointed, through Art Pearl, to work out a detailed proposal for the new careers component and get the program underway. One might say that the Portland New Careers Program got started in reverse; for the program proposal was submitted after the funds for its establishment had already been allotted.

${ }^{25}$ The following information was obtained in an interview with Mr. Robert Willitz, Director of Portland New Careers, conducted April 30, 1970. 
In this instance, Portland was assured of a CEP program and did not have to push for funding.

Guidelines handed down by the Federal Government for setting up the program were very minimal. They were as follows:

1. minimum age of participants was to be 18;

2. contracts were to be set up only with non-profit agencies;

3. careers were to be in the area of human and social services;

4. career ladders were to be developed.

It was the intent of the Federal Government that such guidelines be flexible in order to encourage the autonomy of the various state programs.

After presenting appropriate agencies with a tentative proposal, work-shop sessions were conducted for the purpose of setting up contracts and discussing how the new carrerists (aides) would fit into the various agency settings. Consultants from Washington, D. C. were also present at these sessions, which continued throughout the summer of 1968 . After some dropped out, nine agencies remained, and separate contracts were set up with each. Multnomah County Public Welfare (MCPW) was one of these nine. Bob Oulette, State Personnel Director, signed the contract in behalf of MCPW. One factor which has caused some difficulty since the program started was the fact that there was little communication 
during this time between the representatives from Salem and Multnomah County personnel who, while present at the general briefings, were not present when contractual negotiations took place. Mr. Willitz saw this as a lack of developmental work in preparing for the aides' entrance into the agency.

The decision to use preprofessional aides at Multnomah County Public Welfare represents an attempt on the part of the agency to become more responsive to the needs of the community and to improve communications between the agency and the consumers of agency services without increasing administrative costs. 26 Recipients were to be given preference in applying for aide positions. Certain of these aides were to become regular employees of the agency, while others were employed for the purpose of training them for employment in the public and private sectors. The new careers concept was to be followed in the recruitment, training and employment of such aides. In October of 1968 , the first six aides began their training at MCPW. These six were selected from CEP candidates by a panel of community persons, including the Multnomah County Personnel Director. These aides entered the agency as Welfare Aide I's (which is an established Civil Service Classification). At this time, service

26 Harold Miller, "Guidelines for Use of Pre-professional Aides," Draft \#2, State of Oregon, Public Welfare Division (November 11, 1968), p. 1 . 
and eligibility functions had not yet been separated--though the agency was in the process of planning separation--and a career ladder could be only roughly outlined.

The original plan was to maintain the aides as a unit under one supervisor for the first phase (six weeks to three months) of training. This consisted of orientation and evaluation of skills and interests. 27

(Later, aides were to be integrated into ongoing units or teams as these developed in the process of reorganization.) Orientation included giving the aides a beginning knowledge of agency structure, function, philosophy, personnel practices, casework concepts, and community resources. Possible tasks were suggested and checked by the aides either as those they were already prepared to do or those for which they would require training.

Following orientation was a six-month on-the-job work and training period. A variety of placements were made during the first three months with the aides sharing their learning experiences in group sessions. This pattern continued throughout the second three months except for the fact that some of the aides took on special projects and some were rotated to other departments--either to meet learning needs or in response to agency changes. After a year with

${ }^{27}$ The following outline of the aides'training activities was taken from a "Progress Report on New Careers Welfare Aid Program," by Kay Stenberg for Oregon State Public Welfare (May 27, 1969), pp. $2-3$. 
the agency, some aides moved into Welfare Aide II positions. These aides became regular employees, remaining with the agency after their contract expired (November, 1970).

The preceding has been just a bare outline of the aides movement through the agency. To supplement this, one needs some idea of the part played by the Portland New Careers Staff in the training of these aides. Two days or 16 hours release time was allowed the aides, part of which was spent in taking college courses in psychology, cognitive skills, sociology et cetera and part of which was spent in core training, which focused on the development of interpersonal and work skills and remedial education. "Classes placed a heavy emphasis on changing the 'system' and indoctrination on the New Careers theory as superior to other poverty solutions. " 28 If there was a problem concerning one of the aides, they would say that one must look at how the system can change in order to eliminate the problem. Along these same lines, they believed that no person could fail and assumed that the inability to perform was a direct result of not having the right job assignment. Lastly, aides were told that they all had what it takes to become professionals--all they needed was the training. The effects of this philosophy upon the program will be taken up in the next chapter.

28 Ibid. , p. 4. 
The New Careers program at MCPW was not adopted, then, to meet the requirements of the 1967 Social Security Legislation. The program was considered to be a kind of pilot project, as the state was considering it as a possible means of implementation. And, since the new careers aides were already in the agency when the legislative requirement went into effect, they did serve a part in fulfilling the requirements, but strictly on an ex-post facto basis.

\section{WORK INCENTIVE PROGRAM ( WIN)}

\section{Early Establishment}

The following section will trace the evolution of the WIN program, its establishment in the 1967 Social Security Legislation, and its implementation here in Oregon.

In reviewing the evolution of WIN, one finds that:

Within the last ten years, there has been growing interest in Congress in the establishment of work and training programs for people on the Federally-aided public assistance programs. . . . The Work Incentive Program, which was established by the Social Security Amendments of 1967, is the last such attempt to institute such a program. 29

Prior to 1961 , most commentators on social welfare did not deem work

${ }^{29}$ Frederick B. Abnes, "The Work Incentive (WIN) Program: Establishment and Early Implementation, "Library of Congress, Legislative Reference (June 5, 1969), p. 3. The following outline of the programs leading to the establishment of WIN is drawn from this same reference. 
and training programs appropriate for welfare recipients because persons in categories for the blind, disabled, and aged were not considered capable of becoming a productive part of the labor force. Mothers on ADC, it was contended, should remain home to care for their children. Then, in 1961, Congress passed an amendment allowing the states to cover, under AFDC, families which were in need because of unemployment. It was with this addition of presumably employable parents to the rolls that the Community Work and $\mathrm{T}$ raining (CW \& T) Program was authorized. The Public Welfare Amendments of 1962 removed the prohibition against welfare recipients working off grants in which there was federal matching. Two years later, with the passage of the Work Experience Program (Title V of the Economic Opportunity Act), a large amount of money was injected into existing work and training programs, which had only been established in about 12 states at that time. Cash payments and work and training expenses for needy families with AFDC unemployed parents were authorized in those states which either hadn't taken the AFDC option or had not established such programs. CW \& T expired on June 30, 1968; and, in the following year, the Work Experience Program was phased out. Since the Social Security Legislation of 1967 has already been thoroughly reviewed in Chapter I, the following discussion will be limited to those points necessary for establishing a framework within which the action taken by Oregon to implement the legislation can be 
analyzed. In a paper which was issued to the states by the Federal Government, the purpose and potential of the policy were stated as follows:

The 1962 Federal legislation concerning the training and effective use of sub-professional staff as community service aides. . . provides a means for public welfare agencies. . to expand and improve the range and quality of their services, to make them more immediately responsive to changing needs in the community, and to fulfill their goals of service to people.

The legislation is a direct and forward looking response to several separate but closely-related needs in our social and economic situation. 30

Among these were listed the need for manpower, particularly in the human service fields; for the productive employment of large numbers of people outside the labor market; for increasing mutual respect, understanding, and communication among all groups of people in the community--for those who have never experienced poverty to increase their knowledge of the poor and for those who are poor to participate in community services and policy-making groups. In the implementation of this policy, it was stressed that the target group for employment as sub-professional staff was to consist of recipients and other poor persons. Also stressed was the development of a career ladder which would allow persons, according to their abilities and through

\section{0 "Interpretation and Guidelines for Implementation of} Policy and Requirements Relating to the Training and Effective Use of Subprofessional Staff as Community Service Aides and of Volunteers," Xerox copy obtained from Helen Ellsworth, Aide Trainer, MCPW, p. 1. 
experience and training, to advance to positions of increasing responsibility and reward.

Developments in Oregon

Due to a legal barrier, Oregon was given until July 1,1969 , to implement plans for meeting the requirements of the 1967 legislation. The means for implementation was first suggested in a "white paper" (position paper) written and presented by Oregon Representative L. B. Day at a subcommittee meeting on Ways and Means in February of $1969 .^{31}$ At this time Andrew Juras, the chief administrator of Oregon Public Welfare, was presenting his budget to the subcommittee for approval. In Mr. Juras' proposed budget, a statewide salary increase for state employees, funds for increasing staff, and an upgrading of food and shelter standards were called for. Representative Day's alternative was to cut out any money for additional staff, redirecting this (1) to further upgrading of food and shelter standards from Mr. Juras' $\$ 7$ million to $\$ 11$ million, and (2) to the employment of recipients in case aide training programs, with the cost

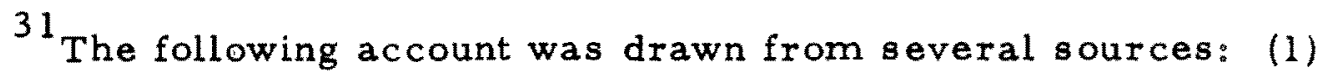
an interview with L. B. Day, May 12, 1970; (2) Song Cho et al., "A Multi-Dimensional View of the Case Aide Training Program in Marion County Public Welfare Commission, "submitted by graduate students of the Portland State University School of Social Work in December, 1969; and (3) L. B. Day's position paper, "A New Shake for the Tax Payer and Welfare Recipients, "unpublished. 
of this added service staff to be met by the difference between Federal matching for assistance payments and that for services. The service opportunity placement was to be a "one-year assignment to some segment of the agency to build a variety of skills which would qualify the participants to move out into other service employment, which is now becoming increasingly available in many communities. $"$ " Of primary importance was the "training," not the work the agency might receive from the aides. It should also be pointed out that the training was not just for training's sake, but was intended as a "meaningful approach in improving self-esteem and helping people move into desirable positions. ${ }^{33}$ The focus then was to be on the rehabilitation of the total individual, rather than merely a modification of his employment status, according to Mr. Day.

In carrying out this plan, Mr. Day suggested that 1000 persons be placed in these aide training positions for the first biennium. The WIN program, he determined, would provide the best channel for implementing the proposal; for the first three months of training would be supplied by WIN, thereby saving the state a considerable sum of money. 34 The legislature, seeing this as a way not only to save money

${ }^{32}$ Day's position paper, p. 6.

${ }^{33}$ Song Cho et al., "A Multi-Dimensional View. . .," Section A. p. 2 .

${ }^{34}$ Much of this information was obtained in an interview with Sister Anne Paula Merrick, State Aide Trainer, on November 5, 1970. 
but also to solve the staff shortage problem, was ready to buy the idea. In the meantime, Wilbur Finch (Director, Staff Development) who had been appointed by Andrew Juras to head up the program, asked Louise Smith, Supervisor of Staff Development (MCPW), to write up some of her experiences. No one else in the agency had had any acquaintance with setting up a program involving the training and use of aides. It was, to a great extent, on the bas is of her recommendations that the welfare administration decided it would not be able to handle much over 150 aides. In addition, it was known that WIN was not obligated to pay for the first three months training, but only to provide an orientation period which might last anywhere from one to five days. The problem then confronting the administration was getting across to the legislators that the agency at that time could not possibly absorb 1000 aides and that after the WIN orientation, the aides would not be already trained and ready for work--this training function would have to be assumed by the agency itself. It was finally agreed that (1) 165 training positions would be allocated for the biennium (July 1 , 1969-July 1, 1971), and (2) WIN would serve as the avenue through which to administer the program.

Something further here needs to be said concerning the reasons for Oregon choosing to go the WIN rather than the New Careers route. For one thing, the Oregon legislature wanted to take only recipients; and WIN participants must be in one of the ADC categories. There 
was also some talk that the departments of the government should get together (Employment Service, which is over WIN, and the Welfare Department). Primarily, however, the choice was more of a reaction to the new careers philos ophy; for example, that part which maintained that no careerist could fail, making it at best difficult for the agency to transfer or drop an aide who really was not "making it" in the program. This is mentioned only to give some indication as to why the New Careers Program was rejected as a means of implementing the 1967 legislation. More of the underlying dynamics will be discussed in the chapter concerned with the problems the aide program has encountered.

In getting the program underway, directives were sent out to the various WIN counties, seven of which agreed to have aides in training by October of 1969. One of the seven was Multnomah County, to which 50 slots were allocated. At that time, there were in the agency three of the original six New Careerists who started in October, 1968; two additional New Careerists, one of whom started in April and the other in September, 1969; and nine Model Cities aides who started in May and June, 1969. The Model Cities aides were hired outright by the agency due to pressure from L. B. Day to "get things moving, "and started as Welfare Aide I's. The first five were selected from 205 candidates interviewed by CEP. At the time they entered training, Helen Ellsworth assumed the position of Welfare 
Aide Trainer, which later replaced the aide supervisor position previously held by Kay Stenberg. The above all come under the title of service aides. In addition, there was also a group of 12 WIN clerical aides which started training on October 1, 1969. (Twelve more were added in February, 1970. $)^{35}$

In September of 1969, the positions of State Aide Trainer and Welfare Aide Specialist were created and filled by Sister Anne Paula and Jim Burri, respectively. Sister Anne Paula set up general guidelines for training the aides who would be starting in October. It was left to the discretion of the individual counties to set up their own specific plans, following the given curriculum; that is, how they planned to set up their programs, who they were going to use, et cetera. This way, the aides were "trained into" the context of the agency in which they would be working. They could learn in the process of doing. From this standpoint, it was probably better that WIN did not accept responsibility for training the aides during the first three months.

\section{WIN Operating Structure}

With this background, the structure of the WIN system can be delineated. The overall operating structure, greatly simplified, is as

${ }^{35}$ The above dates and figures were obtained from Helen Ellsworth, Aide Trainer, Multnomah County Public Welfare. 
follows: recipients are referred by county welfare agencies to training programs run by the State Employment Service, which is under the direction of the U.S. Department of Labor. Beginning with the referral process, it is the function of county welfare agencies to refer individuals to WIN. In making such referrals, there are those which are mandatory (able-bodied men, youths $16-23$ years of age--not in school and without plans), and those which are voluntary (ADC mothers). Once the mandatory and voluntary referrals have been separated, it must be decided if the referral is appropriate, and should be referred, or inappropriate. Persons in the latter category might include those who are ill or who live too far away from training facilities. Appropriate referrals are received by the WIN team which consists of a counselor, job development specialist, and coach (see Appendix B for WIN referral process). At this point, each applicant is interviewed and perhaps tested in order to determine what his objectives are and, if they are feasible, how best he can reach them. This part of the process is what is known as arriving at an employability plan. Applicants may be referred to another agency, rejected, or sent back to the welfare agency, which would in turn determine the number of aides to be hired and select from those referred back by WIN. Those selected go through from one to five days of WIN orientation before entering the agency as trainees. This begins the first three-months training period (WE/T). During this time, it is 
WIN's responsibility to provide a $\$ 30.00$ per month incentive payment and to check on each trainee's progress in the agency. This function is carried out by the team "coach," an indigenous worker, whose role it is to act as an intercessor or advocate in making sure the trainee gets the best service the team can offer. ${ }^{36}$ Welfare takes the responsibility of helping the aides to remain in training by maintaining their grants and providing transportation, day care, clothing payments, et cetera.

A structural clarification seems in order at this point. After the separation of eligibility and service functions within the agency, two aide classifications were established, one the clerical trainee (the first group of which started in October, 1969) and the other the aide trainee, which is the equivalent of a service aide trainee (the first group of which started in July, 1970). Aides from both classifications go through the Work Evaluation and Training period (WE/T), which serves as an assessment period for both the trainee and the agency. All aides are assigned to units (consisting of one supervisor and five or six staff members)--either service units (aide trainees) or units whose primary function is related to assistance tasks (clerical trainees). The specific tasks of the aide vary according to the type

${ }^{36}$ WIN Technical Assistance Handbook, prepared by the Office of Human Resources Development and Training Operations of the U.S. Employment Service, Oregon (November, 1968), p. 20. 
of unit to which he is assigned. With respect to training during this first three months, however, two procedures were stressed for both groups. 37 First, the focus should be on introducing the aide into the agency through a well-planned orientation program and providing him with the beginning skills needed to carry out his assignments. Second, the entire staff should be oriented with respect to their redefined roles and responsibilities as well as to those of the aides. This orientation should be planned prior to and in conjunction with the employment and training of the aides.

At the end of the first three months, the trainee or the supervisor can request that the trainee be referred back to WIN if it seems that the agency placement is not going to work out so that it will be satisfactory for both parties. Most trainees do continue with the agency and are moved into the civil service classification of Office Trainee, which is a six-month durational appointment. At this point, they are put on the payroll, which means that the $\$ 30.00$ incentive payment is discontinued. In the case of men, the grant is also dis continued. Women, however, receive an earnings disregard and thereby draw a partial grant as well as a salary. This six-month appointment constitutes the Trial Service period, during which

${ }^{37}$ Sister Anne Paula Merrick, Guide for Supervisors, Staff Development Section, Oregon State Public Welfare Division (March, 1970), p. 39. 
training continues. By the end of this period, the aide trainees must have qualified for the position of Welfare Aide I or be terminated by the agency. They are qualified on the basis of supervisor and trainer ratings rather than written examination. If they qualify (which, again, most do), they are considered to be regular employees with non-durational status. This procedure differs somewhat for the clerical trainees, who, after successful completion of the Trial Service period, enter a third period lasting for another six months. During this period they must pass a clerical examination which moves them into a Clerk II classification. This would qualify them for departmental promotions to fill clerical vacancies within the agency. If there are no clerical vacancies or if they fail to pass the examination, their training will be terminated at the end of the six months. Aide trainees, then, are given nine months and clerical trainees 15 months to qualify for positions as regular agency employees. Before bringing this section to a close, there are a few significant factors pertaining to the training of these aides which should be mentioned. First, they can apply for up to 16 hours educational release time after the three-month WE/T period. WIN pays for tuition, books, and supplies. Secondly, it was stressed that assignment should relate to the experience of the aide, his prior background, his innate capacities, and his development while in training. Supervisors, however, are warned against giving aides the mistaken 
impression that their poverty background and life experiences are sufficient for them to help people in a meaningful way. Thus, while it is recognized that aides do bring to the agency special knowledge (i. e. , money management, using community resources) and a capacity to relate to and communicate with the people with whom they will be working, it is also recognized that work in the human service field requires other kinds of specialized knowledge; for instance, knowledge of social work principles, concepts, and methods, and of the agency program and the procedures instituted to carry out that program. Lastly, it was consistently noted that aides differ from baccalaureates in the way they learn. This fact, it was stated, necessitates a change in the teaching role of the aide supervisor from the traditional academic approach to one which is built around the concepts of participation and learning-by-doing; for many of the aides have had prior employment experiences which were limited to the assignment of specific tasks, explicitly taught, as each was to be performed. Such experiences can impair one's capacity to generalize. 38 Supervisors and others who work with aides must, therefore, learn to assess the strengths and weaknesses of each aid, to build upon the strengths and to work with and through the weaknesses.

The preceding section has traced the legislation leading up to the 38 Guide for Supervisors, p. 61 . 
establishment of WIN in the Social Security Amendments of 1967;

outlined the steps taken by Oregon to implement this legislation;

delineated briefly the WIN operating structure; and suggested certain training issues basic to the Welfare Aid Program at Multnomah County Public Welfare. 
CHAPTER III

\section{ANALYSIS AND CRITIQUE}

\section{OVERVIEW}

The preceding chapter hopefully has provided a basic understanding of the legislation and philos ophy underlying the development of the Welfare Aide Program and will serve as a reference point to the following discussion. To avoid unnecessary redundancy, the reader will be referred back to material presented in that chapter when a structural clarification seems in order.

The purpose of the present chapter is to examine more closely the program which has evolved in Oregon, and specifically at Multnomah County Public Welfare. While it is recognized that this county is only one among thousands in the nation, it is felt that many of the fundamental problems which have been encountered here are representative of those encountered elsewhere and that they are indicative of the general lack of foresight shown in the original legislation calling for the establishment of programs utilizing aides. It is not intended, however, that this would serve to expiate the exrors which have occurred due to faulty programming on the part of the state itself; nor is it intended that the successes which the program has experienced should be attributed entirely to the legislative action 
taken by Congress in 1967.

Truly the problems encountered have been diverse, and as with any emergent program, have changed--often rapidly--overtime. Since it would, therefore, be a most difficult undertaking to examine them all, the discussion will be limited to those which have persisted since the program's onset and those which have just recently been identified. With reference to the latter, this is not to say that the problems have only recently become apparent, but rather that they have prior to this appeared in the form of unrelated grievances and annoyances. To further lend structure and a degree of continuity, the analysis will focus on difficulties related to the program's three primary components: the administration, the staff members (with whom the aides work), and the aides themselves. Within each of these divisions, there will be an attempt to examine not only the problems which have derived from certain weaknesses in that area, but also those perceived by the members of each group.

The majority of the data cited in this chapter was drawn from administrative correspondence regarding the aide program and individual interviews with representatives from the various levels of staff directly involved in the program. Due to the fact that the primary problems with which the program has been confronted have arisen within the service rather than the clerical segment of the program, the major emphas is has been in this area. Those 
interviewed from Multnomah County thus included 12 supervisors who had service aides assigned to their units as of January 1, 1971, and all but two of the 13 service aides attached to said units. (In one case, there were two aides assigned to one unit.) Those from the multi-service center and ER \& $T$ were not interviewed. The first of these interviews was conducted on January 22, 1971, and the last was completed on March 19, 1971. An attempt was made to keep the time span as short as possible in order to control for changes in program which might have influenced the respondents and thus weakened any conclusions drawn.

One of the primary difficulties encountered in researching this area was the fact that the program has been in such a state of flux since the state first embarked upon the task of developing a means of implementing the 1967 Social Security Legislation. It is a major thesis of this paper that the principle cause of the problems to which this program has been subjected has been the gross lack of clarity in the goals set down by the administration. This indecisiveness has not only stimulated many of the changes which have taken place since the program got underway but has, at the same time, been perpetuated by those changes. Now the difficulty was not necessarily in the changes that were made, for many were necessary and beneficial, but rather in the fact that the changes were unrelated to any clearly specified objective, with the result that the change was often resisted, 
misunderstood, or simply dismissed. However, while achieving clarity of goal--that is to say, a clear understanding of what you are trying to accomplish--is the first and essential step to be taken in getting any program underway, it by itself constitutes nothing more than a futile effort if the policies established to implement that goal are inconsistent with it. Thus, even when goals are clearly set forth, they may become confused by the policies instituted to carry them out. This also has very much been the case with the aide program.

It has been the weakness in these two areas--goal setting and policy development--that has resulted in one of the program's major sources of difficulty, that being goal confusion. A historical review of the various phases through which the aide program in Multnomah County has passed over time will serve to bring this concept into a clearer perspective.

\section{ADMINISTRATION OF PROGRAM}

\section{Community Senior Workers}

Under a grant from the City-County Council on Aging, the first group of aides was brought into the agency in October of 1968. Funding for salaries was provided through a Congressional Appropriation to the Department of Labor which contracted with the National Council on Aging to administer the program. 
The goal of this program was to provide part-time employment in the helping services for persons over 55 who find themselves out of the usual job market because of their age. 1

To implement this goal the following policy was established. With regard to the training component, it was thought that the agency could draw upon the knowledge, skills, and experience which these aides brought to the job, thereby greatly decreasing the time which would otherwise be expended for their training. In the assignment of tasks, the age and physical capacity of the aide was to be a primary consideration; and, as a result, they were limited to service rather than clerical functions. Candidates for the program were selected on the basis of their interest in providing service to people and their ability to work on a half-time basis (as this was one of the stipulations for employment).

One of the first problems which arose as the program got underway was the obvious incongruence between the job description and the tasks the aides were actually capable of performing. One practical difficulty stemmed from the fact that most of the suggested tasks required field visits of one kind or another; but four of the five did not have a valid driver's license, and all encountered some difficulty in stooping or bending and walking long distances. Thus, they were

$1_{\text {Helen Ellsworth and Louise Smith, "The Welfare Aide Program }}$ in Multnomah County, "Multnomah County Public Welfare, Oregon (November, 1970), p. 2. (Much of the following information is drawn from this same reference.) 
confined to service tasks which could be performed in the office.

This pointed up the need to set up some basic criteria for the selection of future aides, which in turn would serve to $\mathrm{screen}$ out of the program many vary capable individuals through whom the program's goal could otherwise have been achieved. A second problem area which also served to screen individuals out of the program was that of salary. One of the original six aides was forced to drop out of the program because her employment made her ineligible for assistance, and her earned income was insufficient to cover her medical expenses. ${ }^{2}$ It did not pay her to work; and yet the goal of the program was "to provide part-time employment." In this instance, then, there was evidenced a degree of inconsistency between the program's goal and its policy.

At present, only three such positions remain at the agency. This resulted from the fact that in July, 1970, the Council on Aging changed its focus to home care for the elderly; and only one of the aides had an assignment which was related to this goal. The number of positions allocated to Multnomah County was therefore reduced by two. Even though the agency lodged a formal protest with the Council, the two positions had to be terminated. ${ }^{3}$

2 Ibid. , p. 2.

${ }^{3}$ For a more detailed analys is of this program, see: Louise Smith, "A Summary of Multnomah County's Participation in the 
New Careerists

It was just a month after the Senior Aides were placed at

Multnomah County that a group of five Service Aides joined the staff under the sponsorship of the Portland New Careers Program. Onehundred percent of the participants' salaries was paid by New Careers for the first year, and 50 percent for the second year, after which time the agency agreed to provide regularly-classified Civil Service positions. 4

The goal of this program was to provide a combination of onthe-job training with formal education, both of which would carry college credit, to provide the participants with the opportunity to earn a full salary while preparing themselves to become fully qualified employees of the agency. 5

At the end of the two-year program, the participants would have earned an Associate of Arts (AA) Degree and the security of fulltime paid employment under Civil Service. Accordingly, they were to be looked upon as social workers in training. It is quite clear then that the program was to have a training focus. To implement this goal, 16 hours educational release time was given the aides for the purpose of attending school and core trainer meetings with other New

National Council on Aging Senior Community Work Project," Multnomah County Public Welfare, Oregon (1969).

${ }^{4}$ For more complete information concerning the development of this program, see Chapter II, pp. 40-44.

${ }^{5}$ Ellsworth and Smith, p. 3. 
Careerists. The other three days were to be spent in the agency for supervision and in-service training which would build upon and give experience in the application of the educational component. With this program focus, it became imperative that the agency commit itself to building a career ladder which would offer a real means of advancement to the aides. The responibility of the New Careers Program, beyond funding, included the provision of a core trainer who would conduct group meetings with the aides outside the agency setting. Such meetings were set up to train the aides around the New Careers philosophy and to provide a source of encouragement and support through group sharing. Consultation to agencies which were experiencing difficulty in implementing the program was also to be made available through New Careers staff.

The problems encountered in the implementation of this program have been many indeed, but so have the lessons learned. Only time will prove which has had the greatest impact. The chief problems perceived by administrative personnel stemmed from what were referred to as "philosophic differences" between the agency's program and that of New Careers. A memo sent from Wilbur Finch, State Director of Staff Development, to Fred Kaatz, State Director of Social Services, concerning a conference with the Multnomah County staff to discuss the training and use of welfare aides shows 
quite clearly what the disposition of the administration was in April, 1969. ${ }^{6}$ The first point of difference noted was concerned with the belief on the part of the New Careerists that one must look at how the system can change in order to eliminate the problem. According to the administration, this point of view overlooked the influence and part played by both personality factors and the factors in the individual's current life situation. A second point of difference was found in the view that "no person can fail." It was assumed that the inability to perform on the job came as a direct result of not having the "right" job assignment. While the administration conceded that this could be a factor in some instances, it was clearly stated that the service goal of the agency would take precedence over the special training needs of the aide. A third point of difference became very apparent when the agency requested the removal of one of the new careerists who was encountering great difficulty in her assigned position and whose functioning in that position was seen to be far from adequate. Because their contract allowed for termination only if mutually agreed upon by the agency and the New Careers faculty, dismissal of the individual in question was greatly delayed and, it was felt, to the detriment of

${ }^{6}$ Wilbur Finch to Fred Kaatz, "Our Conference With Multnomah County Staff to Discuss the Training and Use of Welfare Aides, "Interoffice memo: Oregon State Public Welfare Division (April 11, 1969). This memo will be referred to throughout much of the following analysis. Only special references will hereafter be cited. 
the aide. It was concluded therefore that the agency should think seriously before entering into another contract which would not give the agency sole prerogative for deciding if and when a new careerist should be terminated from the agency program.

One can see from this that the relationship between the agency and the New Careers staff was not a cooperative one. Communication was poor and riddled with feelings on both sides that neither was living up to the other's expectations. Agency personnel saw the New Careers staff as being "eager, idealistic, inexperienced, and somewhat disorganized," while they in turn saw the agency as "strictly establishment" and therefore resistant to change. As other problem areas are discussed, it will become more and more apparent that the goals of this program were not stated explicitly nor were they operationalized in terms of policy statements which clearly conveyed the expectations each party had in relation to that goal.

Another problem area also outlined in the aforementioned memo was concerned with the aide's position or role within the agency. Partly because of the emphasis in the aide's formal training upon the fact that they were in training to become social workers and partly also because of the mixed feelings on the part of caseworkers with regard to what they should ask the aides to do, there was much ambiguity about what the actual role of the aide was. Were they there as supplemental staff or were they to be a substitute for the 
caseworker. At that time, the aides were all in one unit (aide pool model); and all referrals had to be cleared through their supervisor, Kay Stenberg. This process did serve to screen out inappropriate referrals but also demonstrated the role confusion which was taking place. There was great concern that as the aide became involved in providing services to a client which would require a series of contacts, the caseworker might withdraw, not maintaining his needed involvement in the coordination of planning for the case. ${ }^{7}$ It was also pointed out that if confusion as to the aide's role did exist between the caseworker and the aide, it would most certainly be passed on to the client. As a result, the relationship between the caseworkers and the aides was often marked by misunderstanding and frustration. Contributing to this was the lack of consistency between the aides' formal education and their in-service training. What was taught in the classes sponsored by New Careers contradicted that which was deemed acceptable practice within the agency.

A third problem area closely related to the last had to do with a picture of the aide which evolved in the minds of the administrative program personnel. The aide's attitude was generally described as resentful, rebellious, and quite rigid. Because of their prior recipient status, they brought with them to the job hostility toward 7 Ibid., p. 3 . 
the agency, and also a belief that because of their prior status they could better understand and communicate with clients. This often expressed itself in terms of over-identification with the client. It was felt that many of these attitudes came as a direct result of the New Careers "indoctrination" which focused on the "evils of the system." With regard to training, it was stated that the aides must be approached differently in teaching because they learn from the concrete, from their own reference point, rather than the abstract. In general, they were unaccustomed to performing on any basis that involved more than explicit instruction concerning each task. In addition, they require a great deal of support and encouragement whereas a person with a BA comes to the agency with the ability to be self-stimulating and self-starting. Further drawing a comparison between the aides and professional staff, it was pointed out that the aides tended to be quite status conscious.

Unlike the professional staff who may complain about the poor working conditions but concentrate upon the job at hand, the conditions and environment of the New Careerist is of much more vital importance to him--and to the point of immobilization ... The major difference between welfare caseworkers and aides is the sophistication in dealing with their feelings. 8

Somewhat related to this was the concern on the part of the professional staff over the question of confidentiality, which had been posed

${ }^{8}$ Ibid., p. 5. See also the "Progress Report on New Careers Welfare Aide Program, "by Kay Stenberg (mimeographed) for Oregon State Public Welfare (May 27, 1969), p. 6. 
since an increasing number of former clients had come to work in the agency and therefore had gained access to case records. This is reflective too, it would seem, of the confusion over what was seen as a dual role of the aide--past recipient and client, present co-worker and staff member.

Based upon their experience to that date, the Multnomah County staff recommended and stressed the need in planning and budgeting: (1) to provide for sufficient training and supervisory staff to meet the training obligations the agency would have to assume in such a program, (2) to provide necessary equipment and other supportive environmental factors, and (3) to provide for the increase in work which would be generated because of these new staff members. 9 From the preceding comments, it would seem that the aides were looked upon as a special group of people having special needs, requiring special training, and costing extra money. A final comment squeezed in at the bottom of the last page did note, however, that "these persons do seek out and find many unmet needs which would not be met without their presence."

It comes then as no surprise that the agency adopted the position that it did not want to negotiate any further contracts with New Careers. After the original contract expired in November, 1970, the program was to be phased out. The aides of course were to remain

${ }^{9}$ Interoffice memo (April 11, 1969), p. 6. 
with the agency, as they would be regularly-classified employees by that time.

What is proposed here is that a certain predisposition had been built up with respect to the use of aides at Multnomah County Public Welfare, and that this predisposition was quite negative. According to Sister Anne Paula, who entered the program in September of 1969 , the material which had been written up on the aide program was intentionally written in such a way as to point up the negative aspects in order to discourage the legislature from adopting New Careers as the primary means for implementing the 1967 legislation. 10

The memo from which much of the preceding material was drawn did appear just two and one-half months prior to the deadline (July 1 , 1969) for fulfilling the legislative requirements and just two months after Representative Day's proposal concerning the employment of recipients in case aide training programs was accepted. ${ }^{11}$ Thus, therewas a great deal of pressure being exerted--especially by $\mathrm{Mr}$. Day--on State Staff Development as well as on the agency to get something going. It is very likely, therefore, that the administration would over-emphasize the negative aspects of their experience with New Careers, not only for the purpose of discouraging it as a means

${ }^{10}$ Taken from an interview with Sister Anne Paula Merrick (November 6, 1970).

11 See Chapter II, p. 47 for further information concerning this proposal. 
of implementation, but also to show that it was simply unrealistic to talk in terms of bringing 1000 para-professionals into public welfare for training at that time. Other than this, however, the atmosphere within the county was reportedly quite good. People were reacting more against the New Careers philosophy than against the idea of utilizing aides within the Welfare Department. But, the programs which have followed have not borne this out; for many of the problems which the program is presently encountering certainly are reflective of certain attitudes, feelings, and misunderstandings which arose during this time. This carry over will be examined more fully in the section which deals specifically with the WIN Aide Program, which was mandated by the 1969 legislature as the only means through which aides may now be brought into the agency.

A final comment should be addressed to the part--too often underplayed--the agency had in the discontinuance of the New Careers Program; for this resulted from weaknesses in both systems, not just New Careers. Seeing now the kinds of difficulties which did develop, it is interesting to look back at the original goal of the program: to provide the participants with the opportunity to earn a full salary while preparing themselves to become fully qualified employees of the agency. And it will also be remembered that the focus was to be on training these aides for social work positions; thus they were considered pre-professionals rather than 
para-professionals. This meant, of course, that the agency would have to make provision for their upward mobility; it would have to build a career ladder. And this it undertook to do. But the New Careerists were given reason to believe that a career ladder would be developed much more rapidly than it was. ${ }^{12}$ At present, all of the aides hold Welfare Aide II positions and have either obtained their AA degree or are nearing completion, and there is no place else to go--they are "dead-ended." They do not hold social work positions; they are still aides, and they will remain aides until such time as the agency lives up to the agreement which was made originally or until they are able themselves to expend the time and money necessary to complete the remaining two years of college education which is now required to obtain a $B A$ degree. The latter option is realistically not a feasible one for most of the aides whose present salary is sufficient only to cover living expenses. Nor is it feasible in terms of the tremendous amount of perseverance necessary to complete two full years of schooling with only eight hours per week educational release time available. It would definitely take longer than two years, and realistically would be closer to four. It is understandable that so

${ }^{12}$ Taken from an interview with Helen Ellsworth (March 23, 1971), who was the Aide Trainer for Multnomah County until January, 1971, when she was appointed to the position of State Aide Trainer under the new Public Service Careers Program. 
much anger has arisen around this issue.

What happened, it seems, is that the agency undertook a task for which it was unprepared. The goal was and certainly is a valid one, but it ". . . was too remote and unachievable within the time limit of the program itself, $1{ }^{13}$ and also within the limits of the agency's knowledge and experience. This shows clearly the necessity of looking carefully at what exactly will be required if the stated goal is to be reasonably achieved. In this case, the expectations were set too high. New Careers tended to lump all of the aides together without individualizing their capacities or even their motivation for climbing the career ladder; and the agency supported this by telling the aides that a career ladder would be ready for them. It almost seems that in the beginning stages, the aides were left with little choice. The expectation was set for them. It was interesting that in interviewing these aides, only one expressed a real desire to go on and become a caseworker. ${ }^{14}$ Of the others, one thought she might, one was unsure, one said she definitely did not want to be, and the other said she would if that was the only way she could get financing for further education. These were quite satisfied with what they were doing except for the fact that they did feel somewhat constrained by their

\section{${ }^{13}$ Ellsworth and Smith, p. 4.}

${ }^{14}$ The interviews were conducted during the period of January $22-\operatorname{March} 19,1971$. 
position as aides, which they saw as being quite narrowly defined in terms of the responsibility and decision-making power assumed to go with that position. (This point is more fully discussed in the section on Aides.)

This latter issue is directly related to a failure on the part of the administration to follow through with another of its commitments, that being to develop clear job descriptions. This problem first began to be spelled out clearly late in 1969 , as it became apparent that there was no precise delineation of the appropriate areas of functioning for the aides. No job boundaries had been established either with regard to each category as an entity or with regard to the developmental process within each category. ${ }^{15}$ Since no provision had been made to extend these boundaries, tasks tended to remain static, growing neither in complexity nor in the degree of skill required to perform them. Of course, to make such a determination would necessitate a thorough-going task analysis. Such an analysis would provide a basis for differentiating performance expectations. Training could then be so organized as to enable the aides to develop skills in a sequential order. A system such as this would also allow for individualization in the developmental patterns of the aides. This

${ }^{15}$ Helen Ellsworth to Louise Smith, "Consideration of Certain Problems Affecting the Welfare Aide Training Program," Interoffice memo: Oregon State Public Welfare Division (November 18, 1969), p. 2. Much of the following information is drawn from this same memo. 
whole concept is, of course, intimately related to the development of a career ladder. While it is feasibly possible to build a career ladder without differentiating tasks and the skills needed to perform them, it is certainly not realistically possible; for there is really no other valid basis upon which to discriminate between steps. The length of time one has been with the agency (a measure which is often used) may or may not say something about the quality of the work done during that time. Thus, the agency really could not afford to develop a career ladder without meaningful job descriptions of the kind described. Failure to do this has resulted in confusion, ambiguity, frustration, and anger--all of which could have been held to a minimum had the agency's goals and expectations been more in line with what it could realistically produce.

\section{Model Cities}

In May of. 1969, just six months after the New Careerists began their program, five aides were hired to work in a newly-developed segment of the Public Welfare agency in Multnomah County, the Model Cities Department. Two months later, three additional aides joined this group. The distinguishing feature of the Model Cities Aides was the fact that their salaries were paid entirely from agency funds; no outside sponsors were involved. They were brought onto the staff under the Welfare Aide classification which had been created as a 
result of the New Careers program. While the program was described as, ". . a part of a special demonstration project to test the use of pre-professional staff in a public welfare agency. . . the focus of which was to be on learning what tasks are appropriate for aides, . . the goal of this program has never been clear. 16 Ambiguity in policy formulation has been the consequent result.

To understand the nature of the policy which did develop, one must again look back to what was happening just prior to the establishment of this program in April of 1969. The "Day Bill," as it came to be known, had just been adopted and, as was stated before, there was a tremendous amount of pressure to begin programming. Needless to say, there was little time to develop a program constructively. And, as often times happens, the only alternative was to put something together hurriedly and call it a test project. This is not intended to give the impression that such was not done with the best of intentions; for those involved did see it as a good opportunity to practice and test the team concept on which they were really sold at that time. This concept was a divergence from the supervisory model followed by New Careers in that each aide was to be attached to a single unit rather than to an aide pool. Other than this divergence, however, the project was to be patterned after the New Careers model.

${ }^{16}$ Ellsworth and Smith, p. 4. 
The expectation was that they would be given the educational release time to attend school and obtain their AA degrees, with the thought in mind of moving them into social work positions, perhaps as assistant service workers after that. This, of course, was based on the belief that a career ladder was being built and would be in operation within the not-too-far distant future. This expectation was passed along down the lines from Personnel to Sister Anne Paula to Louise Smith in Multnomah County and finally to the aides. Insofar as the aides are concerned, this expectation became fixed in their minds; this is what everyone had told them, this is what they believed, and this is what they were looking forward to.

A word about their selection seems significant at this point: "The selection criteria included that they be economically disadvantaged and that they be residents of the area served by the Model Cities Department. "17 with such general criteria, it is interesting that all of the aides selected had earned a high school diploma, had hopes of continuing their education, and had all been quite involved in community work prior to their selection. They also tended to be very outgoing, very assertive, and very determined. It seems, then, that the "goals" of the program did have some bearing on the kind of people chosen to take part in it. They wanted individuals who were 17 Ibid. , p. 4. 
"upward bound," who would take full advantage of what was being offered, and this is what they got.

The aides wasted no time in getting to work and, as one of their first projects, developed an educational plan which stated the purpose, objectives, and means by which it could be implemented. The plan shows clearly the aides' readiness and willingness to become involved in program development (see Appendix C). It is of little wonder, then, that the aides voiced great frustration when, by August, this plan which had been submitted to Staff Development in May--four months prior--had neither been answered nor responded to. ${ }^{18}$ The aides were also resentful that they had not been included or consulted in the writing of a new project for the coming year. This was interpreted as unwillingness on the part of the agency to learn firsthand the problems in the community. 19

The matter of the nature and degree of the aides' participation in programming was just one area in which problems began to develop. Four other areas of dissatisfaction were delineated in the Aide Trainer's progress report on the Model Cities Aides which was written three months after they had joined the staff. ${ }^{20}$ The first of

$18 \mathrm{Jim}$ Burri to Bertha Roth, "Welfare Aides in the Model Cities Department, "Interoffice memo: Oregon State Public Welfare Division (August 14, 1969), p. 1.

19 Ibid. , p. 1.

${ }^{20}$ Helen Ellsworth to Louise Smith, "Report on Model Cities Service Aides," Interoffice memo: Oregon State Public Welfare 
these was their increased hostility toward the service workers which seemed to be based on the following. Some of the service workers with whom they were working held bachelor's degrees in fields unrelated to social services and were not equipped with profes sional skills. The aides felt also that they were working longer and harder than either the assistance workers or the service workers with the accompanying feeling that there existed an inequity in differential pay. It seemed that large salaries were being paid to workers who were not delivering adequate services. The aides therefore advocated that pay be based on merit rather than tenure. With regard to service delivery and particularly to clients as the recipients of service, the aides saw the service workers as being ill-equipped to work effectively due to their lack of knowledge about the community--its problems, its customs, its resources, its needs. In some instances, they also saw a lack of sensitivity toward clients, instances in which confidentiality was broken. Related to both of these--the fact that they saw themselves as representatives and as advocates for the black community-they felt that they were in a better position than the white service workers to effectively relate to and communicate with black clients. This claim on the part of the aides--that they worked harder than the service workers and that they were better equipped for the job--might

Division (August 21, 1969). Much of the following information was drawn from this material. 
be viewed as high handed and arrogant by some, but there was apparently an element of truth in it; for the workers felt very threatened by the aides. 21 The aides did move into an all-white service staff; and, since as individuals they were very assertive by nature, as a collectivity which was trying to interject itself into program development and policy making, they probably did appear quite threatening. But again, following a New Careers model, this was the role ascribed to the aides--to be a member of a team which was working together toward the best possible system of service delivery and to be an advocate for the client about whose needs they had special knowledge. For the most part, therefore, the breakdown in staff relations can be seen as deriving from the tremendous time pressure which did not allow for proper establishment or communication of goals.

The second area of dissatisfaction expressed by the aides was related to their increased questioning of the value of services in the Model Cities community. They felt that the level of service to that area had always been low and that specialized services were not really being provided. They also saw many clients as being resistant to social services and accepting them only because of their fear of the authority of the white caseworker, who has the power to cut off

21 Conference with Helen Ellsworth, State Aide Trainer (March $30,1971)$. 
their grants. Thus, in setting priorities, it seemed that the clients need for more money took precedence over their need for services. Directly related to this was the aides' dissatisfaction with the financial limitations of Welfare. There was never enough money for special needs particularly in the area of medical services, and they saw people suffering because of this. Much of their blame was projected on the State Administration and particularly on the State Administrator. And it seems that the administration in turn was quite threatened by this. In his report of a meeting with the aides and other administrative personnel, the Project Coordinator reported that, ". . they [referring to the aides] also attacked our low standards and said that if standards were higher, there would be less need for medical expense. 122 He concluded his report with the following remarks:

It appears to me that although the aides are more direct in expressing their feelings, they stated many of the current problems which service workers and supervisors in both Multnomah and other counties have expressed with more professional language and in nicer terms. . . We must help the aides work through their feelings, possibly with greater care than we do with other staff members, or it is very likely that such outspoken criticism of our agency will be threatening to a great many people. 23

It would have been interesting to have had him explain who the "great many people" were who would have been so threatened.

$$
\begin{aligned}
& 22 \text { Interoffice memo (August 14, 1969), p. } 1 \text {. } \\
& 23 \text { Ibid. , pp. } 2-3 \text {. }
\end{aligned}
$$


Increased anger about the use of themselves as aides constituted the last major area of dissatisfaction. It seemed that they were being used either as specialized aides or as "flunkies" assigned to do odd jobs. This dissatisfaction first emerged when two of the five aides were placed in Intake on July 1. Prior to this, they were each attached to service units and had been involved in what they considered to be meaningful job assignments. In these units, they had also begun to build good working relationships with some of the service workers, and they were really feeling a part of the team effort. When another aide was assigned to medical transportation, it seemed that this was being lost and that the team concept which they were hired to test was being abandoned, as far as their participation was concerned.

While the preceding does describe to some extent what was happening, it does not really explain why it was happening. Some of the significant factors appear in the following statement made in reference to the aides in the Model Cities Program:

These aides have not had the same advantages of financial support with formal education that all the other aides have had. Their in-service training has been less formalized and has been less consistent than with other groups. Because of the departmental and administrative problems, due primarily to work overload, these aides have lacked consistent and strong supervision, and there had not been an opportunity for a good analysis of the appropriateness of their task assignment.

Their supervision, their assignments, their training have all 
changed from time to time with little warning or preparation. 24 Perhaps an example from each of the distinct areas mentioned will better convey the nature of the difficulties being encountered.

With regard to the aides' formal education, early in 1970 , an eight-hour cut back in educational release time for the new WIN Aides coming into the program as well as the rest of the aides already in programs was proposed. ${ }^{25}$ This came as a part of the changes taking place in the way the program was moving; and more specifically, from seeing the aides as social workers in training to seeing them as supplemental staff who could take the load off the caseworkers and do it for less money. With this kind of objective emerging, there would be little need for formal education. There was even talk of abandoning the training component altogether. Such a proposal was strongly reacted to by those closely involved with the aide program, by those who knew how essential training was to the development of the aides. The reaction grew into a struggle, fought with a barrage of verbal and written correspondence. A particular concern was voiced for the Model Cities Aides who were still in school and to whom commitments had been made concerning their formal education. Another broken commitment might have fixed their hostility and anger toward the

\footnotetext{
${ }^{24}$ Ellsworth and Smith, p. 4.

${ }^{25}$ Conference with Helen Ellsworth (March 30, 1971).
} 
administration for good. Fortunately, the administration did agree to make an exception in the case of the Model Cities Aides and to continue the 16 hours per week release time until they received their AA degrees. It was also agreed that the incoming WIN Aides would be given 16 hours release time for the first nine month training period and then be reduced to eight hours upon their classification as regular agency employees.

The aides' in-service training has been characterized by shifting and inconsistency. At one point the aides were moved from the back portion of the building up front to where center staff was located. This left an all-white service staff in back and a practically all-black staff out front. The reason given for this was over-crowding. Set apart this way, they formed a tight nucleus. This move thus served to break down the relationship they had had with the caseworkers. At th time of the aides'move, they were not given mailboxes, and were not receiving mail addressed to "all-staff." Such actions certainly do brutalize staff relations and can destroy any possibility of using a "team" approach.

In the area of supervision, keeping communication lines open has been a major problem. Whenever a crisis such as those mentioned above would arise, Helen Ellsworth (Aide Trainer) was called in by the aides, with the result that they were using her as a means to channel their complaints. Each time this happened, the 
administrative staff would promise to begin meeting with them on a regular basis so there would be an opening up of communication; and each time there was a failure to follow through. Consequently, they have continued to call Mrs. Ellsworth in on a "crisis intervention" basis and, one would suspect, have become very skeptical about using channels as a means for getting things done.

Lastly; and certainly as a consequence of the weaknesses in the aforementioned areas, no well-defined job descriptions were ever developed. Recommendations to develop job descriptions were responded to with recommendations to help the aides work through their feelings and change their attitudes. But, as was pointed out as early as August, 1969, ". . the aides will continue to feel frustration until their actual assignments more closely approximate their earlier job expectations. $1{ }^{26}$ There was no career ladder emerging; and they too, upon completion of their AA degrees, would be dead-ended. They were led to believe that it would be worth their while to expend the extra effort and time necessary to attend college; but the agency found that it could not build career ladders as fast as it had built the hopes and aspirations of the people who were to climb them.

And this brings us the full circle--right back to the necessity of establishing goals with their related expectations and developing

26 Interoffice memo (August 21, 1969), p. 2. 
"enabling policies," which will make the achievement of such goals possible.

WIN Aides

Before outlining the goals and policies of the WIN Aide Program, it is important to examine the disposition of the aide program in general prior to the introduction of the first WIN service aides in July of 1970. Of course, there were clerical aides placed through WIN in Multnomah County as early as October 1, 1969. But the focus here will be on those occupying service aide positions, as this is where the greatest degree of goal confusion has taken place.

The first WIN counties to have aides in training were:

Clackamas, Deschutes, Jackson, Linn, Marion, Multnomah, Malheur, and Umatilla, This was in October, 1969. During the first few months, when these counties were getting their programs underway, each was visited by the State Aide Trainer from Staff Development. By February, 1970, 12 of the 14 WIN counties had aides in training. Two reports which were written (one in early December and the other in early March) as a result of these visits provide a summary impression of the various programs during those first few months. 27 One of the primary concerns expressed was with the Director of Staff Development, "Welfare Aide Program," Oregon State 
training of the aides. Job descriptions were neither clear nor structured, and there was no growth in the complexity of tasks consistent with skills. The difficulty in structuring tasks comes in part from the fact that the aide's individual strengths and weaknesses must be taken into account; some aides naturally progress more rapidly than others and must be assigned tasks which build upon their increasing skills. This process was also complicated by the fact that the aides were limited to providing mandatory services, with the result that caseworkers were finding it difficult to keep them constructively busy. For the aides, this meant that they were sometimes left with little or nothing to do, which was certainly not the most appropriate way to use their special abilities and experience to best advantage. For the clients, this meant that in many cases they were being deprived of needed services. Caseworkers were further limited in making assignments because of the difficulty in distinguishing between clerical and service tasks. And again, this was a disservice not only to the caseworkers and the aides, but also to the clients who they are employed to serve.

More supervisory time is necessarily required when such constraints exist. Supervisory spans are too large as it is without

Public Welfare Division (December 5, 1969); Sister Anne Paula, Welfare Aide Trainer to Jim Burri, Aide Planning Specialist, "February Report," Interoffice memo: Oregon State Public Welfare Division (March 5, 1970). 
without supervisors having to spend their time instructing their caseworkers in the proper use of welfare aides--an area which they themselves often find ambiguous. Training seemed to be progressing better in those counties which employed an aide trainer, for then there was someone to whom questions could be referred for clarification. Beyond this, however, a general need to allow counties more latitude in developing their individual programs was stressed. Just as the needs of individuals differ, so do the needs of counties. While it is important that every county set up firm guidelines for the use of aides, it was recognized that this was not a function which the State could carry out for them.

A second area of concern was that related to the referral and selection process. WIN referrals had bogged down though it could not be determined at what point. It was suggested that other sources of referral might have to be considered when, in the future, greater numbers of aides would be employed. This as well as other factors had affected the selection process so that seemingly inappropriate placements were being made. In one instance, a college graduate had been placed in the program; and in another instance, one of the aides had left a good-paying job to join the program. Both aides were interested in the helping services; and the intent, of course, was not to screen such individuals out of the program simply because they had had too much education, but rather to use to full advantage those skills 
and experiences which each brought to the job. The question was whether this could be done in the placements which had been made. This pointed up, too, the necessity of developing a career ladder which would offer a legitimate place to such persons.

A final concern, which appeared in the February Report, was voiced in response to certain of Mr. Day's criticisms which had appeared in a recent paper. The first of these criticisms was the claim that Welfare was using the aides to fill staff needs and not working toward helping the aides to become more independent. This was denied, and the commitment and enthusiasm which were displayed by both the aides and the agencies involved--despite their difficulties-was cited as proof of this. His second criticism was not new to persons involved in the program, for he had been complaining that the program "wasn't moving fast enough" since its establishment. In response to this, the writer could only reply that $\mathrm{Mr}$. Day did not realize the amount of preparation required in getting the recipients ready for aide positions nor did he understand the problems currently confronting the various counties. If things were to "move faster," certain facts would have to be faced; such as, the lack of space in county offices, the lack of cars available for field visits, the lack of trainers and supervisors--not to mention financial resources for formal education--needed to meet training needs. Without adequate provision in these areas, the career ladder would become a 
meaningless succession of steps from Welfare Aide I to II to III and so on.

In reviewing this Report, it seems that the reaction was rather strong--and justifiably so--not only because of Mr. Day's recognized lack of understanding of the program's needs, but also because of the many positives which were seen by those closely involved with the program.

Of most significance is the commitment shown by the aides, wherever I go. They want to work for Public Welfare. Despite all the difficulties they might have encountered, they are all anxious to continue.

Another significant factor. . . is the commitment of the counties. As a whole, they are really putting lots of effort into making this program a success. 28

At this point in the program's development, then, various problem areas were being identified, but the outlook in general was quite good.

This was shown also in the responses received on a questionnaire distributed to supervisors, caseworkers, and aides in six county offices. A summary of the responses which had been received and tabulated as of January, 1970 shows the reaction to the program at the staff level. $^{29}$ Just as in the State Trainer's Report, problems were apparent. In answer to the question of what they saw as the biggest

28 Interoffice memo (March 5, 1970), p. 1.

29 Sister Anne Paula to Gordon Gilbertson, "Responses on Questionnaire on Aide Program, "Interoffice memo: Oregon State Public Welfare Division (January 29, 1970). 
problem, supervisors and caseworkers most frequently responded that it was the lack of time for proper planning around training, while the aides responded that it was the uncertainty and confusion of the program. The fact of the program's uncertainty and indefiniteness was underscored in the supervisors ${ }^{\prime}$ and caseworkers' responses to what they disliked most. In view of this, it is not surprising that what they considered to be needed most was a more definite program and resources to meet training needs (supervisors), more guidelines and help in the use of aides (caseworkers), and more training (aides). The best solutions for the problems were seen as coming from more experience and sharing; and problem solving was considered almost unanimously to be the duty of all concerned, though some of the aides did tend to look more to persons in authority positions (State staff, supervisors, Mr. Day) for leadership in this area. On the positive side, the aides stated that what they liked most was the opportunity to serve and the interest of their fellow staff members, who they also felt had been the biggest help to them. Caseworkers and supervisors agreed that the additional service to clients and thus better coverage of needs had been the biggest help to them. Both noted that they liked the willingness and enthusiasm displayed by the aides in providing service. While all groups responded that the program should continue and expand it was interesting that the aides were the only ones who strongly recommended that the program be planned more carefully. 
One could speculate that they tended to feel the impact of the current problems more than the other staff members, perhaps because their own futures were so intimately related to the future of the program. It thus became extremely important to them that the program got off to a good, sound start.

The aim of the preceding section has been to acquaint the reader with some of the problems confronting the WIN Aide Program at its onset; and in the section that follows, an attempt will be made to link these problems with the concept of goal confusion, presented at the beginning of this chapter. That goal confusion did exist is apparent by the very fact that the counties were so unsure of the limits within which they were to operate. It was recognized that,

... the state [had] been delinquent in clarifying the program, its basic goals and working principles. The program [had] changed from week to week. Tasks that were approved one week are off the list the next. This [had] led to much confusion. 30

How could counties be expected to train without understanding the purpose for which training was being done. This question was raised most pointedly when the cutback in educational release time was proposed; for this cutback, as a policy statement, would indicate a refocusing of objectives. Prior to this, the objectives followed were those written by Wilbur Finch and adopted by Sister Anne Paula when she assumed the position of Welfare Aide Trainer for the State. These ${ }^{30}$ Interoffice memo (March 5, 1970), p. 1. 
were the only ones available to her at the time. Her first request, upon accepting the position, was for a statement of the program's goals and objectives. 31 In response to this, Mr. Kaatz told her to "write her own;" his only goal at the time had been to satisy Mr. Day. The goals set forth by Mr. Finch were as follows:

1) To enrich and expand social services to clients.

2) To develop training and career opportunities for welfare recipients and persons of low income in the helping professions. 32

Considering the implications of the second, one can understand why the reaction to the cutback was so strong. Education plans had been developed, counties were told that trainees could attend school up to three half-days a week, aides were encouraged to go on to school to work toward their AA degrees, educational contracts were in the process of being set up for the aides with various community colleges--all in accordance with the assumed goals of the program. When you cut back your training component, what happens to the goals of the program? It begins to look like the main goal of the program is that which Mr. Juras implied when he spoke to administrators early in October of 1969. Bringing aides into the agency was the only

31 The following is taken from an interview with Sister Anne Paula Merrick (May 29, 1970).

${ }^{32}$ Wilbur Finch, The Training of Welfare Aides in Providing Social Services to Clients, Oregon State Public Welfare Division, Staff Development Section (June 1969), pp. 3-4. 
means by which he could offer additional staff to the counties. 33 Here then is a prime example of a program's goals being confused by the policies established to implement them.

The other source of goal confusion suggested at the beginning of this chapter was the constant state of change in which the aide program has been involved. A brief review of the major changes in program will demonstrate more clearly the process through which goals have been modified and will also serve as a basis for examining the carry over from those early programs to the present one.

In the first aide program (Community Senior Workers), the goal was to provide part-time employment in the helping services for persons over 55 who find themselves out of the usual job market because of their age. It is evident that the focus of this program was quite limited and that it was not intended as a possible means of implementing the 1967 legislation. However, the experiences in working with these aides did teach the agency some important lessons-particularly about devoloping selection criteria and the grave difference seemingly little things like a driver's license and health factors make with regard to the aide's success in the program.

The goals of the New Careers Program have exerted the greatest influence on the present program. New Careers was to provide a 
combination of on-the-job training with formal education so that participants would be able to earn a full salary while in training. The objective was to move these aides into social work positions within the agency. Thus, it was strictly career-oriented. As was stated earlier, such a goal has broad implications with regard to program planning; and in this instance the administration found that it was unprepared to meet the commitments it had made in relation to these goals. On the basis of this experience, New Careers was rejected as a means of implementation. However, when this decision was made, there was no reassessment as to what the goals should be; and, as a result, when the Model Cities aides came in May, 1969 , they were still given the idea that it would be to their advantage to work toward an AA degree. Because this program was to a large extent a product of the pressures being exerted at the time by Mr. Day, these aides experienced a much more difficult time in getting the supports necessary to help them toward their goal. Had the agency really been committed to this goal, more of an attempt would have been made to provide such supports. It seems, however, that there was increasing doubt about the appropriateness of this goal, which probably came in large part as a result of the negative experiences the agency had had in trying to implement it successfully with the New Careerists.

It was in the midst of this doubt and confusion that the present 
WIN Aide Program got underway. And, since the goals still had not been reassessed, the program again started out with a heavy training emphasis and career orientation. Educational release time was reduced to eight hours per wekk after the first nine months under WIN. but aides were still being encouraged to work toward an AA degree during these nine months. Thus, there was a training position with only a halfway training program. ${ }^{34}$ Policy became more and more remote from the goals. When the next cutback in training time was proposed, it became quite clear that the development of training and career opportunities was no longer a major goal.

What then was the goal and what is it now. The "stated" goal is as follows:

- . to provide additional staff to perform services to clients through the use of preprofessional persons. . . The aides gain competence in providing services through work experience, inservice training, and formal education. 35

Certainly, this represents quite a change and demands that refocusing be done in other areas, particularly the aides'training and supervision. Most supervisors agree that supervision is geared largely to the goals of the supervisee, insofar as they are realistically attainable by the individual in question. It therefore follows that the aide whose goal it is to become a caseworker will be supervised and trained differently than one whose goal it is to remain an aide. (There is no difference with regard to quality of supervision implied here nor should

34 Ibid. , pp. $1-2$.

${ }^{35}$ Ellsworth and Smith, p. 6 
there be.) And, to take it one step further, the program goals which are communicated to the supervisor will also have a great bearing upon the way the aide in that unit is trained.

That the goals of the WIN service aide program were not clearly communicated and that they had become confused with those of prior programs--at least in Multnomah County--became quite evident in comparing the responses which were given by supervisors when they were asked to define the goals of the program. Major disagreement occurred over the issue of whether program objectives were focused on the agency or on the aide. Were the aides there as supplementary staff for service to clients or were they there to obtain training around employability skills. There was a fairly even split on this issue. Of those who saw the objectives as centering around agency needs, some viewed the aides as a means simply of providing additional staff, some as a means of expanding service, and others as a means for training apprentice caseworkers. Those who tended to view the program as being more aide-centered saw the agency in terms of what it was providing for the aide--a job, experience and training, employability skills. There was a difference in opinion as to whether the aide was intended to remain with the agency or was being trained to work elsewhere. Lastly, the majority felt that implicit in the program's objectives was the idea that removing recipients from the roles by giving them jobs in public welfare would save the state money and provide "cheap labor" at the same time. They agreed that this was not 
only an inappropriate goal but also an unrealistic one in terms of the aides' cost to the agency. It was significant that nine of the 12 expressed negative attitudes toward the way the program has been administered--primarily in regard to the lack of clarity or the inappropriateness of program goals.

\section{Negative Predisposition}

To conclude this section, the authors will examine the hypothesis that a negative predisposition had been built up with regard to the use of aides at Multnomah County Public Welfare and that this has at least indirectly affected the state's program. What is being said then is that the state's early experiences with the aide program (particularly New Careers) influenced the development of the program which was mandated to fulfill the 1967 legislative requirements. This influence took the form of certain biases related to the worthwhileness of the program and the nature of the aides. It is recognized, of course, that the first programs were experimental; they were intended as pilot projects to test the use of aides, and it is only reasonable that past experience would be taken into account in the structuring of present reality. But in the case of the aide program, there had been several changes in the goals and policies of the program which made the application of past experiences inappropriate in certain instances. As an example, aides who are in training to become social service 
workers should not receive the same kind of training nor should they be evaluated in the same way as those who are planning to remain aides. Likewise, judgments which are made concerning the way individuals learn and respond under one set of conditions do not necessarily apply in a dfferent situation.

Referring back again to the memo dated April 11, 1969, which was a report of the experience to date with the aides who had come to the agency in October and November of 1968 (Community Senior Workers and New Careerists), one will recall that much of the correspondence written at that time was intended to discourage the choice of New Careers as a means for implementing the 1967 legislation. Yet, many of the statements made in that memo appeared in the guidelines prepared for the training of welfare aides by county welfare departments in Oregon. In the guidelines printed in June, 1969 the Director of Staff Development stated:

In developing these guidelines, I have drawn heavily upon the experiences of Multnomah County who under the direction of Louise Smith. . . and Kay Stenberg. . . have developed and tried various patterns of training for Welfare Aides. 36

Later, in March of 1970 , when the agency was preparing for the introduction of the first WIN Aides, a similar statement appeared in the new Guide for Supervisars:

${ }^{36}$ Wilbur Finch, The Training of Welfare Aides in Providing Social Services to Clients, Oregon Public Welfare Division, Staff Development Section (June, 1969), frontispiece. 
Credit for this guide rightfully goes to many people. Much help came from the Multnomah County Staff who did the initial experimental work with aides. 37

Many of the statements which appeared in the memo and later in these guidelines were concerned with the aides' approach to learning and their job readiness. Compare, for example, the following three statements:

1) One of the advantages which has been gained in the past by having a permanent staff with at least their Bachelor's degree is that these people have come with some ability to be selfstarting and self-stimulating. However, with Welfare Aides, they are less likely to have previously performed work that involved more than a kind of explicit instruction to each task that is assigned. [Memo, p. 4]

2). . because of his education, the caseworker comes to the agency with an ability to be self-starting and self-stimulating in the way he learns the tasks of his new job assignment. The Welfare Aide, on the other hand, is more likely to have had prior employment experiences which were limited to the assignment of specific tasks, explicitly taught, as each was to be performed. [June, 1969, p. 4]

3). - because of his education, the Caseworker comes to the agency with an ability to be self-starting and self-stimulating. The Welfare Aide, on the other hand, is more likely to have prior employment experiences which were limited to the assignment of specific tasks, explicitly taught, as each was to be performed. [March, 1970, p. 61]

The point here is not to argue the correctness of these statements, but rather to point out that they convey a certain picture of the welfare aide, which may or may not be representative of the present aides.

${ }^{37}$ Sister Anne Paula Merick, Guide for Supervisors, Oregon State Public Welfare Division, Staff Development Section (March, 1970), p. i. 
Another series of comments which appears in both the June, 1969 and March, 1970 guidelines describes some of the problems which were to be anticipated and planned for in the training of welfare aides. All of these comments were drawn from the April, 1969 memo. Brief segments of the most significant of these will be presented to give a clearer understanding of the picture being presented of the aides. Statements from the June, 1969 guidelines are omitted in the following, as those from March, 1970 were copied directly from them.

Memo (April 11, 1969), pp.4-5:

1) aides bring considerable hostility towards the agency to this job because of their past dependency.

2) aides quickly become aware of the differential treatment of clients by different caseworkers and resent this.

3) their image of "professional" as being detached unfeeling, and unconcerned. . . must be handled.

4) they. . see little difference between their own skills and the skills of a caseworker.

5) aides, as they learn about new resources. . first want to know if they and their friends can have these.

6) the major difference between caseworkers and aides is the sophistication with which they handle these feelings.

7) the conditions and environment of the new careerist is of much more vital importance to him.

Guidelines (March, 1970), p. 63:

1) because of their prior dependency many trainees are going to come with considerable hostility and fearfulness of the agency. 
2) aides can be sensitive to what they perceive to be the differential treatment of clients.

3) aides may come with an image of "the professional" as being detached unfeeling and unconcerned about a client.

4) aides may tend to see little difference between their skills and those of the caseworker.

5) as a new resource is available to clients, the aide may first want to know if he and his friends can take advantage of this opportunity.

6) if aides differ markedly from the new caseworker. . . it is more likely to be in the sophistication with which these attitudes are expressed.

7) the working and environmental conditions can be of critical importance to some staff, including the Welfare Aide.

The conclusion to be drawn from such a comparison is this. Too much emphasis was placed on the agency's (MCPW) experience in the New Careers Program--to the extent that it has biased individuals and predisposed them to think about the aides in certain ways. It is true that the program had its problems and that the agency should guard against setting itself up to face the same kinds of problems again. But the way it is presented, the responsibility for this is placed with the aides and the New Careers philosophy, with little mention being made of the administration's failure to follow through on its commitments--for whatever reasons. So, the aides received a "bad press." To what extent this is being applied to the present WIN Aides will be discussed in the next two sections which analyze the program from the perspective of the staff and the aides. 


\section{STAFF PERSPECTIVE ON THE PROGRAM}

To begin, the persons included in this category are the caseworkers and supervisors who have worked with the aides. Material for this and the following section is drawn primarily from the individual interviews conducted at Multnomah County Public Welfare with the WIN service aides and their supervisors. During these interviews, many issues and points of interest were set forth. In order to cover as much material as possible, only those concerns which were shared by the majority of the persons interviewed will be elaborated upon.

Lack of Clarity in Role Definitions

As was stated before, one of the areas of greatest ambiguity has been in defining the role of the aide and his position in the agency; and this has resulted largely from the confusion in program goals. One supervis or commented that the aides come in as recipients who are still on welfare and that putting them to work in the agency does seem intended as a means of providing them with some kind of service--a "corrective experience," at least in terms of economic security. According to Mr. Day, of course, the experience was to do much more than this; it was to give such persons "the chance to feel worthwhile." Other supervisors saw the aide not as a person to be 
served, but as one capable of providing service. In some cases this meant simply performing tasks previously done by caseworkers. In others it meant opening up unique areas of service. What the aides provide in the latter case is a new input, an input which may be more crucial at certain points in the life of the client than that offered by the caseworker. Another interesting distinction was made by two supervisors who have New Careerists in their units. They saw the role of the New Careerist as not only being different from that of the WIN service aide, but also as providing more status and better opportunities to persons occupying such positions, with the chief distinguishing factor being the goal. Whereas the New Careerist assumes the role of an apprenticed caseworker, one in whom the agency encourages and cultivates a desire to move upward, the WIN aide is delegated the role of providing tangible services to clients and does not receive agency support if he aspires to move out of this position.

The ambiguity in the aides' role is reflected in the supervisors' assessment of their own positions in relation to the aides. Supervision is geared to the training needs of the aide, and these are determined by the role in which the aide is expected to function. Six of the 12 supervisors felt that their supervisory responsibilities were not clear. Four others said that their positions were clear enough, and indicated that it had been left up to them to use the aides in the way that seemed 
most appropriate. The remaining two stated that it had not posed a problem. There was a general dissatisfaction voiced concerning the orientation which had been given and the materials provided describing the service aide trainee program. Louise Smith and Helen Ellsworth met with the supervisors prior to the aides' placement in units for two three-hour training sessions. After that, meetings were held primarily on a crisis-intervention basis where problems were apparent. Admittedly, this has been one of the weaknesses in the program; and steps are now being taken to alleviate it. (These will be discussed further at the end of this chapter.) It is interesting that four of the six supervisors who felt that their positions were unclear were also the supervisors in whose units the aides had been experiencing the most difficulty. This is from the standpoint not only of the aides but also of the supervisors. Both expressed feelings of dissatisfaction and of failure. To what extent personality factors were involved in this could not be determined. It is felt, however, that a clearer statement of purpose and a clearer definition of roles in the beginning, with consultation provided on an ongoing basis, could have served to counteract, if not to prevent, the emergence of such factors. This is not to say that personalities would have been changed, but only that a better and more mutual understanding of what was expected could have been reached. 
Major Consequences of Goal Confusion

The confusion over goals and resulting ambiguity in roles has affected four major areas of the program: the aides' relationship to the caseworkers, the training of the aide, the aides' assessed effectiveness, and the supervisors' disposition toward the program. With regard to the first, 50 percent of the supervisors considered the relationship between the caseworkers and the aides to be very good, meaning that the aide was well accpeted and was given the opportunity to participate. In these units, the supervisors were quite enthusiastic about the use of aides. Though two indicated that they had been skeptical prior to the aides $\mathbf{s}^{\prime}$ coming, their experience had been such a good one that it had changed their attitude. In three of the remaining six cases, the relationship was considered to be satisfactory; but there were indications that the aides, while generally accepted, were not really used. There was resistance on the part of the caseworkers to involve the aides in cases. In the last three, the relationship was felt to be totally negative; and in each of these this was attributed to the personal qualities of the aide. There was a noticeable lack of any comment to the effect that caseworkers feel their positions are threatened by the aides. One supervisor did state that if the aides were threatened, it was by the agency and the question of the direction in which it has been moving (especially since the Management 
1970 Report). It cannot be denied that a closer look is presently being taken at the diploma, especially the BA, and just what it means in terms of ability to do the job. Does a BA in English Literature or Speech really prepare a person adequately to fill the caseworker's position; this is the question being asked--not whether the position itself is a legitimate one. It has been suggested that even though this feeling that their jobs are being threatened may not be expressed directly by the caseworkers, it is expressed through less direct means, such as their unwillingness to involve the aides in case activities or their complaint that aides really cost the agency more instead of less, both in terms of time and money.

The only conclusion which the authors can draw from this mix of feelings and thoughts is that the lack of clarity in role definitions is again being reflected. The caseworkers, at least in Multnomah County, were given no training around the use of aides, except in units where difficult problems developed; and this of course was after the fact. Certainly the aides have felt the impact of this, for nearly all expressed concern that the caseworkers be educated around the aide's role and displayed a real understanding of the bind into which caseworkers are placed when such education has not been given: they do not want to offend the aide by asking them to do menial tasks, and yet they must be careful not to expect too much. The result has been that some aides are used primarily in a transportation capacity while 
others are carrying almost full responsibility for some cases. This experience is certainly not unique to Oregon, for as recently as January of this year, paraprofessionals in Washington emphasized the need for adequate preparation of staff. 38

This concern was voiced in a slightly different way by a few supervisors who reacted to the fact that the aide program was imposed upon the agency. They would have liked for there to have been more effort in preparing both the aides coming in and people who would be working with them. In their judgment, the program had been presented in a way which was not conducive to its being utilized effectively by the workers and therefore seemed more of a burden than a help because of the resistance which it had elicited. What is being overlooked here it seems is this. Even if a program is "imposed" this does not necessarily mean that it will be implemented ineffectively. More important than the fact of its imposition is staff's commitment to the purpose underlying it, which of course must be spelled out carefully. As Dr. Zapharis stated at a recent conference on Oregon's aide program,

It doesn't matter if the program was imposed or not. The question is dowe see it as having potential? And if we do, let's make it work! 39

${ }^{38}$ Conference on Social Work Education, "Associate Degree Students Speak: Review of Paraprofessional Careers in Social Work," Seattle, Washington (January, 1971).

${ }^{39}$ Dr. Alex Zapharis, Conference on Welfare Aides. Salem, Oregon (December 17, 1970). 
In the second area which has been affected, that of training, supervisors were asked to respond primarily to three questions. The first dealt with "who assumes major responsibility for training." Though six responded that they had primary responsibility--at least with regard to unit activities--much uncertainty was expressed. In many cases, they saw this responsibility as being shared with the trainer (Helen Ellsworth), but could not clearly define the limits of authority. Further, there was little knowledge about the kind of input the aides were receiving in their weekly training sessions with the trainer--were they gripe sessions, therapy sessions, or did they focus on the development of helping skills. The second question, dealing with the type of training given within the unit, reflects this uncertainty. In only one-third of the units an ongoing training program had been set up. The aide in each of these units was a New Careerist. In the remaining two-thirds, training was generally task related, with the aides receiving instruction either prior to or just after assignments were made. Other training was received through unit meetings, joint conferences, and consultations. What seemed really tragic was the fact that in a few cases where difficult problems had arisen, the tendency of the supervisor was to involve the aide less and less rather than attempting to offer new opportunities for meaningful participation. In such instances, the supervisor's commitment to the program can be seriously challenged. Over half the 
responses to the third question, regarding the extent to which supervisors felt they were adequately prepared to supervise an aide, were quite negative, with supervisors again attributing this to the inappropriateness of the materials presented to them and to the very simple but important fact that they were not given sufficient time to do a good job of training.

Closely associated with the training issue is that of the aide's effectiveness on the job, as assessed by the supervisor. Seven of the aides were evaluated as being very effective, five as being effective within certain limits, and one as being ineffective. Those supervisors who thought their aides to be very effective were for the most part excited about the use of aides and anxious to utilize them in new and different ways. Those who judged their aides to be effective but attached certain conditions to that judgment (such as the statement, "She does well what she does.") were the same supervisors who tended to define the aide's role rather narrowly. These aides tended not to be assigned tasks of increasing complexity and responsibility. A subject which has been a matter of great debate has been whether or not the aides can be more effective in some areas than cas eworkers. Of the ten supervisors who responded, five felt that aides can, by virtue of their poverty background, better relate to and therefore provide more effective service to low-income clients than caseworkers. One supervisor commented, 
The aides can be very directive, give advice and get away with it. They accomplish things with problem families of lowincome with only a fraction of the effort to establish a relationship. They more easily gain the client's trust because they're not identified with the establishment.

Some social workers, especially those who have been caught up in the struggle for professional identity, would balk at such statements because this kind of "grass-roots" social work is deemed inappropriate and unprofessional. But as another of the supervisors commented, "if that's what the client needs, then that's what will be most effective." The role is a new and exciting one, legitimate in its own right. It should not be looked upon as a limited set of tasks carved out of the caseworker's area of responsibility.

Compare this stance to that of the other five supervisors who tended to be more judgmental, to see the prior experiences of the aides as a restrictive factor, one which more often than not would interfere with their ability to provide service. Among this group, there seemed to be what might be called an aura of professional snobbery, a tendency to disvalue the contributions of anyone who had not subjected themselves to the ardors of academia for a period of more than 12 years. It must be noted, however, that this tendency was not necessarily consistent with their evaluation of the aides' effectiveness; for in two cases where the aide was seen to be very effective, the supervisor still did not see the aide as possessing a special insight into the problems of the poor. And two others, who 
had seen their aide as being somewhat limited in their effectiveness, felt that certainly some aides do possess such insight. What is hoped accounts for this difference is objectivity on the part of the supervisor who is able to see this potential in other aides, though perhaps not in his own.

The fourth area to have been affected is the supervisors' disposition toward the program-- what is its future and what should it be. Six of the supervisors felt that the aide program should become an integral part of the agency structure. Of these six, two had been apprehensive at first, but now feel that, as one supervisor put it, "This has been so successful, I hope it continues." Five of the remaining six thought the program would continue, but felt that it should not "as it is now"; a change was needed either in the approach, structure, or focus of the program. There seemed to be a general feeling, too, that the program should be more agency-centered rather than aide-centered. The attitude of the last supervisor is summarized in the following statement.

It will be a passing program if they ever stop to think of the cost of the program to the people. Aides are the most expensive part of public assistance in terms of the benefits we've gotten from them.

Needless to say, the relationship between this supervisor and the aide has not been a workable one; however, the point here is not to place blame, but only to note the degree of influence a bad experience 
can have and thereby to emphasize how important are the preparatory stages in program development in terms of working through preestablished biases.

\section{Areas in Need of Change}

One last is sue which should be discussed emerged in response to the question of what the supervisors would most like to see changed about the present program. The responses ran something like this.
Selection process (screening techniques)
Clarification of program's purpose
6
Educational scheduling
Addition of supervisors
1
Support of aides as workers with a special area of competence
1
Insufficient knowledge of total program to respond 2

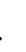

We will focus here on the selection process, as it has been a matter of concern to a majority of the supervisors, even though it may not have been mentioned in response to this particular question. Screening was considered inadequate in that it did not answer the following questions:

1. Is the aide educable.

2. Is the aide's life situation stable enough to allow him to be on the job on a regular basis. 
3. Does the aide possess personal characteristics which would be useful in a service capacity.

4. Is the aide going to be helpful to the agency.

It was interesting that each of the items above was suggested by supervisors who had had difficulty with their aide in the particular area mentioned. In all but one case, the supervisors whose experience had not been a satisfactory one saw a need for change in the selection process. That the role of experience is a crucial one was also demonstrated in a comparison of the positions of two supervisors, both with aides who came up through New Careers. The criteria for selection was deemed entirely inadequate by the first who stated that, "the only qualification is that the individual be willing and on welfare." The second made the following comment,

The New Careerist comes to the job better prepared and with less personal hang-ups due to a better screening process.

This again takes one back to the matter of goal and what kind of persons would be needed to fulfill these goals. When the program was first getting underway, the preliminary guidelines concerning the recruitment and selection of aides stated that,

Preference should be given to applicants who have undeveloped potential for employment, in which there may be no work history or in which there are no marketable skills. Preference should be given to applicants who are "hard to place" or "hard core" unemployed. 40

${ }^{40}$ Harold Miller, "Guidelines for Use of Pre-Professional Aides, "p. 18. 
Needless to say, though the agency has wanted to be flexible, it has not be able to adhere to these guidelines, primarily because of training constraints. Supervisors were, in general, doubtful about the training potential and educability of persons such as those mentioned above. One of the more adamant supervisors stated,

If the goal is to help the hard-core poor, then put them in the caseload, don't put them in as an aide. . . Most of them have so many problems in their own homes that they can't function on a job. It would be compounding their pathology.

What this comes down to is a matter of priorities: is the aide coming to the agency to provide needed services from the moment he steps in the door, or is he coming to receive training which will enable him--within a reasonable length of time--to function well in a service capacity. If the agency begins looking for people with a high degree of job readiness, it seems that someone has missed the point, that the agency is again simply resorting to the "cheapest way out." Perhaps the agency really is not prepared to offer meaningful training to the hard-core unemployed; for that does require a great deal of skill and an investment of resources which are not available right now. But we should be looking ahead to and planning for the time when this possibility can be realized. In the authors' judgment, supervisors can be helpful in such planning; for they come up against the day-to-day contingencies which make it difficult for an aide to succeed. Some of those mentioned by supervisors were the following: the health of the 
aide, plans for child care, placement preference, knowledge of geographic locations, possession of valid driver's license, nature of the unit into which an aide is being placed. (It was noted that some units, by nature of their function, are not good training placements.) One supervisor also voiced the concern that,

While people with such handicaps should have an equal opportunity to get off from assistance, they shouldn't be made to feel that it's a disgrace not to.

This certainly seems to be a valid observation, one which truly speaks to the prevailing attitude toward the poor. At the other extreme, however, there are those who would screen out anyone who had not completed their GED, who had more than three children, and whose case record had not been checked thoroughly for evidence of the individual's suitability. Until such time as we have more experience in dealing with such attitudes, it would seem that the best we can do is to more carefully screen the supervisors into whose units aides are being placed.

This brings us back again to the matter of goal. Why are the aides here--to be junior cas eworkers? If this is the goal, then perhaps an alteration of the selection process is in order. More and more, however, the desirability of a goal such as this is being questioned. One supervisor asked,

If you start from the basis that the non-professional has something to offer that the BA caseworker does not, then why send them through a process that will destroy this resource. 
Other supervisors expressed this same concern, for they feel that the very qualities which make the aides' service unique--their spontaneity, frankness, directness, informality--somehow are lost in an attempt to "professionalize" them. The Aide Trainer for Multnomah County felt that this was one of the problems with the New Careerists. Once they got into the educational system they began to see things differently. Even their zest for helping is dempened as they are crammed full of social work jargon and values. The worst part is that for many of the persons who come into the program, a complete transformation cannot be accomplished. They don't enter the system lower-class and come out middle-class; for these class levels denote far more than socio-economic status, they are inextricably linked to one's identity. But not to belabor the issue, the point is simply that as goals finally are established in the aide program, they must allow for flexibility, enough flexibility so that the aide is given the opportunity to exercise choice. This means of course that choices must be open to him and that he be given as clear an understanding as possible what each choice might entail in terms of present and future commitments.

\section{AIDE PERS PECTIVE ON THE PROGRAM}

With this brief summary of the concerns and issues which have been raised by staff, we come at last to the aides themselves. Of the 
11 aides who were interviewed, four were New Careerists who entered the program on November 18 and December 22, 1968, and April 7, 1969; the remainder were WIN service aide trainees, all of whom started in July of 1970, and are just in the process of completing their Trial Service Period.

\section{Self-Image and Role Prescriptions}

How does it feel being an aide? This was the first question asked the aides. Eight of the responses were positive, one negative, one inappropriate, and one no response. A small sampling of the responses really shows how enthusiastic these aides are.

1. It feels good to work. I like people... helping.

2. I feel real great. It's not the best-paying job I've ever had, but it's the best job.

3. I like the idea of working. I feel a lot better about myself.

4. I enjoy what I'm doing.

Common among all of the positive responses were three attitudes: a desire to work, an enjoyment of working, and an enjoyment of the job being done. Considering the magnitude of the problems some of these aides have encountered while in the program, their optimism is particularly refreshing. This optimism was one of the first things which really stood out as being characteristic of the aides. A few of the aides also commented that their working has had a positive effect on their family life. The children liked the idea of mother working and of not being on welfare any longer. This had encouraged them to 
take more responsibility in the home.

It was interesting that while they had positive feelings about being aides, at least half reacted negatively to the title aide, when asked what they would most like to see changed about the program. The aides felt that it had a certain stigma attached to it, that it characterized the aide as a "flunkie," someone to run errands and do chore work. It seems that the aides here were responding to the negative predisposition which the authors propose had been built up. The term "aide" had taken on a certain meaning which the aides themselves felt was inappropriate. This proposition is further supported by the fact that a better orientation of staff with regard to the use of aides was also cited as a major area in need of change. Caseworkers, they felt, were unsure of what could be assigned and tended therefore to be hesitant. Such uncertainty is bound to be an inhibitory factor, one which stifles creativity in the use of aides. It also inhibits the development of a good working relationship between staff members, which in turn means that the service deliver system is not functioning as best it could be.

This should not be misconstrued to mean that the day-to-day relationship between the staff and aides was bad; for 8 of the 11 interviewed felt that staff was generally friendly, warm, and accepting. The other three had somewhat mixed feelings, but at no point did they place the blame for this with the caseworker. What did come out, 
however, was that the supervisor in many instances set the tone of the relationships within the unit. If the supervisor was positive in his relationship with the aides, the caseworkers were encouraged to be also. Since the aide's role, then, was communicated to the caseworkers through the supervisor, the aides strongly recommended better orientation of supervisors. The aides tended not to attribute the cause of problems to personality factors but rather to misunderstanding of the aide's role.

$\underline{\text { Training and Supervision }}$

The section which follows will address itself to the aides' training, with special emphasis upon the role of supervisor in that training. Seven of the aides indicated that the training they received was adequate, two that it was inadequate, and two had mixed feelings about it. Most of the supervisors have adopted the method of having conferences around certain issues or task assignments. In some instances this is extended to the supervision of caseworkers, though in the majority of cases caseworkers continue to have regularlyscheduled conferences. Thus, the aides'training is primarily unstructured and operates on the bas is of the "open door policy." Most of the aides function very well in such a setting; but some find it quite uncomfortable, primarily because they do not know what is expected of them. These aides, in general, tend to be more unsure of 
themselves--with the result that they have not used the open door policy and have not registered their discontent. In placing the aides, there was an attempt to put those aides who were felt to be less secure into more structured units; but perhaps there could be ongoing consultation with each of the units in addition to this in order to prevent the development of such difficulties.

Another area related to training in which some dissatisfaction was also expressed was the lack of increasing responsibility. Several aides stated that they oftentimes see needs to be met and would like to go ahead, but are constrained because they must seek the permission of those in authority over them. This, they feel, is an unsatisfactory system, but one which would be more workable if the limits of their authority were more clearly defined and allowed them some latitude in decision-making. This is a simple task by no means; but once it has been accomplished, the aides can truly be used to fulfill one of the most beneficial of the program goals--the expansion of human services.

Effectiveness on the Job

Dissatisfaction concerning this matter was also reflected in their assessment of their own effectiveness. It was interesting that the aides did not take the term effectiveness to mean simply doing well the tasks which they were assigned but rather as conveying the idea of 
being able to work to their fullest potential. The feeling expressed by the aides that "anybody could do what I'm doing, "really conveys the message that, "what I'm doing doesn't require much skill, "but also that "I could be doing more." The aides are eager--to learn, to be more involved, to help; and this eagerness seems to be a product of their optimism, the feeling that they do have something to offer. Six of the aides did perceive themselves to be better able to work in some areas with clients than caseworkers, primarily because of their own past experiences, but also because they have more time to spend. An example cited by one of the supervisors may be of interest here. The aide attached to this supervisor's unit has been working with a 19-year-old retarded black boy who has been trying to get himself promoted out of foster care. The aide has been seeing him three to four times a week, trying to help him get settled in a job and an apartment.

The kid messes up on the job, gets fired then the aide picks up the pieces again and puts him back together. The aide is really the only one he has to depend on.

The aides feel that they have a greater sense of the clients' frustration and therefore can be more understanding of some of the reactions of clients. One aide commented that,

The system makes it hard to become independent. There never seems to be quite enough training or assistance provided to get away from it.

Some might react to this, saying that the aides are not in a position to 
make a realistic appraisal of their qualifications. It seems, however, that the aides are keenly aware of their limitations; and they want the best possible supervision and training available to help them overcome these limitations.

\section{Future Goals}

The kind of training desired by the aides derives in large part from their own future goals. There is quite a bit of diversity in the aides'goals and, at this point, very few are fixed. Four of the 11 aides interviewed indicated an interest in becoming caseworkers, which for three would mean first obtaining a GED followed by four years of college, if not more. Three others thought they might become caseworkers, but are really unsure right now. The remaining four saw themselves as working toward a Welfare Aide II position with the idea in mind of making a career of being an aide. One of these also wanted to obtain an AA degree.

Goals, of course, mean little if one has not the means by which to achieve them; and in this regard the aides were asked if they felt that the program is presently structured in a way which would help them reach their objectives. The responses here were quite revealing. Those who expressed a desire to become caseworkers but who have not had any college training as yet see someplace to go--at least to Welfare Aide II. And, while they know that at present there is no 
career ladder beyond the AA degree, they have hopes that by the time they are ready, there will be one. Those, on the other hand, who have already attained their AA degrees (with the exception of one) were in the second category with those who were unsure about becoming caseworkers. While they would like to continue to advance, there is no place for them to go--unless it's to college for however many years it would take to complete 90 more credit hours with only eight hours release time per week and no help with financing. Clear back in November, 1969, this same issue was discussed. "It might appear," it was said "that they're just being led on. Hopes must be built on clearly-defined practices." One cannot help but wonder if the agency's delay in acting upon this recognition has not influenced the aides' "choice" of career goals. Will the aides who are now working for their Aide II classification and who plan to make a career of being an aide find a career waiting for them when the time comes.

The Aide Trainer noted that most of the aides had shown little interest in taking classes and had not even used the 16 hours per week release time available because a career ladder had not been developed. This is not a sign of defeatism or apathy, however; for the aides are surprisingly optimistic about the future. They have faith in the agency and the administration. Look for example, at the following statements:

Improvement is coming. The agency people are interested in improvement. 
.. I believe they're trying to work on something so we'll have a better chance of working our way up. . . . If I continue to work with the agency, I'll have a good future ahead.

During the interviews, the aides seemed to be defending the agency and were for the most part very hesitant about saying anything negative about it. Some did intimate, however, that other aides were somewhat frustrated and angry over certain issues; but these "others" only amounted to three when it came to expressing these feelings during the interviews. And even in these cases, hostility was not projected onto the agency nor did the aides want to just forget the whole thing, as some might predict. They were very firm about staying with the program in spite of the difficulties. In speaking of the possibilities for advancement, one aide commented that she would stay with the agency even if she could not advance because she likes the work so. well.

It is this kind of attitude which best seems to characterize the aides' position--they enjoy the work, they are optimistic about the program, and they see it as the base upon which their future plans are being built. They are not out to replace anyone; and if this idea is coming through, it is not from the aides. What they want is the opportunity to do a job in which they can find some personal fulfillment and from which they can earn a decent living. And, at present, the majority of the aides feel that they can find this with Public Welfare. 


\section{STATISTICAL ANALYSIS}

The section which follows is intended to acquaint the reader with the basic statistical facts of the aide program. As was stated in Chaptey II, the Oregon legislature authorized 163 Aide/Clerk Trainee and Welfare Aide positions, to be filled by July 1, 1971. Approximately 63 of these positions are currently filled with salaried personnel. Of the 163, 111 are Welfare Aide positions and approximately 52 are used for Clerk Trainees, which is a limited duration position. In July of 1970 , additional positions were requested and granted; and it is expected that 165 more positions will be requested for the next biennium, beginning July, 1971.

While these figures give a general idea of the number of persons involved in the aide program, they do not indicate how many, upon entering the program, have met the program's goals and how many have not, and the reasons for either their success or failure to do so. It is felt that such information certainly is of value in presenting a more balanced view of the aide program; but to present such facts for the entire State would represent an undertaking beyond the scope of this study. The authors therefore feel that the data from Multnomah County (to which over one-third of the positions are presently allotted) would provide a fair sample to work from.

A total of 62 persons have entered the county aide training 
program since November $18,1968 .{ }^{41}$ A total of 29 have come in as service aide trainees. Of these 29, nine are New Careerists, nine are Model Cities Aides, two are former WIN clerical trainees who transferred to service aide positions, and the remaining nine are WIN service aide trainees. Seven of these 29 who entered the program have left the agency. Two did so because they found jobs outside the agency and are therefore considered to have met program goals. Of the remaining five, three "dropped out" due to multiple problems and two were terminated by the agency. Only these five are considered not to have met the goals of the program.

The 35 persons who have been in the clerical training program all entered through WIN. Twenty-four of these are still with the agency, 14 in the training program and 10 in permanent agency positions. Of the remaining 11 , one found a job outside the agency and one was placed in a full-time school program. Thus, 26 of the 35 have met program goals. Of the nine who have not met program goals, six "dropped out" due to multiple problems, two left due to pregnancy, and one resigned to marry.

Looking at the program as a whole, of the 62 who entered the program, a total of 46 are still with the agency either in a training capacity or a classified Civil Service position. Fifty therefore have

${ }^{41}$ Ellsworth and Smith, p. 6. The following data is drawn primarily from this report. 
met program goals.

It is interesting to note that six of the nine who "dropped out" did so during the initial three month $W E / T$ period. It would appear that these six were not ready for a full-time training program due to a variety of personal problems which were not sufficiently resolved to permit them to assume additional respons ibility. ${ }^{42}$

\section{CONCLUSION: A PROGRAM ON THE MOVE}

On June 19, 1970, application for a grant (Plan B--Public

Service Careers Program) was made to the Department of Health, Education, and Welfare by Oregon Public Welfare Division, Social Services Department. ${ }^{43}$ This perhaps was the single most important step in terms of its future implications for Oregon's Aide Program. The proposed project period was to be from July 1, 1970 to March 31, 1972, during which time a total of 165 entry positions would be filled, 80 Aide Trainees and 85 Clerk Trainees. In addition 63 existing staff positions were also to be upgraded: 30 Aide Trainees, 19 Aide I and II, and 14 Clerk Trainees. Enrollees were to be employed in each of the following program areas: Aging, Community Services, Medical Services, Assistance Payments, Rehabilitation Services. The projected cost of this program was estimated at $\$ 497,385.65$.

\section{Ibid.}

${ }^{43}$ State of Oregon Public Welfare Division. Dept. of Social Services, "Application for Grant: Plan B-Public Service Careers Program, "June 19, 1970. 
The preliminary and basic objectives for Oregon's utilization of this grant were set forth in the grant proposal. ${ }^{44}$ The basic objective stated therein was to improve the current Aide Program and to offer increased employment opportunities to low-income groups, including all recipients of Public Assistance. To implement this, the following steps were deemed necessary.

1. implementation of job task analys is

2. development of new job classifications

3. identification of training components necessary to implement the findings of the Task Analys is

4. examination of the current job classifications and entry criteria

5. development of training materials for staff

6. examination of the traditional model of supervision

7. development of a vertical and horizontal career ladder It is of great significance that each of these steps is related to one of the basic problems with which Oregon's Aide Program has been confronted. The need, for example, to develop a meaningful career ladder with the related need for a task analysis was recognized long before this proposal was written. What this points out, it seems, is that through the process of implementing an aide program and

44 Jim Burri, "Preliminary and Basic Objectives for Oregon, Public Welfare Division 'Public Services Career Program', Plan B, " submitted in June, 1970. 
experiencing the great difficulties involved in that process over a two-year period, Oregon has discovered the basic prerequisites for the development of such a program. It is unfortunate that the Federal Government in mandating this program did not spell these out. Certainly, there was material which could have been drawn upon. Even a text as basic as Pearl and Riessman's New Careers for the Poor pointed out the need for establishment of job categories and careful delineation of job levels. In addition to this, pilot projects could have been conducted for the purpose of determining the prerequisites for developing aide programs. Perhaps this would have involved a greater initial investment of time and money, but it seems that such an investment in the beginning would have yielded significant dividends in terms of the overall savings to the States. It is not being suggested that the Federal Government should have taken responsibility for planning individual state programs; the necessity of allowing enough flexibility so that states could develop the kind of program which would best meet their needs is clearly recognized. However, preliminary guidelines and the accompanying financial aid to utilize and work within such guidelines would certainly not limit flexibility. Rather it would provide the structure necessary for using such flexibility most constructively.

The states, of course, should assume primary responsibility in program development. In this regard, Oregon was somewhat 
delinquent and delayed in meeting its commitments. The authors sincerely hope that this same lack of commitment will not be evidenced in the Public Service Careers Program. While it is recognized that the results of the task analysis will most likely entail radical changes in the structure of Public Welfare,such change must be viewed in terms of its future benefits, as well as its present costs. It would be tragic indeed to waste the investment being made by not following through with or by only superficially fulfilling the objectives set forth. 
CHAPTER IV

THEORETICAL MODEL

\section{INTRODUCTION}

In attempting to conceptualize a theoretical model for the utilization of welfare aides in a public welfare department, it is the authors' intent to formulate a plan that could be implemented given a number of changes in the present welfare system. Within the following guidelines there are a number of conclusions that cannot be justified by research data. The main reason for this is that little research in this area has been produced which would allow one to make conclusive value judgment decisions. The areas that have not been sufficiently researched do not affect the theoretical framework of the authors' model. However, future research could alter some of the inner workings as presented in this proposal, and these changes should be made as further research is completed.

Certain assumptions made by the authors should be stated at the outset. One is that a need for aides in the public welfare depart ment does exist. This means that there is work available in the agency that could be adequately performed by welfare aides. The second assumption is that the use of aides is something which can be considered to be good for the individual aide. This latter assumption 
may be related to several factors, including: an improvement in economic conditions for the newly-employed individual, an opportunity to increase formal and informal education, a chance for personal growth. The third assumption is that society will benefit from such a program. This could mean that there would be some reduction in the number of welfare recipients. It could also mean better services would be provided for those people who remain on public assistance. It could further mean that more jobs would be created. These assumptions are not necessarily considered to be good by the authors, but we do consider them to be relevant in terms of constructing a social policy. It is also the authors' belief that regardless of the value judgments placed upon the three assumptions, a welfare aide program can have positive effects within the set of assumptions by meeting certain objectives that are to be presented in the proposed model.

After careful evaluation of the existing legislation and programs, combined with what the authors consider to be the merits of a welfare aide program, the list of objectives, as stated later, was derived as necessary and most important in providing for the best possible schema. The goals are interrelated, and the deletion of any one of them could create the same result as that obtained in cutting off one leg of a three-legged stool. The programs as they now exist have been unduly concerned with establishing a ranking priority of goals. 
If, as an example, the first eight of ten objectives are fulfilled in a program, this is sometimes considered a success. However, it has been too often overlooked that the failure to complete objectives nine and ten may mean the beginning of a slow deterioration of the other eight accomplishments. Thus, each is essential to the totality of the program and each is an integral part of the model.

\section{GENERAL OBJECTIVE}

The following is a list of the objectives of the theoretical model. General Objective: To establish a welfare aide program which will provide full-time permanent employment for low-income persons in county public welfare agencies in jobs that enhance the effectiveness of said agencies.

\section{Permanent Employment}

In examining the general objective cited above, one might question the emphasis placed on the words "permanent employment." Some argue that public welfare should be used as a training ground for low-income people so they can locate jobs in the regular job market. This may be fine when examined from a distance, but on closer scrutiny there are a number of propositions that must be critically tested. One such problem is that a public welfare department is not designed to be a general job training institution. The practical 
experiences gained by an individual in an on-the-job training program in the public welfare department may be only generally related to work that is performed in a privately-owned firm. The one specific area of job training offered by a public welfare department which could serve as a vehicle to employment in another firm is the clerical position. Other jobs for aides, especially the lower job classifications, are not so related. Take as an example the aide whose function it is to drive welfare recipients from one place to another. The only job for which this kind of experience would prepare him is that of a chauffeur. Since there is not an abundance of chauffeur jobs available, the employment of a person as a transportation aide would in no specific way guarantee that individual a job outside of the public welfare agency.

One proposed solution to this particular problem is for the public welfare division to employ aides to do specific jobs that will lead to an assured job in the private sector of the economy. However, the authors do not consider this to be an adequate solution for the following reasons. If a clothing manufacturer wanted to hire a person to do a specific job, then the firm most likely would want to do its own training. It has been argued, of course, that at least temporary training through public welfare would qualify the individual for such a training position. Underlying this argument is the assumption that working people possess certain general traits; such as, punctuality, 
industry, ability to complete tasks. Therefore, if the aides are taught these general traits by the agency, they will possess the basic prerequisites for finding and maintaining a job. The authors' contention is that this inference is not justified and that until such time as documentation can be presented to prove that certain general traits do lead to the employment of an individual, this should not be made an objective of the program. However, it is possible that an aide employed by public welfare may, by his own choice, decide to seek other employment and be successful in obtaining and maintaining the job; but this should only be viewed as a secondary beneficial result of the program.

Security and trust can also be related to the concept of permanent employment. As a result of employing the poor in job training or temporary work situations which were presented as opportunities for permanent employment, the poor have come to look upon such situations with doubt and distrust. Too often they have been given job training for jobs that are non-existent. They have also been the first to be released from work when economic troubles have beset their employers. A simple solution to the security dilemma is to guarantee a permanent place for the individual in the agency which trains him. This would serve to dispel the aides' distrust of the program and the agency because the aides could then see the program as presenting a real opportunity for job security. 
From an agency point of view also permanent employment is an important characteristic. Employers prefer a stable staff. It takes time for individuals to adjust to work tasks, and they usually become more productive as time passes. Many individuals become stale after a certain period of employment. If this happens to an aide, it should be handled in the same manner as with other employees. Business firms want loyel employees who will continue over the years to give a high level of performance to the organization. If the work that aides perform is considered valuable to the agency, then longevity of employment is desirable.

\section{Enhancement of Agency}

The second aspect of the overall objective of this program is that aides should be performing tasks that benefit the agency. This means that they serve to help meet the goals and objectives of the agency. In regard to the concept of meaningful employment, the public welfare division should be placed in the same category as a private business firm. An employer never employs an individual to perform meaningless tasks. Administrators would consider this tabe unsound fiscal policy, and the administrators of public welfare should be permitted to use the same line of reasoning.

At the present time there already exist a number of potential jobs in a public welfare division that could be filled by aides. It is 
true that using the criteria of "beneficial to the agency" may decrease the number of potential jobs for low income people. However, the model that is presented in this thesis does not attempt to solve the welfare problem of this nation nor does it attempt to miraculously create thousands of jobs. It would be capricious for the authors to claim more than a program that would provide permanent employment for some persons who do not have the opportunity under the existing programs.

\section{SPECIFIC OBJECTIVES}

With the preceding explanation of the general objective of the model, the component parts can be more closely examined. It must be kept in mind that each succeeding objective is an attempt to fulfill the overall objective.

A. To facilitate the mobility of those aides who desire to progress through the organizational structure by providing appropriate formal education and to keep employed as an aide the individual who elects to remain at the same job level.

B. To provide all supportive services necessary to ensure that any extenuating circumstances which might deter the work of the aide are minimized.

C. To create jobs for aides that would not put them in direct conflict with those people who are already employed by the agency.

D. To provide pay and fringe benefits to the beginning aide that would be sufficient to make the aide position an attractive and lucrative one compared to a public welfare grant. 
E. To provide increase in pay based on upward movement by the aide and length of time employed by agency.

F. To provide the means for aides to improve their formal education so that the lack of such education is never the factor which limits the opportunity of an aide to be in line for a higher position.

G. To provide excellent training and supervision for the aides.

\section{Determination of Job Categories}

One area which must be examined is concerned with the nature of the tasks that the aides should be performing. It is the authors' feeling that the best way of determining these jobs is to evaluate the needs of the agency based on the needs of the clientele it serves. The real difficulty in meeting the needs of clients, of course, is determining what those needs are. Business establishments spend large sums of money and invest much time in deploying marketing studies. The public welfare department in this state and most others almost totally neglects such studies. One possible reason for this is that service to clients is not a product which those in power really want to sell. Many people have the attitude that it should be at least somewhat difficult to satisfy one's desires if one is on public assistance. Another reason for the lack of research in this area is the general lack of concern as to whether the consumers of public welfare are receiving the best possible services. Behind this notion is the feeling that these are people who should be happy to receive whatever is given to 
them as charity. A third reason is that expanded services may mean an expanded payroll, and most people who have control over welfare expenditures are constantly looking for ways to cut the cost of operation--not add to it.

The failure to provide quality services should not be used as a form of discouragement to remove people from the welfare rolls. Seemingly, such a means has not proven effective in the past, as there has not been a sharp or even a slight decline in the number of people on public assistance in recent years. However, the reasons for persons having to be on welfare are really a separate issue. One point in favor of giving a higher quality of service, which is related to the purposes of this proposed welfare aide plan, is the fact that more jobs will be created.

\section{Service Area Model}

The service area model which is delineated in the section which follows is an important construct in the development of the theoretical model. The following statements will attempt to justify the use of a service area model as the basis of organization for public welfare. The areas of service presented cannot be factually substantiated due to the fact that insufficient research in the area of client needs has been done. Because there is insufficient research available, the following list of job categories is presented only to suggest possible 
areas of service within which aides might work.

1. Transportation

2. Housing

3. Organizing food cooperatives

4. Hourly care for children

5. Preparation for moving into a home

6. Facilitation in the utilization of community resources

7. Homemaker services

8. Home health follow-up work

9. Providing warm meals and companionship for elderly

10. Establishing free clothing distribution

It is imperative in establishing job categories that horizontal as well as vertical mobility be provided for. The provision of horizontal mobility would allow an aide to move from one service area to another, thus giving him greater freedom of choice in determining the job to which he is best suited.

Transportation will be used as an example of how one such service area will fulfill the main goal of this model. At the simplest level of entry into the transportation area, an aide need only to have a driver's license. The aide would then be assigned driving duties, including the provision of transportation for welfare recipients to enable them to get to medical assistance, the food stamp store, etc. As this kind of job requires little skill, it would be placed near the 
bottom of the pay scale. When an aide, who begins at this level shows he is capable of assuming more responsibility, he will be able to advance to another job when an opening occurs. Within the area of transportation there might also be the position of transportation coordinator. This person could establish routes as requests come in from social service workers, assign the routes to the drivers, and generally help the drivers in the completion of their tasks. This person would either have more education or practical experience than the aide who drives the route. The reader can begin to see that the definition of aide or para-professional is not the one that has been traditionally used. The aide who is the coordinator could be a former driving aide, a newly-employed aide who comes to the job with related experience, or an aide who has advanced from another service area.

The transportation service area also fulfills the other half of the requirement--that of being beneficial to clients. For those clients who nèd medical transportation, those for example who are too ill to use public transportation, or for whom such transportation is not easily accessible, this service becomes quite valuable. It also makes more sense to have an untrained aide at a low wage perform this job than a social service worker at a much higher wage.

A second, more complex example of an area of service is that of organizing a food cooperative. While this is not a traditional area of agency service, it is one which could be explored if this model were 
to be implemented. Possibly the lowest level job in this area would be shopping for certain items to compare costs. From this job, an aide might move to a position of bookkeeper for the cooperative. There could be intermediate steps, and the top position could be the manager of the cooperative. For one to become manager of the store, formal education in Business Administration would be one of the requirements. Included and possibly in view of the formal education, work experience could be another requirement. It would be possible for the individual who began as a transportation aide with a high school diploma to later become the manager of a food cooperative. This is an example of how horizontal and verticle mobility would permit an aide, by a succession of steps, to move within the service area model.

To be consistent with the general objective, the food cooperative must be beneficial to the clients served by the agency. By using large sums of food stamps and money contributed by clients, the cooperative would be able to purchase food items through wholesale outlets. This savings would then be passed on to the clients.

A third example of service will be shown schematically to give the reader a clearer picture of how these areas of service could be established structurally. The example used will be in the area of housing for welfare recipients. 
Level 1. Checking ads and screening living quarters suitable for rent or purchase

Level 2. Examining and classifying homes passing first examination

Level 3. Matching suitable living quarters with recipients needing them

Level 4. Federal housing program expert--creating more low-cost living areas through better use of existing Federal programs

Level 5. Liais on with existing low-income housing agencies

In order to evaluate the work that is done by the aide, each service area should have a set of objectives. Furthermore, each job should have specific operational objectives which would provide a bas is for measuring the effectiveness of service and the job performance of the aide.

One major reason for using a variety of job levels within a service area is that an aide who stays within this area of service and reaches level five will have gained through his experience a broad base of knowledge in the area of housing. When he deals with an agency such as the local housing authority, he will be much better equipped to handle a problem than a social service worker who may have had only limited experience in dealing with the intricacies of a housing program. The concept of developing specialists in a number of areas is one that would enable welfare recipients to receive better services. At the present time, there is a social service worker who 
is expected to provide total service for the client. In the service area model here presented, the role of the social service worker would entail determination of need and referral to appropriate service areas. He would also act as an advocate for the client to ensure that the services required are actually provided.

\section{Individual Career Determination}

The potential for upward mobility is considered to be an important objective of the program. From the aides' point of view, it provides incentives in terms of pay, job diversity, opportunities to learn new skills, and for some simply a feeling of accomplishment. Implicit in this is the assumption that such things are valued by the low-income persons who a re to be employed as aides. Upward mobility can have a secondary effect on the aide's total job outlook as he develops his skills to the point that he is prepared to compete for a job outside the public welfare system. An example of this might be the person who administers a food cooperative. He could have acquired enough managerial skill and knowledge of retail food store operations that a good job in a supermarket would be a possibility. If this were the case, an opening in the aide program would be made available. However, the caution should again be given that this is only a secondary effect of upward mobility--not a primary objective. 
in the agency. If there exists in the agency a feeling that attainment of better jobs is possible, then many individuals may attempt to improve their position in the agency. Such an attitude tends to foster the establishment of higher goals for the individual, in terms of knowledge of work subject matter, fuller use of capabilities and skills, and a potential desire to better one's economic position.

A corollary to this theme is that of providing the formal education which is required to perform certain functions within the agency. A person, for instance, whose goal it is to manage a food or clothing cooperative should be given college course work in various areas of Business Administration. This would not be forced upon the individual; but if the aide chooses to pursue such education, all financial needs should be met by the agency. The necessary work release time would also have to be provided. The complete acceptance of the concept of providing higher education for those aides who qualify and choose this pursuit is consistent with the concept of opening every avenue of upward mobility. It is the feeling of the authors that if a study were conducted in which all relevant variables and inputs were considered, the cost of educating the motivated aide would yield much higher benefits than that of keeping the aide employed at a job level which would not permit him to realize his full potential. One can now begin to see that the model presented here is concerned with the long-term effects of the program on the individual, the institution, and society 
rather than a short-term statistical gain.

This model must also take into account the individual who is not as highly motivated and who does not share the same values as the upwardly-mobile person. One example of a job role for such an individual would be that of transportation aide. An aide who desires to function in this capacity should be encouraged to do so. Pressure should not be exerted on the aide to move up the career ladder. The aides should be given every possible support not only in working toward their goals but also in realistically determining them; and in this determination, the agency's needs remain an important factor.

\section{Supportive Services}

The individual aide should be given those supportive services necessary to ensure continuous employment. An example of a supportive service that should be included is adequate day care for the aide's children. The day care should not become an extra financial burden for the new worker. In fact, if day care costs are paid for by the aide and this in effect makes a welfare grant worth more than permanent employment, then the program is a self-defeating one.

Full medical and dental care should also be provided for the aide. One of the greatest causes of absence from work is illness. From an economic perspective, it would be better for the agency to provide an adequate preventative medical insurance program for the aide than to 
have a high rate of absence from work due to illness. A healthy person also has one less problem to detract from his work than one who is working, for example, with a toothache. It is imperative that the cost of maintaining these supportive services not deflate wages so the economic incentive to work is lost. Other areas that should also be considered as supportive services are: family counseling, child guidance programs, homemaking services, and transportation. These and many more are services which the agency presently offers to welfare recipients.

The provision of supportive services is important in maintaining an economic incentive to work. Such provision is particularly important in the case of aides who have certain needs which they alone cannot resolve. When this is true, then the employing agency should do all in its power to alleviate the problems. If an agency is hesitatnt to provide supportive services from an administrativeeconomic viewpoint, then the following recommendation is offered. A thorough cost benefit study should be done; and to be a valid study it must carefully consider all costs that are primary, secondary, and tertiary when these services are not provided. It is the authors' considered opinion that anything which hinders the ability of the aide to adequately perform his task is a cost item. 
Financial Provisions

The next objective is related to the value of certain economic benefits which, if implemented, would serve to improve the efficiency of the model. There is much evidence that in this society the opportunity to gain pay raises and to improve fringe benefits is a motivating factor in keeping people in the employ of an agency. Such evidence derives from observation of labor demands in ngeotiating contracts. The people employed by public welfare as paraprofessionals should be given wage increases and fringe benefits over a period of time commensurate with private industry. There is another practice in this country that is quite stringently adhered to--that of providing pay increases as job responsibilities increase, either due to advancements within the organizational structure or to the length of time the individual has been in the employment of a company. The increased pay for a job advancement fits well with the objective of encouraging upward mobility for those who want it. Increases in pay as reward for the years of service rendered is consistent with other objectives. It helps encourage people to want to remain in the permanent employment of the agency. It also provides salary increases for the worker who does not acquire new job responsibilities but remains on the job. Such provisions hopefully would be sufficient reward to keep the person from quitting the job and returning to public assistance. 
Increasing fringe benefits also encourage permanent employ-

ment. A person with a pension plan or group life insurance policy will have to consider that some of his benefits will be lost if he quits the job. Since retirement plan benefits are based on a person's salary, this fringe benefit is especially important to the person who wants to increase his salary either by moving up the hierarchical chain of jobs or by extending his term of service.

Training and Supervision

Another specific objective that must be met is based upon the need for an adequate training and development program for the aides. Since there are a variety of aspects to a training program, the program must distinguish one area of training from another. During the beginning period of employment, a general agency orientation should be given so that the newly-employed individual would know the objectives of the agency, how the agency fulfills those objectives, and how his new job role will help to further the goals of the agency.

An ongoing form of training is closely related to good supervision. In addition to regular supervision, training in the specific service area that the individual aide is to be employed must be provided. This training would consist of specific subject material which would facilitate the individual's advancement in his service area. If, for example, a person was working as an aide in the food 
cooperative as a shopper and buyer, he would begin to receive training in bookkeeping so he could develop his skills for the next job classification. The individual who does not choose to move upward would not be given this same advanced training. His training would come more in the area of extended supervision intended to help him meet his current job expectations. Training in different service areas must also be made available to the aide who has the capability and the desire to progress and for whom there does not exist an opportunity for advancement in his service area. This is an important feature that further facilitates mobility opportunities for the individual. It also encourages the aide to remain in the employ of the agency by reinforcing the concept of permanent work.

Because there is so much emphasis placed on training in this plan, the public welfare division should develop first-class trainers to work with the aides. It would be likely that a team of trainers would be needed to meet all the training needs of the agency. The need for trainers who are effective is important enough that money should be allocated for the training of such persons. The entire training process must be developed so that each area of training is developed to meet the objective of both the welfare aide program and the objectives of the agency. If it is felt that training on an individual basis is needed in certain cases, this should be implemented as a plausible alternative to group training. It cannot by overemphasized 
that the purpose of training is to enable people to perform better than they are now performing through the introduction of new materials and skills.

Supervision is another integral part of the developmental program for the aides that should be provided by the agency. This is different from the training function, as it deals more with the individual in his present setting and with enabling that person to function more productively. The same recommendation that was made for the development of trainers is also being made for supervisors--that they be kept abreast of the latest developments in their field so they will have the tools with which to be effective.

\section{Alleviation of Role Conflict}

One serious problem that must be averted is the conflict between the aides and other workers in the agency. Take, for example, the situation where two groups of employees have similar job descriptions but are treated in an unequal manner. If an aide is performing the same job as a non-aide, he must be treated equally. This does not mean that all the proposals which have been presented in this paper for the aides should be rescinded. One solution to this dilemma is that those who are not aides should, when needed, be given the same benefits that are provided for aides. In this proposal, the public welfare agency would implement a plan for employing and serving the 
total person. There truly is no more appropriate agency to undertake such a program; for, if any of the people employed fail to maintain their jobs, they might continue to draw support from the agency in the role of a client rather than an employee. If all workers are not given equal benefits, irreconcilable differences may develop. Jealousy between groups because of salary differential, job promotions, types of jobs available will destroy any possibility of attaining harmony within the agency. The functioning effectiveness of the agency could decrease as a result of an unwillingness of the various groups to work together in helping meet the objectives of the agency. The special interest group would become more important than the public welfare division.

\section{IMPLICATIONS FOR FUTURE RESEARCH}

The authors, in the preceding chapter, have attempted to present a general theoretical model for the utilization of welfare aides in a public welfare setting. It is recognized that much research needs to be done before the specific factors involved in the implementation of such a model can be delineated. The job categories, service areas, and training programs herein discussed were intended only as suggestions of ways in which the objectives of the model could be met. That this would differ from area to area and from agency to agency is fully acknowledged and entirely in keeping with the authors' purpose. 
It is felt, however, that the overall-objective, which forms the basis of the model, and the specific objectives, which serve as the means through which the overall objective is accomplished, must be quite rigidly adhered to if a program for welfare aides is to yield the very positive results which it has been shown can be produced. 


\section{A SELECTED BIBLIOGR APHY}

\section{GENERAL REFER ENCES}

Abnes, Frederick B. "The Work Incentive (WIN) Program: Establishment and Early Implementation, "Library of Congress, Legislative Reference, (June 5, 1969).

Brager, George. "New Concepts and Patterns of Service: The Mobilization for Youth Program." An article printed in Mental Health of the Poor, by Riessman, Cohen, and Pearl. New York, 1964.

Burgess, Ernest W., et al. "The Chicago Area Project," Yearbook of the National Probation Association, 1937.

Cho, Song et al. "A Multi-Dimensional View of the Care Aide Training Program in Marion County Public Welfare Commission." Presented by graduate students of the Portland State Univ. School of Social Work, Portland, Oregon in December, 1969.

Cudaback, Dorothea. Summary Report on Welfare Service Aide Project, sponsored by California Department of Social Welfare. University of California: School of Social Welfare, $\overline{R e s e a r c h}$ Projects Office (September 19, 1968).

Day, L. B. "A New Shake for the Taxpayer and Welfare Recipients," unpublished position paper presentedbefore a sub-committee hearing on Ways and Means, Oregon State Public Welfare in Feb., 1969.

De Schweinitz, Karl. England's Road to Social Security. New York; 1961 .

Dickens, Charles. Oliver Twist. New York, 1963.

Finch, Wilbur. A Training Course on the Supervision of Case Aides, Training Aid Number 39A, State of California Human Relations Agency, Dept. of Social Welfare (August, 1970).

Finch, Wilbur. The Supervision and Training of Case Aides: A Reading Reference for Supervisions and Staff Trainers, Training Aide Number 39B. State of California Human Relations Agency, Dept. of Social Welfare (August, 1970). 
Harlem Youth Opportunities Unlimited, Inc. Youth in the Ghetto: A Study of the Consequences of Powerlessness and a Blueprint for Change. New York, 1964.

Harrington, Michael, The Other America. Baltimore, 1962.

Harvey, Mary. Summary of Supervisor's Seminar, Portland New Careers Program. Fall term, 1969.

Hiland, John E. Employment of the Poor as Preprofessionals. Supplement No. 5. Public Welfare--Challenge to Validity.Prepared by the Technical Assistance Project APWA. July, 1968.

Kobrin, Solomon, "The Chicago Area Project--A 25 Year Assess ment," The Annals of the American Academy of Political \& Social Science, Philadelphia, CCCXII. March, 1959).

Multnomah County Public Welfare, Oregon. Personal Interviews with selected Aide Supervisors and Aides. January 22-March 19, 1971 .

National Committee on Employment of Youth. "The New Nonprofes sional," American Child (Winter, 1967).

National Social Welfare Assembly. Salaries and Working Conditions of Social Welfare Manpower in 1960. New York, 1960.

New Careers. Draft of progress report, Portland New Careers Program. February, 1970.

Pearl, Arthur and Frank Reissman. New Careers for the Poor. New York, 1965.

Powell, Lawton H. and Alfred E. Goldman, "The Role of the Psychiatric Aide: A Report on the Norristown Seminar." Mental Hygiene, XLVI (April, 1962).

Powledge, Fred. New Careers. Public Affairs Pamphlet Number 427, Public Affairs Committee, Inc., 1968.

Riessman, Frank. "The 'Helper' Principle," Social Work, $\mathrm{X}$ (April, 1965).

Riessman, Frank. The Revolution in Social Work: The New Nonprofessional. Training Department - Mobilization for Youth and Urban Studies Center, Rutgers University. October, 1963. 
Reissman, Frank and Hermine Popper. Up from Poverty--New Career Ladders for Nonprofessionals. New York, 1968.

Richan, William C, "A Theoretical Scheme for Determining Roles of Professional and Non-Professional Personnel, "Social Work, VI (October, 1961).

Tawney, R. H, Religion and the Rise of Capitalism. New York, 1962.

Weed, Verne and William H. Denham. "Toward More Effective Use of the Non-professional Worker: A Recent Experiment, "Social Work, VI. (October, 1961).

Wiley, Wretha. Designing Jobs and Careers in Model Cities Program. New Careers Development Center. New York, September, 1967 . 


\section{PUBLIC DOCUMENTS}

U.S. Congress, House of Representatives. Committee on Ways and Means. President's Proposals for Revision in Social Security System, Hearings, 90th Cong., 1st sess., 1967, part 1.

U. S. Congress. House of Representatives. Committee on Ways and Means. President's Proposals for Revision in Social Security System, Hearings, 90th Cong., lst sess., 1967, part 2.

U. S. Congress. House of Representatives. Committee on Ways and Means. President's Proposals for Revision in Social Security System, Hearings, 90th Cong., 1st sess., 1967, part 3.

U. S. Congress. House of Representatives. Committee on Ways and Means. President's Proposals for Revision in Social Security System, Hearings. 90th Cong., 1st sess., 1967, part 4.

U. S. Congress. House of Representatives. Committee on Ways and Means. Social Security Amendments of 1967. Report No. 544. 90th Cong., 1st sess., August 7, 1967.

U. S. Congress. House of Representatives and Senate. Joint Committee House Ways and Means and Senate Finance. H. Res. 12080 , Social Security Amendments of 1967 brief description of Senate amendments. 90th Cong., lst sess., August 5, 1967.

U. S. Congress. House of Representatives and Senate. Joint Committee House Ways and Means and Senate Finance. Summary of Social Security Amendments of 1967. 90th Cong., 1st sess., December, 1967.

U. S. Congress. Senate. Committee on Finance. Social Security Amendments of 1967, Hearings. 90th Cong., Ist sess., 1967, part 1 .

U. S. Congress. Senate. Committee on Finance. Social Security Amendments of 1967, Hearings. 90th Cong., Ist sess., 1967, part 2.

U. S. Congress. Senate. Committee on Finance. Social Security Amendments of 1967, Hearings. 90th Cong., 1st sess., 1967, part 3. 
U. S. Congress. Senate. Committee on Finance. Social Security Amendments of 1967. Report No. 744.90th Cong., lst sess., November 14, 1967 .

U. S. Congress. H. Res. 12080, 90th Cong., lst sess., 1967. Congressional Record, CXIII, part 17.

U. S. Congress. H. Res. 12080, 90th Cong., lst sess., 1967. Congressional Record, CXIII, part 24.

U. S. Congress, H. Res, 12080,90 th Cong., Ist sess., 1967. Congressional Record, CXIII, part 25.

U. S. Congress. H. Res. 12080, 90th Cong., lst sess., 1967. Congressional Record, CXIII, part 26.

U. S. Congress. H. Res. 12080, 90th Cong., lst sess., 1967. Congressional Record, CXIII, part 27.

U. S. Dept. of Health, Education and Welfare. section-by-section analysis and explanation of provisions of H. Res. 5710 , Social Security Amendments of 1967. 90th Cong., 1st sess., 1967.

Old Age Social Disability Health Insurance Amendments. Statutes at Large, Vol, LXXXI (1968). 
III. STATE OF OREGON: PUBLICATIONS AND CORRESPONDENCE

Burri, Jim. "Preliminary and Basic Objectives for Oregon, Public Welfare Division 'Public Services Career Program', PLAN B," submitted to Dept. of Health, Education and Welfare. June, 1970.

Burri, Jim to Bertha Roth. "Welfare Aides in the Model Cities Department, "Interoffice memo: Oregon State Public Welfare Division. August 14, 1969.

Burri, Jim to Fred Kaatz. "Results of the Meeting with Mr. De Coss, Mrs. Derby, and Jim Burri," Interoffice Memo: Oregon State Public Welfare Division. October 17, 1969.

Ellsworth, Helen. "Aide Training Program Statistics," Multnomah County Public Welfare, Oregon. November 12, 1970.

Ellsworth, Helen to Louise Smith. "Consideration of Certain Problems Affecting the Welfare Aide Training Program," Interoffice memo: Oregon State Public Welfare Division. November $18,1969$.

Ellsworth, Helen to Louise Smith. "Report on Model Cities Service Aides, "Interoffice memo: Oregon State Public Welfare Division. August 21, 1969.

Ellsworth, Helen. "Suggested Tasks Submitted by All Departments for Welfare Aides, "Multnomah County Public Welfare, Oregon. Summer, 1969.

Ellsworth, Helen and Louise Smith. "The Welfare Aide Program in Multnomah County," Multnomah County Public Welfare, Oregon. November, 1970.

Finch, Wilbur. The Training of Welfare Aides in Providing Social Services to Clients. Oregon State Public Welfare Division, Staff Development Section. June, 1969.

Finch, Wilbur to Fred Kaatz. "Our Conference with Multnomah County Staff to Discuss the Training and Use of Welfare Aides, "Interoffice memo: Oregon State Public Welfare Division. April $11,1969$. 
"Interpretation and Guidelines for Implementation of Policy and Requirements Relating to the Training and Effective Use of Subprofessional Staff as Community Service Aides and of Volunteers," Xerox copy obtained from Helen Ellsworth, Aide Trainer, State of Oregon.

Merrick, Sister Anne Paula. Guide for Supervisors. Oregon State Public Welfare Division, Staff Development Section. March, 1970.

Merrick, Sister Anne Paula, "Responses on Questionnaire on Aide Program, "Interoffice memo: Oregon State Public Welfare Division, January 29, 1970.

Merrick, Sister Anne Paula. Workbook: Welfare Aides. Oregon State Public Welfare Division, Staff DevelopmentSection. January, 1970.

Merrick, Sister Anne Paula to Jim Burri. "February Report," Inter office memo: Oregon State Public Welfare Division. March 5, 1970.

Merrick, Sister Anne Paula to Pat Eaton. "Clerical Training Needs in Aide Program," Oregon State Public Welfare Division. April 20, 1970.

Merrick, Sister Anne Paula to Wilbur Finch. "Welfare Aide Program, "Oregon State Public Welfare Division. December 5, 1969.

Miller, Harold. "Guidelines for Use of Pre-professional Aides," Draft \#2, Oregon State Public Welfare Division. November 6, 1968.

Smith, Louise. "A Summary Report of the Experiences of Multnomah County's Participation in the National Council on Aging Senior Community Work Project," Multnomah County Public Welfare, Oregon, 1969.

State of Oregon Civil Service Commission. Job Descriptions for Welfare Aides. Multnomah County Adopted October, 1968.

State of Oregon Public Welfare Division, Staff Development Section. Annotated Bibliography: Case Aides. September, 1970. 
State of Oregon, Public Welfare Division, Staff Development Section. "Pertinent Effective Dates in the Social Security Amendments of 1967."' Xerox copy.

State of Oregon Public Welfare Division, Dept, of Social Services.

"Application for Grant: Plan B - Public Service Careers Program." June 19, 1970.

Stenberg, Kay, "Progress Report on New Careers Welfare Aide Program, "Multnomah County Public Welfare, Oregon. May $27,1969$.

WIN Technical Assistance Handbook. Prepared by the Office of Human Resources Development and Training Operations of the U. S. Employment Service, Oregon. November, 1968. 


\begin{abstract}
A PPENDIX A
WORK INCENTIVE PROGRAM FOR RECIPIENTS OF AID UNDER PART A OF TITLE IV
\end{abstract}

Sec. 204. (a) Title IV of the Social Security Act is amended by inserting after part B (hereinafter added to such title by section 240 of this Act) the following material:

"Part C - Work Incentive Program for Recipients of Aid Under State Plan Approved Under Part A

"Purpose

"Sec. 430. The purpose of this part is to require the establishment of a program utilizing all available manpower services, including those authorized under other provisions of law, under which individuals receiving aid to families with dependent children will be furnished incentives, opportunities, and necessary services in order for (1) the employment of such individuals in the regular economy, (2) the training of such individuals for work in the regular economy, and (3) the participation of such individuals in special work projects, thus restoring the families of such individuals to independence and useful roles in their communities. It is expected that the individuals participating in the program established under this part will acquire a sense of dignity, self-worth, and confidence which will flow from being recognized as a wage-earning member of society and that the example of a working adult in these families will have beneficial effects on the children in such families.

\title{
"Appropriation
}

"Sec. 431. There is hereby authorized to be appropriated to the Secretary of Health, Education, and Welfare for each fiscal year a 
sum sufficient to carry out the purposes of this part. The Secretary of Health, Education, and Welfare shall transfer to the Secretary of Labor from time to time sufficient amounts, out of the moneys appropriated pursuant to this section, to enable him to carry out such purposes.

"Establishment of Programs

"Sec. 432. (a) The Secretary of Labor (hereinafter in this part referred to as the Secretary) shall, in accordance with the provisions of this part, establish work incentive programs (as provided for in sub-section (b) in each State and in each political sub-division of a State in which he determines there is a significant number of individuals who have attained age 16 and are receiving aid to families with dependent children. In other political subdivisions, he shall use his best efforts to provide such programs either within such subdivisions or through the provision of transportation for such persons to political subdivisions of the State in which such programs are established.

"(b) Such programs shall include, but shall not be limited to, (1) a program placing as many individuals as is possible in employ ment, and utilizing on-the-job training positions for others, (2) a program of institutional and work experience training for those individuals for whom such training is likely to lead to regular employment, and (3) a program of special work projects for individuals for whom a job in the regular economy cannot be found.

"(c) In carrying out the purposes of this part the Secretary may make grants to, or enter into agreements with, public or private agencies or organizations (including Indian tribes with respect to Indians on a reservation), except that no such grant or agreement shall be made to or with a private employer for profit or with a private non-profit employer not organized for a public purpose for purposes of the work experience program established by clause (2) of subsection (b). 
"(d) Using funds appropriated under this part, the Secretary, in order to carry out the purposes of this part, shall utilize his authority under the Manpower Development and Training Act of 1962, the Act of June 6, 1933, as amended (48 Stat, 113), and other Acts, to the extent such authority is not inconsistent with this Act.

"(e) The Secretary shall take appropriate steps to assure that the present level of manpower services available under the authority of other statutes to recipients of aid to families with dependent children is not reduced as a result of programs under this part.

"Operation of Program

"Sec. 433. (a) The Secretary shall provide a program of testing and counseling for all persons referred to him by a State, pursuant to section 402 , and shall select those person whom he finds suitable for the programs established by clauses (1) and (2) of section 432 (b). Those not so selected shall be deemed suitable for the program established by clause (3) of such section 432 (b) unless the Secretary finds that there is good cause for an individual not to participate in such program.

"(b) The Secretary shall develop an employability plan for each suitable person referred to him under section 402 which shall describe the education, training, work experience, and orientation which it is determined that each such person needs to complete in order to enable him to become self-supporting.

"(c) The Secretary shall make maximum use of services available from other Federal and State agencies and, to the extent not otherwise available on a nonreimbursable basis, he may reimburse such agencies for services rendered to persons under this part.

"(d) To the extent practicable and where necessary, work incentive programs established by this part shall include, in addition to the regular counseling, testing, and referral available through the 
Federal-State Employment Service System, program orientation, basic education, training in communications and employability skills, work experience, institutional training, on-the-job training, job development, and special job placement and followup services, required to assist participants in securing and retaining employment and securing possibilities for advancement.

"(e) (1) In order to develop special work projects under the program established by section 432 (b) (3), the Secretary shall enter into agreements with (A) public agencies, (B) private nonprofit organizations established to serve a public purpose, and (C) Indian tribes with respect to Indians on a reservation, under which individuals deemed suitable for participation in such a program will be provided work which serves a useful public purpose and which would not otherwise be performed by regular employees.

"2) Such agreements shall provide--

"(A) for the payment by the Secretary to each employer a portion of the wages to be paid by the employer to the individuals for the work performed;

"(B) the hourly wage rate and the number of hours per week individuals will be scheduled to work on special work projects of such employer;

"(C) that the Secretary will have such access to the premises of the employer as he finds necessary to determine whether such employer is carrying out his obligations under the agreement and this pant; and "(D) that the Secretary may terminate any agreement under this subsection at any time.

"(3) The Secretary shall establish one or more accounts in each State with respect to the special work projects established and maintained pursuant to this subsection and place into such accounts the amounts paid to him by the State agency pursuant to section 402 (a) (19) 
(E). The amounts in such accounts shall be available for the payments specified in subparagraph (A) of paragraph (2). At the end of each fiscal year and for such period of time as he may establish, the Secretary shall determine how much of the amounts paid to him by the State agency pursuant to section 402 (a) (19) (E) were not expended as provided by the preceding sentence of this paragraph and shall return such unexpended amounts to the State, which amounts shall be regarded as overpayments for purposes of section 403 (b) (2).

"(4) No wage rates provided under any agreement entered into under this subsection shall be lower than the applicable minimum wage for the particular work concerned.

"(f) Before entering into a project under any of the programs established by this part, the Secretary shall have reasonable assurance that - -

"(1) appropriate standards for the health, safety, and other conditions applicable to the performance of work and training on such project are established and will be maintained,

"(2) such project will not result in the displacement of employed workers,

"(3) with respect to such project the conditions of work, training, education, and employment are reasonable in the light of such factors as the type of work, geographical region, and proficiency of the participant,

"(4) appropriate workmen's compensation protection is provided to all participants.

" $(\mathrm{g})$ Where an individual, referred to the Secretary of Labor pursuant to section 402 (a) (19) (A) (i) and (ii) refuses without good cause to accept employment or participate in a project under a program established by this part, the Secretary of Labor shall (after providing opportunity for fair hearing) notify the State agency which 
referred such individual and submit such other information as he may have with respect to such refusal.

"(h) With respect to individuals who are participants in special work projects under the program established by section 432 (b) (3), the Secretary shall periodically (but at least once every six months) review the employment record of each such individual while on such special work project and on the basis of such record and such other information as he may acquire determine whether it would be feasible to place such individual in regular employment or on any of the projects under the programs established by section 432 (b) (1) and (2).

"Incentive Payment

"Sec. 434. The Secretary is authorized to pay to any participant under a program established by section 432 (b) (2) an incentive payment of not more than $\$ 30$ per month, payable in such amounts and at such times as the Secretary prescribes.

"Federal Assistance

"Sec. 435. (a) Federal assistance under this part shall not exceed 80 per centum of the costs of carrying out this part. NonFederal contributions may be cash or in kind, fairly evaluated, including but not limited to plant, equipment, and services.

"(b) Costs of carrying out this part include costs of training, supervision, materials, administration, incentive payments, transportation, and other items as are authorized by the Secretary, but may not include any reimbursement for time spent by participants in work, training, or other participation in the program; except that with respect to special work projects under the program established by section 432 (b) (3), the costs of carrying out this part shall include only the costs of administration.

"Period of Enrollment

"Sec. 436. (a) The program established by section 432 (b) (2) 
shall be designed by the Secretary so that the average period of enrollment under all projects under such program throughout any area of the United States will not exceed one year.

"(b) Services provided under this part may continue to be provided to an individual for such period as the Secretary determines (in accordance with regulations prescribed by the Secretary after consultation with the Secretary of Health, Education, and Welfare) is necessary to qualify him fully for employment even though his earnings disqualify him from aid under a State plan approved under section 402 .

\section{"Relocation of Participants}

"Sec. 437. The Secretary may assist participants to relocate their place of residence when he determines such relocation is necessary in order to enable them to become permanently employable and self-supporting. Such assistance shall be given only to participants who concur in their relocation and who will be employed at their place of relocation at wage rates which will meet at least their full need as determined by the State to which they will be relocated. Assistance under this section shall not exceed the reasonable costs of transportation for participants, their dependents, and their household belongings plus such relocation allowance as the Secretary determines to be reasonable.

"Participants Not Federal Employees

"Sec. 438. Participants in projects under programs established by this part shall be deemed not to be Federal employees and shall not be subject to the provisions of laws relating to Federal employment, including those relating to hours of work, rates of compensation, leave, unemployment compensation, and Federal employee benefits.

"Rules and Regulations

"Sec. 439. The Secretary may issue such rules and regulations 
as he finds necessary to carry out the purposes of this part:

Provided, That in developing policies for programs established by this part the Secretary shall consult with the Secretary of Health, Education, and Welfare.

\section{"Annual Report}

"Sec. 440. The Secretary shall annually report to the Congress (with the first such report being made on or before July 1, 1970) on the work incentive programs established by this part.

"Evaluation and Research

"Sec. 441. The Secretary shall (jointly with the Secretary of Health, Education, and Welfare) provide for the continuing evaluation of the work incentive programs established by this part, including their effectiveness in achieving stated goals and their impact on other related programs. He also may conduct research regarding ways to increase the effectiveness of such programs. He may, for this purpose, contract for independent evaluations of and research regarding such programs or individual projects under such programs. For purposes of sections 435 and 443 , the costs of carrying out this section shall not be regarded as costs of carrying out work incentive programs established by this part.

"Review of Special Work Projects by a State Panel

"Sec, 442. (a) The Secretary shall make an agreement with any State which is able and willing to do so under which the Governor of the State will create one or more panels to review applications tentatively approved by the Secretary for the special work projects in such State to be established by the Secretary under the program established by section 432 (b) (3).

"(b) Each such panel shall consist of not more than five and not less than three members, appointed by the Governor. The members 
shall include one representative of employers and one representative of employees; the remainder shall be representatives of the general public. No special work project under such program developed by the Secretary pursuant to an agreement under section 433 (e) (1) shall, in any State which has an agreement under this section, be established or maintained under such program unless such project has first been approved by a panel created pursuant to this section.

"Collection of State Share

"Sec. 443. If a non-Federal contribution of 20 per centum of the costs of the work incentive programs established by this part is not made in any State (as specified in section 402 (a)), the Secretary of Health, Education, and Welfare may withhold any action under section 404 because of the State's failure to comply substantially with a provision required by section 402 . If the Secretary of Health, Education and Welfare does withhold such action, he shall, after reasonable notice and opportunity for hearing tothe appropriate State agency or agencies, withhold any payments to be made to the State under sections 3 (a), 403 (a), 1003 (a), 1603 (a), and 1903 (a) until the amount so withheld (including any amounts contributed by the State pursuant to the requirement in section 402 (a) (19) (C)) equals 20 per centum of the costs of such work incentive programs. Such withholding shall remain in effect until such time as the Secretary has assurances from the State that auxh 20 per centum will be contributed as required by section 402. Amounts so withheld shall be deemed to have been paid to the State under such sections and shall be paid by the Secretary of Health, Education, and Welfare to the Secretary. Such payment shall be considered a non-Federal contribution for purposes of section 435 .

"Agreements with Other Agencies Providing Assistance to Families of Unemployed Parents

"Sec. 444. (a) The Secretary is authorized to enter into an 
agreement (in accordance with the succeeding provisions of this section) with any qualified State agency (as described in subsection (b)) under which the program established by the preceding sections of this part C will (except as otherwise provided in this section) be applicable to individuals referred by such State agency in the same manner, to the same extent, and under the same conditions as such program is applicable with respect to individuals referred to the Secretary by a State agency administering or supervising the administration of a State plan approved by the Secretary of Health, Education, and Welfare under part $A$ of this title.

"(b) A qualified State agency referred to in subsection (a) is a State agency which is charged with the administration of a program--

"(1) the purpose of which is to provide aid or assistance to the families of unemployed parents,

"(2) which is not established pursuant to part A of title IV of the Social Security Act,

"(3) which is financed entirely from funds appropriated by the Congress, and

"(4) none of the financing of which is made available under any program established pursuant to title $V$ of the Economic Opportunity Act.

"(c) (1) Any agreement under this section with a qualified State agency shall provide that such agency will, with respect to all individuals receiving aid or assistance under the program of aid or assistance to families of unemployed parents administered by such agency, comply with the requirements imposed by section 402 (a) (15) and section 402 (a) (19) (F) in the same manner and to the same extent as if (A) such qualified agency were the agency in such State administering or supervising the administration of a State plan approved under part $A$ of this title, and $(B)$ individuals receiving aid or assistance 
under the program administered by such qualified agency were recipients of aid under a State plan which is so approved.

"(2) Any agreement entered into under this section shall remain in effect for such period as may be specified in the agreement by the Secretary and the qualified State agency, except that, whenever the Secretary determines, after reasonable notice and opportunity for hearing to the qualified State agency, that such agency has failed substantially to comply with its obligations under such agreement, the Secretary may suspend operation of the agreement until such time as he is satisfied that the State agency will no longer fail substantially to comply with its obligations under such agreement.

"(3) Any such agreement shall further provide that the agreement will be inoperative for any calendar quarter if, for the preceding calendar quarter, the maximum amount of benefits payable under the program of aid or assistance to families of unemployed parents administered by the qualified State agency which is a party to such agreement is lower than the maximum amount of benefits payable under such program for the quarter which ended September 30, 1967.

"(d) The Secretary shall, at the request of any qualified State agency referred to in subsection (a) of this section and upon receipt from it of a list of the names of individuals rereferred to the Secretary, furnish to such agency the names of each individual on such list participating in a special work project under section 433 (a) (3) whom the Secretary determines should continue to participate in such project. The Secretary shall not comply with any such request with respect to an individual on such list unless such individual has been referred to the Secretary by such agency under such section 402 (a) (15) for a period of at least six months."

(b) Section 402 (a) of such $A_{\text {ct }}$ is amended by adding at the end thereof before the period the following: 
"; (19) provide--

"(A) for the prompt referral to the Secretary of Labor or his representative for participation under a work incentive program established by part $C$ of--

"(i) each appropriate child and relative who has attained age sixteen and is receiving aid to families with dependent children,

"(ii) each appropriate individual (living in the same home as a relative and child receiving such aid) who has attained such age and whose needs are taken into account in making the determination under section 402 (a) (7), and

"(iii) any other person claiming aid under the plan (not included in clauses (i) and (ii), who, after being informed of the work incentive programs established by part $C$, request such referral unless the State agency determines that participation in any of such programs would be inimical to the welfare of such person or the family;

except that the State agency shall not so refer a child, relative, or individual under clauses (i) and (ii) if such child, relative, or individual is -.

"(iv) a person with illness, incapacity, or advanced age,

"(v) so remote from any of the projects under the work incentive programs established by part $C$ that he cannot effectively participate under any of such programs,

"(vi) a child attending school full time, or

"(viii) a person whose presence in the home on a 
substantially continuous basis is required because of the illness of incapacity of another member of the household;

"(B) that aid under the plan will not be denied by reason of such referral or by reason of an individual's participation on a project under the program established by section 432 (b) (2) or (3);

"(C) for arrangements to assure that there will be made a non-Federal contribution to the work incentive programs established by part $C$ by appropriate agencies of the State or private organizations of 20 per centum of the cost of such programs, as specified in section 435 (b);

"(D) that (i) training incentives authorized under section 434, and income derived from a special work project under the program established by section 432 (b) (3) shall be dis regarded in determining the needs of an individual under section (402 (a) (7), and (ii) in determining such individual's needs the additional expenses attributable to his participation in a program established by section 432 (b) (2) or (3) shall be taken into account;

"(E) that, with respect to any individual referred pursuant to subparagraph (A) who is participating in a special work project under the program established by section 432 (b) (3), (i) the State agency, after proper notification by the Secretary of Labor, will pay to such Secretary (at such times and in such manner as the Secretary of Health, Education, and Welfare prescribes) the money payments such State would otherwise make to or on behalf of such individuals (including such money payments with respect to such individual's family), or 80 per centum of such 
individual's earnings under such program, whichever is lesser and (ii) the State agency will supplement any earnings received by such individual by payments to such individual (which payments shall be considered aid under the plan) to the extent that such payments when added to the individual's earnings from his participation in such special work project will be equal to the amount of the aid that would have been payable by the State agency with respect to such individual's family had he not participated in such special work project, plus 20 per centum of such individual's earnings from such special work project; and

"(F) that if and for so long as any child, relative, or individual (referred to the Secretary of Labor pursuant to subparagraph (A) (i) and (ii) and section 407 (b) (2) has been found by the Secretary of Labor under section $433(\mathrm{~g})$ to have refused without good cause to participate under a work incentive program established by part $\mathrm{C}$ with respect to which the Secretary of Labor has determined his participation is consistent with the purposes of such part $C$, or to have refused without good cause to accept employment in which he is able to engage which is offered through the public employment offices of the State, or is otherwise offered by an employer if the offer of such employer is determined, after notification by him, to be a bona fide offer of employment - -

"(i) if the relative makes such refusal, such relative's needs shall not be taken into account in making the determination under clause (7), and aid for any dependent child in the family in the form of payments of the type described in section 406 (b) (2) (which in such a case shall be without regard to clauses (A) through (E) 
thereof) or section 408 will be made;

"(ii) aid with respect to a dependent child will be denied if a child who is the only child receiving aid in the family makes such refusal;

"(iii) if there is more than one child receiving aid in the family, aid for any such child will be denied (and his needs will not be taken into account in making the determination under clause (7)) is that child makes such refusal; and

"(iv) if such individual makes such refusal, such individual's needs shall not be taken into account in making the determination under clause (7);

except that the State agency shall, for a period of sixty days, make payments of the type described in section 406 (b) (2) (without regard to clauses (A) through (E) thereof) on behalf of the relative specified in clause (i), or continue aid in the case of a child specified in clause (ii) or (iii), or take the individual's needs into account in the case of an individual specified in clause (iv), but only if during such period such child, relative, or individual accepts counseling or other services (which the State agency shall make available to uch child, relative, or individual) aimed at persuading such relative, child, or individual, as the case may be, to participate in such program in accordance with the determination of the Secretary of Labor."

(c) (1) The amendment made by subsection (b) shall in the case of any State be effective on July 1, 1968, or if a statute of such State prevents it from complying with the requirements of such amendment on such date, such amendment shall with respect to such State be effective on July 1, 1969; except such amendment shall be effective 
earlier (in the case of any State), but not before April 1, 1968, if a modification of the State plan to comply with such amendment is approved on an earlier date.

(2) The provisions of section 409 of the Social Security Act shall not apply to any State with respect to any quarter beginning after June $30,1968$.

(d) During the fiscal year ending June 30, 1969, the Secretary of Labor may, notwithstanding the provisions of section 433 (e) (2) (A) of the Social Security Act, pay all of the wages to be paid by the employer to the individuals for work performed for public agencies (including Indian tribes with respect to Indians on a reservation) under special work projects established under the program established by section 432 (b) (3) of such Act and may transfer into accounts as he finds necessary in addition to amounts paid into such accounts pursuant to section 402 (a) (19) (E) of such Act.

(e) Section 402 (a) (8) of the Social Security Act (as amended by section 202 (b) of this Act) is further amended by striking out "; and" at the end of subparagraph (A) and inserting in lieu thereof: "(except that the provisions of this clause (ii) shall not apply to earned income derived from participation on a project maintained under the programs established by section 432 (b) (2) and (3); and". 
APPENDIX $B$

REFERRAL PROCESS FOR WIN TRAINEES

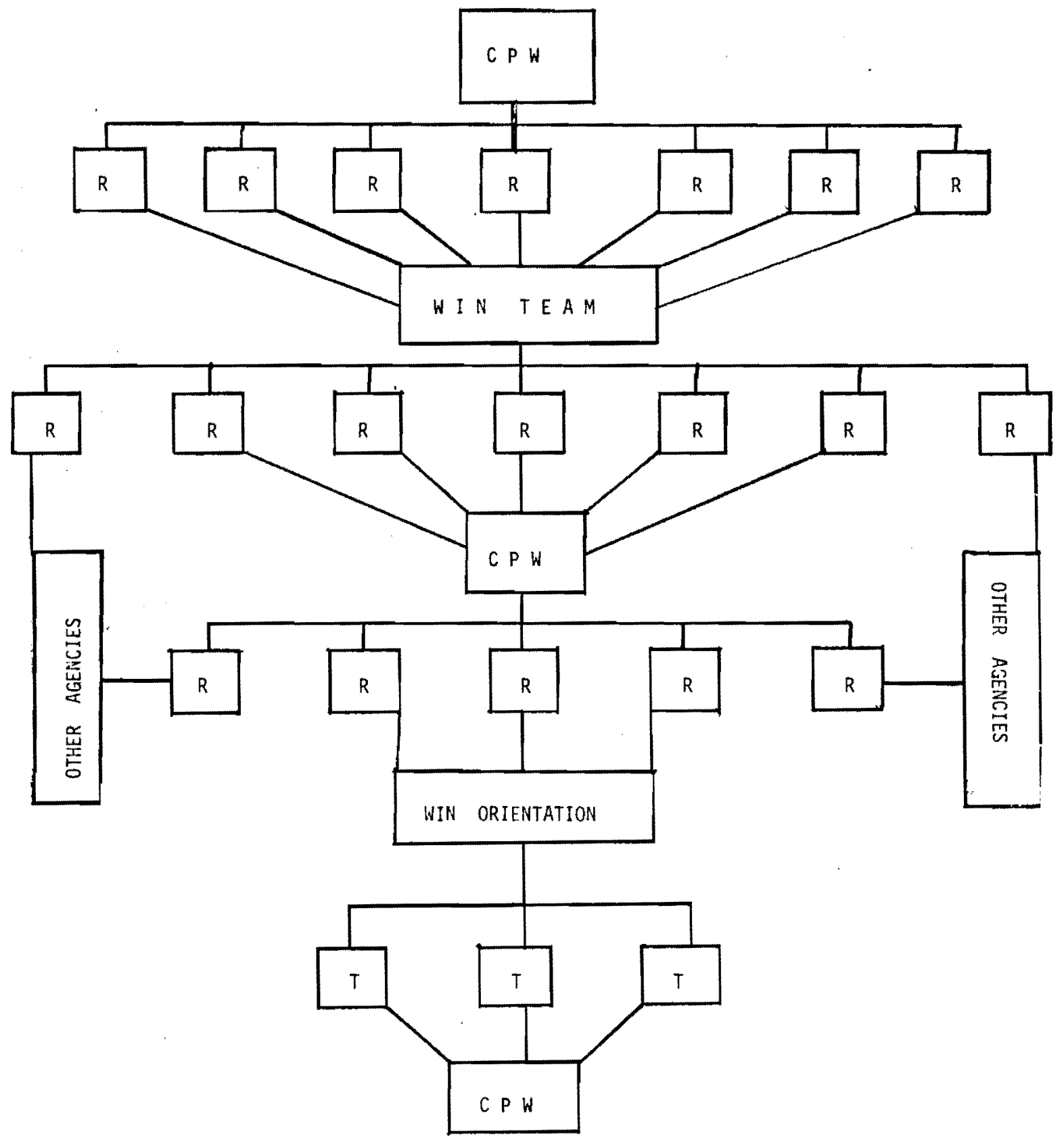




\section{APPENDIX C}

FROM: Welfare Aides, Model Cities Department.

May 23, 1969

SUBJECT: Educational Plan.

The concept of hiring individuals from the Model Cities community to function as Welfare Aides was in itself an innovation. The implementation of this concept brought a ray of hope to a community which has for so long felt nothing but despondency.

We, the Aides, as members of the community believe that we are able to understand the anxieties and issues of our community in a way no trained outsider ever could. We are also aware that as nonprofessionals, we are limited. No matter how great the understanding there are questions and problems that only the formally trained professional is prepared to handle.

We believe that with our unique experiences and position in the community, and a certain amount of formal, job-related, education, our contribution to the agency we work for and the community we work in, could be enormously increased.

We believe that with this education, we could become more than just a group of people hired to do odd jobs. The Aides could add a new and much needed dimension to the agency. We would be in a position to open lines of communication between the agency and the community it serves, which have been closed for much too long.

We submit for your consideration an educational plan which we believe would expand our capabilities greatly. 
1. By using the facilities available at the downtown campus of Portland Community College, let the Aides enroll for nine hours of classes each term. These classes should earn credits toward a two year degree in one of the following areas:
A. Sociology
B. Psychology
C. Social Science

2. Set this up so the Model Cities Program will cover part if not all of the educational expense of the Aides.

3. Give advancement consideration for all college classes taken by the Aides.

4. Give the Aides paid release time from their departments in order to attend classes.

This program can be successfully carried out by releasing the Aides for two days each week, Tuesday and Thursday. This release time will also be available to Aides carrying nine or more hours of evening classes.
Alfred D. Watkins
Clarice Harris
Joyce Washington
Laurel Battles
Josephine Franklin 